\title{
Derivative structures based on the sphere packing
}

\author{
Akihiro Umayahara ${ }^{1}$ and Massimo Nespolo $^{2, *}$ \\ ${ }^{1}$ Graduate School of Science and Technology, Kumamoto University, Kumamoto 860-8555, Japan; ${ }^{2}$ Université de Lorraine, CNRS, \\ CRM2, Nancy, France
}

Received 2 November 2017; accepted

Keywords: Derivative structures, sphere packings, coordination polyhedra.

\begin{abstract}
A significant number of non-molecular crystal structures can be described as derivative structures of sphere packings, with variable degrees of distortion. The undistorted sphere packing model with all the cavities completely occupied is the aristotype, from which an idealized model of the real structure can be obtained as a substitution, undistorted hettotype. The real structure can then be seen as a distorted derivative of the substitution hettotype. In this article we revive the symbolism introduced by Zoltai and Stout to describe the substitution hettotypes and compare these with the corresponding real structures. In most cases, the distortions are small or even negligible. For some structures, a significant departure from the substitution hettotype is observed, which however does not prevent to adopt the same description as a unifying scheme.
\end{abstract}

\section{Introduction}

The three-dimensional stacking of close packed sphere sheets has been used since the dawn of crystal chemistry as a useful and handy model to describe the basic features of a number of crystal structures (Barlow, 1883). The geometry, symmetry and OD (Order-Disorder) theory of sphere packings, as well as the description of the most common structures based on them, can be found in chapter 9 of Volume C of the International Tables for Crystallography (2004). Structures based on sphere packing are traditionally described by Hägg, Nabarro-Frank, Jagodzinski or Zdhanov codes (see a recent discussion in Estevez-Rams et al., 2017). These codes emphasize the stacking of the spheres without explicitly giving an account of the atoms filling the coordination polyhedra obtained by this stacking.

A generalized symbolism was introduced by Zoltai and Stout (1984), which is better suited to describe the stacking of both the spheres (usually electronegative, larger atoms; anions in case of ionic crystals) and the distribution of atoms (usually smaller, electropositive atoms; cations in case of ionic crystals) in the polyhedra formed by the packing of the spheres. This notation was introduced to describe the structure of minerals, although it is by no means limited to the mineral world; despite its versatility, it has not been widely adopted even in the earth science community, possibly because of a limited circulation of the textbook where it was introduced.

In this article, we would like to revive this notation and make aware the structural scientists of its usefulness. The Symmetrical Packing Symbols (or SPS, as it will be called in the following, for the sake of briefness) introduced by Zoltai and Stout (1984) describe any structure based on the stacking of sheets formed by packing of spheres, but the result is in general an idealization of the real structure. This idealization is however far from being excessive, as we are

\begin{tabular}{|c|c|c|c|c|}
\hline Author & Title & File Name & Date & Page \\
\hline $\begin{array}{l}\text { [Akihiro Umayahara, } \\
\text { Massimo Nespolo*] }\end{array}$ & [Derivative structures based on the sphere packing] & $\begin{array}{l}\text { ZKrist_Special_I } \\
\text { ssue2017_Umay } \\
\text { ahara-Nespolo- } \\
\text { revised.odt }\end{array}$ & 12.12 .2017 & $1(17)$ \\
\hline
\end{tabular}


going to show by comparing the structural models obtained in this way and the real structures taken from the literature. For this purporse, we need to remind the reader of a few definitions.

An aristotype (Megaw, 1973), or basic structure (Buerger, 1947), is a real or fictitious high-symmetry structure from which lower-symmetry structures (known as hettotypes or derivative structures) can be obtained by reducing the point and/or translational symmetry. Hettotypes are classified in substitution structures and distortion structures. Substitution structures are obtained when two or more different kinds of atoms replace one kind of atom in the aristotype, which leads to a decrease in the space-group symmetry. Atomic sites that were equivalent in the aristotype are split into two or more different sites in the hettotype, a phenomenon known as splitting of Wyckoff positions (Wondratschek, 1993). The sphere packing model can be seen as the aristotype in which the cavities are filled in a homogeneous (disordered) way. Hettotypes are then obtained by partial occupation of cavities or ordered distribution of the M atoms in the cavities. The result is a substitution, undistorted derivative structure. The real structure may differ from it by some distortion. In the following, we start from known or hypothetical aristotypes (cavity-filled $c c p$, $h c p$ and so on), derive undistorted substitution hettotypes with a distribution pattern of the $\mathrm{M}$ atoms which corresponds to that of real structures, and compare the result with the real structures, considered distorted substitution hettotypes. In many cases the undistorted and distorted hettotypes are actually quite close, which justifies the description of the real structure by the SPS. The analysis we present below has been obtained with the help of the Bilbao Crystallographic Server (Aroyo et al., 2006), in particular the routines WYCKSPLIT (Krumova et al., 1998), to compute the splitting of Wyckoff positions in the group-subgroup transition between the aristotypes and the hettotypes, and COMPSTRU (de la Flor et al., 2016) to quantify the degree of similarity between the undistorted hettotype and the real (distorted) structure. The results are expressed by four similarity parameters:

- the degree of lattice distortion $S$ is the spontaneous strain (the square root of the sum of eigenvalues of the strain tensor divided by 3 );

- the maximum distance $\mathrm{d}_{\max }$ shows the maximal displacement between the atomic positions of the paired atoms;

- the arithmetic mean, $\mathrm{d}_{\mathrm{av}}=\sum_{\mathrm{i}} m_{\mathrm{i}} u_{\mathrm{i}} / n$, where $m_{\mathrm{i}}$ is the multiplicity of the Wyckoff position in the primitive unit cell, $u_{\mathrm{i}}$ is the atomic displacement of the i-th atomic position and $n$ is the number of atoms in the primitive unit cell;

- the measure of similarity $\Delta$ is a function of the differences in atomic positions, weighted by the multiplicities of the sites) and the ratios of the corresponding lattice parameters of the structures (Bergerhoff et al., 1999).

\section{Symmetrical Packing Symbols (SPS)}

Spheres of equal size can be packed on a plane to form two densest sheets:

- the hexagonal sheet, in which each sphere is surrounded by six other spheres; the layer group is $P(6 / \mathrm{m}) \mathrm{mm}$ (notation after Dornberger-Schiff, 1959: the parentheses identify the direction lacking periodicity);

- the tetragonal sheet, in which each sphere is surrounded by four other spheres; the layer group is $P(4 / \mathrm{m}) \mathrm{mm}$.

When the spheres are in contact with each other, the highest packing efficiency is obtained. It is however possible to form sheets of the same symmetry with some space left empty between the spheres, which are no longer in contact. If $a$ is the two-dimensional cell parameter (hexagonal or tetragonal) and $D$ is the diameter of the sphere, the ratio $n=a / D$ is 1 for the densest sheets and larger than 1 when the spheres are not in contact (Fig. 1). The packing efficiency is a function of $n$ (Table 1).

The SPS notation assigns an alphabetical symbol to positions in the unit cell whose site-symmetry group is higher than 1 and its principal symmetry element is perpendicular to the plane of the sheet. In particular (Fig. 2):

- for the hexagonal sheet, $\mathrm{A}$ is on the sixfold axis, $\mathrm{B}$ and $\mathrm{C}$ are on the threefold axes, D, E and $\mathrm{F}$ on the twofold axes;

Author

[Akihiro Umayahara, Massimo Nespolo*]
Title

[Derivative structures based on the sphere packing]
File Name Date Page

ZKrist_Special_I $12.12 .2017 \quad 2$ (17)

ssue2017_Umay

ahara-Nespolo-

revised.odt 
- $\quad$ for the tetragonal sheet, S and D are on the fourfold axes, E and F are on the twofold axes.

The two-dimensional fractional coordinates of these sites in the plane of the sheet are given in Table 2, where the sitesymmetry groups are expressed with respect to the two-dimensional symmetry of the plane of the sheet, $6 \mathrm{~mm}$, and $4 \mathrm{~mm}$, and to the three-dimensional but diperiodic symmetry of the sheet, $P(6 / \mathrm{m}) \mathrm{mm}$ and $P(4 / \mathrm{m}) \mathrm{mm}$.

A three-dimensional structure is obtained by stacking sheets along the out-of-plane direction. The second sheet can be put on any of the symmetrical position above the first sheet, giving rise to the following possibilities:

- $\quad$ for the hexagonal sheet: A-A, A-B (equivalent to A-C), A-D (equivalent to A-E and A-F);

- for the tetragonal sheet: S-S, S-D, S-E (equivalent to S-F).

A stacking of the type A-A or S-S is observed in covalent structures but not in ionic ones. The packing efficiency for a three-dimensional stacking for the hexagonal or tetragonal sheet is called Symmetric Packing Index (SPI) and is given in Table 3. In the empty space left by the stacking of sheets, atoms of variable size can find place. Because of the high symmetry of the sheets and of their stacking mode, this empty space is partitioned in highly-symmetric cavities, that can be easily classified (Tables 4 and 5). In the following, structures based on sphere packings are described with the first sheet in the position compatible with the origin of the space group. The cavities are then classified as follows:

- in the plane of the hexagonal sheet: two triangular cavities of opposite orientation, in correspondence of the positions with site-symmetry $(\overline{6}) m 2$, that will be indicated in the following as $\mathrm{t}_{1}$ and $\mathrm{t}_{2}$ (Fig 2, top);

- between pairs of hexagonal sheets stacking according to the A-A (or B-B or CC) topology: two trigonal prisms of opposite orientation, on the vertical of the $t_{1}$ and $t_{2}$ cavities, that will be indicated in the following as $P_{1}$ and $P_{2}$ (Fig. $3)$;

- $\quad$ between pairs of hexagonal sheets stacked according to the A-B topology (or any pair taken from the A-B-C triple): two tetrahedra of opposite orientation and one octahedron. Above the position with site-symmetry group (6)/ $\mathrm{mmm}$ of first sheet one of the triangular cavities of the second sheet occurs; between these two positions, a cation can take place in a tetrahedron pointing down the stacking direction (indicated as $\mathrm{T}^{-}$below). Similarly. below the position with site-symmetry group (6)/ $\mathrm{mmm}$ of second sheet one of the triangular cavities of the first sheet occurs; a cation can take place in a tetrahedron pointing up the stacking direction (indicated as $\mathrm{T}^{+}$below). Finally, between two triangular cavities in the two sheets, a cation can take place in an octahedral coordination (Fig. 4);

- $\quad$ in the plane of the tetragonal sheet: one square cavity, in correspondence of the D position (Fig. 2, bottom); in the case of an S-D stacking, this cavity is bounded by two spheres in the S position on the two opposite sides, leading to an octahedron;

- between pairs of tetragonal sheets stacking according to the S-S topology: one cube, in correspondence of the D position (Fig. 5);

- between pairs of tetragonal sheets stacked according to the S-D topology: two tetrahedra of different orientation (indicated as T1 and T2 below), above the E and F positions, and an octahedron, on the vertical of the S or D position (Fig. 6).

In the following, the atoms playing the role of spheres will be indicates as $\mathrm{X}$, those occupying the tetrahedral cavities as $\mathrm{T}$, those entering the octahedra as $\mathrm{M}$.

The SD stacking mode gives rise of a unit cell of type $t I$, with however a ratio $c / a$ of $2^{1 / 2}$ (under the hypothesis that all spheres are identical and each sphere touches four spheres in the plane of the sheet and two spheres on its vertical). A change of basis $\mathbf{a b c} \rightarrow \mathbf{a}-\mathbf{b}, \mathbf{a}+\mathbf{b}, \mathbf{c}$ leads to a $c F$ unit cell, so that the symmetry of the SD stacking (for $n=a / \mathrm{D}=1)$ is actually cubic (Fig. 6). Further, the SD stacking coincides with the ABC stacking: the same structure looked upon from the cubic $\langle 001\rangle$ or $\langle 111\rangle$ directions can be interpreted respectively as SD or ABC (Fig. 7).

Author

[Akihiro Umayahara, Massimo Nespolo*]
Title

[Derivative structures based on the sphere packing]
File Name

ZKrist_Special_I ssue2017 Umay ahara-Nespolorevised.odt 
The presence of atoms in the cavities above is described by a fraction giving the occupancy of the cavity, replaced by a dash (-) when the cavity is empty. The position of this symbol identifies the cavity: for cavities between pairs of sheets, the symbol goes in parentheses between the two sheets, whereas for cavities in the plane of the sheet the symbol is put directly after the literal code. When cavities are fully occupied or completely empty, two different SPS can normally describe the same structure, in terms of coordination polyhedra centred on the electropositive ("cations") or the electronegative ("anions") atoms. About the role of anion-centred polyhedra, see Krivovichev (2009), as well as computational applications in Eon and Nespolo (2014), and Nespolo (2016). Further, from the SPS, one gets directly the stoichiometry, as we are going to show.

\section{Analysis of real structures and comparison with their undistorted hettotype}

In the following, we derive substitution hettotypes from the sphere packing aristotypes and compare them with the real structures. The relation between the aristotype and the undistorted substitution hettotype is described through Bärnighausen trees (Bärnighausen, 1980; see details in Müller, 2017). Bärnighausen trees relate an aristotype and its hettotypes through a chain of intermediate (real or fictitious) structures in which each step is a symmetry decrease corresponding to a maximal subgroup. In our case, for the sake of compactness, we short-cut the intermediate steps, if any, and give directly the aristotype-final hettotype relation, building thus a sort of contracted Bärnighausen tree. Furthermore, in cases like rutile, the relation between the aristotype and the hettotype is indirect, thorough a common subgroup.

The comparison of various crystal structures with a single hettotype (which also indirectly means the comparison of those structures among them) has to take into account the difference of size of the atomic species. Two structures in perfect 1:1 correspondence with the same hettotype but composed of atoms with a large size difference would have large values of the similarity parameters (defined in the introduction) because of the difference in the corresponding linear cell parameters. These structures have the same topology and thus the same type of polyhedra, although of different size, and this difference should influence the linear cell parameters, not the interaxial angles. In other words, differences in the linear cell parameters are unrelated to the topology of the structures being compared but result from a difference in atomic size, whereas difference in interaxial angles are considered a result of the deviation of the real structure from the topology of the hettotype. To abstract from the influence of the atomic size, we rescale the hettoype by multiplying the linear cell parameters, as obtained by desymmetrization of the aristotype, by the factor $\left(\mathrm{V}_{\mathrm{S}} / \mathrm{V}_{\mathrm{H}}\right)^{1 / 3}$, where $\mathrm{V}_{\mathrm{S}}$ is the volume of the unit cell of the real structure and $\mathrm{V}_{\mathrm{H}}$ is the volume of the unit cell of the hettotype. Concretely, let $\mathbf{G}_{\mathrm{A}}, \mathbf{G}_{\mathrm{H}}$ and $\mathbf{G}_{\mathrm{S}}$ be the metric tensors of the aristotype, hettotype and real structure respectively, and $\mathbf{P}$ the matrix relating the basis vectors of the aristotype to those of the hettotype. The calculation is performed as follows.

$$
\begin{gathered}
\mathbf{G}_{\mathrm{H}}=\mathbf{P}^{\mathrm{t}} \mathbf{G}_{\mathrm{A}} \mathbf{P} ; \mathbf{V}_{\mathrm{H}}=\operatorname{det}\left(\mathbf{G}_{\mathrm{H}}\right)^{1 / 2}=\operatorname{det}(\mathbf{P}) \operatorname{det}\left(\mathbf{G}_{\mathrm{A}}\right)^{1 / 2} ; \mathbf{V}_{\mathrm{S}}=\operatorname{det}\left(\mathbf{G}_{\mathrm{S}}\right)^{1 / 2} \\
a_{\mathrm{H}, \mathrm{S}}=a_{\mathrm{H}}\left(\mathrm{V}_{\mathrm{S}} / \mathrm{V}_{\mathrm{H}}\right)^{1 / 3} ; b_{\mathrm{H}, \mathrm{S}}=b_{\mathrm{H}}\left(\mathrm{V}_{\mathrm{S}} / \mathrm{V}_{\mathrm{H}}\right)^{1 / 3} ; c_{\mathrm{H}, \mathrm{S}}=c_{\mathrm{H}}\left(\mathrm{V}_{\mathrm{S}} / \mathrm{V}_{\mathrm{H}}\right)^{1 / 3}
\end{gathered}
$$

where $\mathbf{P}^{\mathrm{t}}$ is the transposed of $\mathbf{P}, \operatorname{det}()$ is the determinant of the matrix in parentheses, $a_{\mathrm{H}, \mathrm{S}}$ is $a_{\mathrm{H}}$ rescaled (ditto for $b$ and $c)$.

The structural data used in the analysis below are as follows: Li3Bi: Zintl and Brauer (1935); sphalerite: Skinner (1961); coloradoite: de Jong, (1926); tiemannite: Earley (1950); chalcopyrite: Knight et al. (2011); gallite: Abrahams and Bernstein (1973); bornite: Tunell and Adams (1949); sulvanite: Trojer (1966); periclase: Hazen (1976); manganosite: Pacalo and Graham (1991); wustite: Fjellvag et al. (1996); bunsenite, lime, nickeline and breithauptite: Wyckoff (1963a); pyrolusite: Wyckoff (1963b); monteponite: Zhang (1999); galena: Noda et al. (1987); alabandite: McCammon (1991); hongquiite: Rostoker (1952); anatase: Howard et al. (1991); pyrite and marcasite: Rieder et al. (2007); sperrylite: Stassen and Heyding (1968); vasesite: Nowack et al. (1991); bravoite: Petruk et al., (1969); cobaltite; Bayliss (1982); ullmannite: Bayliss (1977); gersdorffite: Foecker and Jeitschko (2001); magnetite: Haavik et al. (2000); violarite: Vaughan and Craig (1985); polydymite: Lundqvist (1947); greigite: Skinner et al. (1964); pentlandite: Pearson and Buerger (1956); zincite, bromellite, greeenockite: Xu and Ching (1993); wurtzite: Kisi and Elcombe (1989); enargite: Pfitzner and Bernert, (2004); cubanite: McCammon et al. (1992); argentopyrite: Yang et al. (2009); troilite:

Author Title File Name Date Page

[Akihiro Umayahara, [Derivative structures based on the sphere packing]

ZKrist_Special_I $12.12 .2017 \quad 4(17)$

Massimo Nespolo*]

ssue2017_Umay

ahara-Nespolo-

revised.odt 
Alsen (1925); $\alpha$-Millerite: Sowa et al. (2004); lollingite: Ondrus et al. (2001); rutile: Swope et al. (1995); cassiterite and plattnerite: Bolzan et al. (1997); arsenopyrite: Bindi et al. (2012); gudmundite: Buerger (1939); manganite: Kohler et al. (1997); diaspore: Friedrich et al. (2007); goethite: Gualtieri and Venturelli (1999); corundum: Kirfel and Eichhorn (1990); hematite: Maslen et al. (1994); ilmenite: Wechsler and Prewitt (1984); brucite: Nagai et al. (2000); covelline, klockmannite: Berry (1954); brookite: Meagher and Lager (1979); forsterite: Smyth and Hazen (1973); molybdenite: Schonfeld et al. (1983).

The systematic analysis we present below requires a large number of figures. Considering the limited space available for printing, all the contracted Bärnighausen trees have been deposited as supplementary material and the corresponding figures are quoted below as "SN", where $\mathrm{S}$ indicates supplementary material and $\mathrm{N}$ is a sequence number.

\section{Structures based on the $h c p$ stacking}

The cell parameters of the aristotype are computed by taking spheres of unit radius. By simple geometric arguments, the cell parameters are then obtained as $a=b=1, c=(8 / 3)^{1 / 2}, \alpha=\beta=90^{\circ}, \gamma=120^{\circ}$. The SPS of the aristotype is $\mathrm{C}(111) \mathrm{B}(111)^{1}$ and the space-group type is $P 6_{3} / m m c$.

The hettotype with partial occupation of all the three types of polyhedra corresponds to the structure of olivine, whose SPS is $C\left(1 / 2^{1} / 8^{1 / 8}\right) \mathrm{B}\left(1 / 2^{1} / 8^{1} / 8\right)$ (Fig. 8). The splitting scheme is given in Fig. S1. The chemical formula obtained from the SPS is $\mathrm{MT}_{1 / 2} \mathrm{X}_{2}=\mathrm{M}_{2} \mathrm{TX}_{4}$, which corresponds exactly to the general formula of the olivine group, $\mathrm{M}_{2} \mathrm{SiO}_{4}$, with $\mathrm{M}$ being principally $\mathrm{Mg}, \mathrm{Fe}, \mathrm{Mn}$. The sharing of faces between octahedra, usually considered a destabilizing factor on the basis of Pauling's third rule (Pauling, 1929), does not represent a structural problem in this case because occupied octahedra are surrounded by empty octahedra and vice versa. The same argument holds for the tetrahedra, which in an $h c p$ stacking share their faces; the low occupancy results in occupied tetrahedra surrounded by empty tetrahedra only. As a matter of fact, olivines are nesosilicates, in which the occupied tetrahedra do not share any element (face, edge, corner) with each other.

The hettotype $\mathrm{C}(1--) \mathrm{B}(1--)$ has both tetrahedra empty and the octahedron fully occupied (Table 4). The space group type is the same as for the aristotype: removal of both tetrahedral cations does not produce a symmetry reduction. Assuming that the same cation occurs in the two inter-sheet regions, the stoichiometry is $\mathrm{M}_{2} \mathrm{X}_{2}=\mathrm{MX}$. This is the structure of nickeline, NiAs, based on face sharing octahedra $\mathrm{NiAs}_{6}$ (Fig. 9), which would be a highly unfavourable configuration for an ionic structure; in these compounds, however, the M-X bond is covalent and the M-M interaction is actually attractive (metallic bond). The same structure can be described as based on edge-sharing $\mathrm{AsNi}_{6}$ trigonal prisms, whose SPS is A(-1)A(1-). The doubling of the symbol, this time with an alternate occupancy of the two types of trigonal prism, indicates an ordered distribution of As: each occupied prism is surrounded by empty prisms and vice versa, leading to edge sharing instead of face sharing. The splitting scheme is given in Fig. S2. The same structure occurs in troilite, FeS, millerite, NiS, and breithauptite, NiSb.

A two-third occupation of the octahedra is realized in the structure of corundum, $\mathrm{Al}_{2} \mathrm{O}_{3}$, hematite, $\alpha-\mathrm{Fe}_{2} \mathrm{O}_{3}$, and ilmenite, $\mathrm{FeTiO}_{3}$. This first two compounds crystallize in $R \overline{3} c$, the latter in $R \overline{3}$ because of the ordering of $\mathrm{Fe}$ and $\mathrm{Ti}$ in the octahedra. The SPS is $\mathrm{C}(2 / 3--) \mathrm{B}(2 / 3--)$ (Fig. 10; splitting scheme in Fig. S3 for corundum and hematite; Fig. S4 for ilmenite).

The octahedra are half-occupied in the structures of marcasite, $\mathrm{FeS}_{2}$, and lollingite, $\mathrm{FeAs}_{2}$ (isostructural, crystallizing in Pnnm: Fig. 11a), rutile, $\mathrm{TiO}_{2}$, cassiterite, $\mathrm{SnO}_{2}$, pyrolusite, $\mathrm{MnO}_{2}$, and plattnerite, $\mathrm{PbO}_{2}$ (again isostructural, but crystallizing in $P 4_{2} / m n m$ : Fig. 12). Pnnm is a subgroup of $P 6_{3} / m m c$, whereas $P 4_{2} / m n m$ is not; however, $P 4_{2} / m n m$ is a supergroup of Pnnm; the relation between the aristotype and the hettotype corresponding to the sulphides is therefore direct, whereas that with the oxide hettotype is indirect, via the common subgroup Pnnm (Fig. S5). The basis vector transformation from $P 6_{3} / m m c$ to Pnnm is $\mathbf{a b c} \rightarrow \mathbf{a}-\mathbf{b}, \mathbf{c},-\mathbf{a}-\mathbf{b}$, with Wyckoff splitting scheme $4 f\left(\mathrm{~T}^{+}, \mathrm{T}^{-}\right) \rightarrow 2 \times 4 g, 2 a$ (M)

1 The triangular cavities in the plane of the sheet being empty in the most cases, we do not explicitly indicate them in the SPS of the aristotype, which is therefore simplified from C--(111)B--(111) to C(111)B(111).

Author Title

[Akihiro Umayahara, Massimo Nespolo*]
[Derivative structures based on the sphere packing]
File Name

ZKrist_Special_I ssue2017_Umay ahara-Nespolorevised.odt 
$\rightarrow 2 a+2 c, 2 c(\mathrm{X}) \rightarrow 2 c$. In the hettotype, the tetrahedra are empty whereas the octahedra are half occupied, in an alternate scheme leading to edge sharing. The SPS inherited from the aristotype is $\mathrm{C}(1 / 2--) \mathrm{B}(1 / 2--)$ : it does show that half of the octahedra in each inter-sheet region are occupied, but it does not tell us which they are. However, if the same octahedra were occupied in both inter-sheet regions, we would have face-sharing octahedra surrounded by empty octahedra, with only weak S-S van der Waals bonds, a description which does not fit at all the physical properties of crystal (hardness $5-7$ for the six compounds). The comparison with the hettotype shows an important rotation about the $\mathrm{M}$ atoms, which leads to very corrugated distribution of $\mathrm{X}$ atoms. As shown in Fig. 11(a) and (b), where the hettotype and the real structure of marcasite are compared, the $\mathrm{X}$ atoms no longer form a plane but a wavy distribution, which results in a large value of the similarity parameters for both sulphides. This can be also measured by the angle BCB between two octahedra sharing a corner, which is around $120^{\circ}$ for marcasite, $126^{\circ}$ for lollingite, $132^{\circ}$ for the hettotype and $130^{\circ}$ for the aristotype. This angle shows that the hettotype is strongly pseudo-symmetric in $P 4_{2} / \mathrm{mnm}$ : if one ignores the relatively small deviation from the tetragonal metric $(b / a=0.94)$, the eigensymmetry of the $\mathrm{Fe}$ is precisely $P 4_{2} / \mathrm{mnm}$, whereas sulphur would need a displacement of less than $0.3 \AA$ to reach the tetragonal symmetry. The large rotation of the octahedra in the real structures leads to a large departure from the tetragonal metric $(b / a=1.22$ in marcasite and 1.14 in lollingite). On the other hand, for the oxides, which are tetragonal, the $\mathrm{BCB}$ angle varies from 129 to $131^{\circ}$ (Fig. 12 shows the rutile structure), just around the value for the aristotype. The anion-centred description does not fit the SPS description.

The same type of structure occurs in compounds with stoichiometry MXY instead of $\mathrm{MX}_{2}$. The presence of different anions implies a symmetry reduction: arsenopyrite, $\mathrm{FeAsS}$, gudmundite, $\mathrm{FbSbS}$, and manganite, $\mathrm{MnO}(\mathrm{OH})$, all crystallize indeed in space groups of type $P 2_{1} / c$, which are subgroups of the Pnnm groups of the $\mathrm{MX}_{2}$ sulphides (Fig. 13; the splitting scheme is in Fig. S6). The rotation of the octahedra about the $\mathbf{c}$ axis is less pronounced with respect to the sulphides; on the other hand, a significant rotation about a occurs. As a result, each plane of $\mathrm{B}$ and of $\mathrm{C}$ atoms in the hettotype is split into two planes in the real structures. Other MXY compounds with the same SPS occur in diaspore, $\alpha$ $\mathrm{AlO}(\mathrm{OH})$, and goethite, $\alpha-\mathrm{FeO}(\mathrm{OH})$, which crystallize in Pnma, where the differences between the hettotype and the real structures are small.

The hettotype with one of the two tetrahedra (the same in both inter-sheet regions) filled has SPS C(-1-)B(--1); the symmetry is reduced to the non-centrosymmetric subgroup of the aristotype, $P 6_{3} m c$ (Fig. S7). The anion site corresponds to Wyckoff position $2 c$ in the aristotype, site-symmetry group $\overline{6} m 2$; it is mapped to the Wyckoff position $2 b$, site-symmetry group $3 m$. in the hettotype, without splitting. Similarly, the octahedral site $2 a$, with site-symmetry group $\overline{3} m$., is mapped in the subgroup to $2 a$, with site-symmetry group $3 m$. and no splitting, but in this type of structure the octahedral site is empty. Finally, the tetrahedral site in position $4 f$, with site-symmetry group $3 m$., is split to two $2 b$ positions with the same site-symmetry group, $3 m$., and of these one is occupied while the other is empty in the hettotype (Fig. 14(a)). Structures corresponding to the hettotype are those of zincite $\mathrm{ZnO}$, bromellite $\mathrm{BeO}$, wurtzite- $2 \mathrm{H} \mathrm{ZnS}$ and greenockite CdS (Fig. 14(a)). The deviations of the real structure with respect to the hettotype are minimal. The anion centred description has SPS A(1--)(-1-): the tetrahedron $\mathrm{T}^{-}$is occupied between A and B and between B and A (Fig. 14(b)).

The same topology occurs also in enargite, $\mathrm{Cu}_{3} \mathrm{AsS}_{4}$, in which however $\mathrm{Cu}$ and As are ordered inside each pair of sheets (Fig. 15). This ordering leads to a symmetry reduction to $P m n 2_{1}$ with a change of basis vectors $\mathbf{a}^{\prime}=2 \mathbf{a}+2 \mathbf{b}, \mathbf{b}^{\prime}=\mathbf{a}-\mathbf{b}, \mathbf{c}^{\prime}$ $=-\mathbf{c}$ and an origin shift $1 / 2,1 / 2,1 / 2$. The splitting scheme is $4 f(\mathrm{~T}) \rightarrow 4 \times 2 a+2 \times 4 b, 2 a(\mathrm{M}) \rightarrow 2 \times 2 a+4 b, 2 c(\mathrm{X}) \rightarrow 2 \times 2 a+4 b$. As occupies one of the $2 a$ sites whereas $\mathrm{Cu}$ takes place in one of the other $2 a$ site as well as in one of the $4 b$ sites (Fig. S8). Despite the significant reduction of symmetry, the deviations of the real structure with respect to the hettotype are small.

A disordered distribution in the two types of tetrahedra occurs in cubanite, $\mathrm{CuFe}_{2} \mathrm{~S}_{3}$, and argentopyrite, $\mathrm{AgFe}_{2} \mathrm{~S}_{3}$. Cubanite crystallizes in Pcmn, an alternative setting of Pnma: for ease of treatment we will describe its structure in the standard setting. The hettotype corresponding to the cubanite structure is obtained by the basis vector transformation $\mathbf{a b c} \rightarrow \mathbf{c},-3 \mathbf{a}-3 \mathbf{b}, \mathbf{a}-\mathbf{b}$, and an origin shift of $0,-1 / 2,0$, with Wyckoff position splitting scheme $4 f\left(\mathrm{~T}^{+}, \mathrm{T}^{-}\right) \rightarrow 2 \times 8 c+2 \times 8 d, 2 a$ $(\mathrm{M}) \rightarrow 4 c+8 d, 2 c(\mathrm{X}) \rightarrow 4 c+8 d$. The $\mathrm{X}$ positions in the hettotype are all occupied, the $\mathrm{M}$ positions are all empty, both the $\mathrm{T}^{+}$and the $\mathrm{T}^{-}$positions are half occupied. Fig. 16(a) shows the $h c p$ aristotype in the Pnma unit cell of cubanite from

Author

[Akihiro Umayahara, Massimo Nespolo*]
Title

[Derivative structures based on the sphere packing]
File Name Date Page

ZKrist_Special_I $12.12 .2017 \quad 6$ (17)

ssue2017 Umay

ahara-Nespolo-

revised.odt 
which the $\mathrm{M}$ atoms have been removed. The black tetrahedra are those occupied in cubanite, the white tetrahedra are empty. The SPS of the hettotype from which the white octahedra are removed is $\mathrm{C}(-1 / 21 / 2) \mathrm{B}(-1 / 21 / 2)$. Within each interlayer sheet, $\mathrm{Cu}$ and Fe are distributed in an ordered way, which is shown in Fig. 16(b), obtained by removing the white tetrahedra from Fig. 16(a) and differentiating the remaining tetrahedra on the basis of their occupation (black: Fe; grey: $\mathrm{Cu}$ ). The contracted Bärnighausen tree (Fig. S9) shows the close similarity between this hettotype and the real structure of cubanite.

The same type of structure occurs also in argentopyrite, $\operatorname{AgFe}_{2} \mathrm{~S}_{3}$, which crystallizes in $P 112_{1} / n$, which is an alternative setting of $P 2_{1} / c$. Here again we use the description in the standard setting. The hettotype corresponding to the argentopyrite structure is obtained by the basis vector transformation $\mathbf{a b c} \rightarrow-2 \mathbf{c}-\mathbf{b},-\mathbf{c}, 2 \mathbf{a}-2 \mathbf{b}$, and an origin shift of $0,1 / 2,0$, with Wyckoff position splitting scheme $4 f\left(\mathrm{~T}^{+}, \mathrm{T}^{-}\right) \rightarrow 6 \times 4 e, 2 a(\mathrm{M}) \rightarrow 2 \times(2 b+4 e) 2 c(\mathrm{X}) \rightarrow 3 \times 4 e($ Fig. S10). The $\mathrm{X}$ positions in the hettotype are all occupied, the $\mathrm{M}$ positions are all empty, the both the $\mathrm{T}^{+}$and the $\mathrm{T}^{-}$positions are half occupied, exactly as in the case of cubanite. Therefore, the two structures have the same SPS. Fig. 17 (a) and (b) show the aristotype in the unit cell of argentopyrite, with and without the empty tetrahedra sites.

A single sheet of octahedra is occupied in the structure of brucite, SPS B(1--)C(---); the lack of cations between C and $\mathrm{B}$, held together by hydrogen bonds, justifies the perfect cleavage and the relatively low hardness, $2 \frac{1}{2}-3$ in the Mohs scale (Fig. 18). The splitting scheme is shown in Fig. S11.

\section{Structures based on the ccp stacking}

The aristotype of the $c c p$ stacking can be described with two SPS: S1(11)D1(11) or A(111)B(111)C(111). The structure of $\mathrm{Li}_{3} \mathrm{Bi}$ (Fig. 19) corresponds exactly to the aristotype; the edge sharing between pairs of tetrahedra and between pairs of octahedra, as well as the face sharing between octahedra and tetrahedra is justified by the huge difference between the $\mathrm{X}(\mathrm{Bi})$ atoms and the $\mathrm{M}$ and $\mathrm{T}(\mathrm{Li})$ atoms. The anion-centred description does not apply in this case; in fact, the structure cannot be interpreted as built by stacking Li layers without finding Li also in a coordination polyhedron.

The conversion from SD description to the ABC description is obtained by taking the primitive unit cell (rhombohedral) of the face-centred cubic conventional cell and expressing it in hexagonal axes. The overall transformation is $-\mathbf{a} / 2+\mathbf{b} / 2$, $-\mathbf{b} / 2+\mathbf{c} / 2, \mathbf{a}+\mathbf{b}+\mathbf{c}$. Most of the structures discussed below are described in terms of their SD configuration, which is easly read off the visualization; the corresponding $\mathrm{ABC}$ configuration is obtained through the axial setting transformation above.

The hettotype with all the octahedra occupied is described by the SPS S1(--)D1(--) or A(--1)B(1--)C(-1-). The role of the cations and anions is perfectly exchangeable in this hettotype so that the same SPS applies to both the cation-centred and anion-centred description. A large number of real structures correspond to this hettotype (Table 8), of which the most famous example is $\mathrm{NaCl}$.

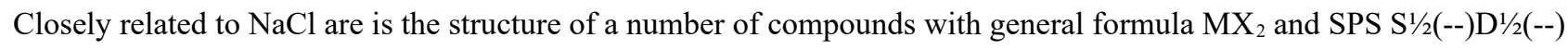
or $\mathrm{A}(--1 / 2) \mathrm{B}\left(1 / 2^{--}\right) \mathrm{C}(-1 / 2-)$ (Fig. 20). The structure of anatase, one of the three polymorphs of $\mathrm{TiO}_{2}$, is only slightly distorted with the respect to the hettotype; the Wyckoff splitting scheme is shown in Fig. S12. The same hettotype correspond also to a series of sulphides or sulfosalts (pyrite, sperrylite, vaesite, bravoite), provided that the centre of mass of $\mathrm{X}-\mathrm{X}$ is considered instead of the position of the two $\mathrm{X}$ atoms (Fig. 21). The $\mathrm{M}$ atoms form the $c F$ lattice complex of position $4 a$ in $P a \overline{3}$; the $\mathrm{X}$ atoms are responsible for the symmetry reduction from $F m \overline{3} m$ to $P a \overline{3}$ (Fig S12). If we replace pairs of $X$ atoms by their centre of mass, they form the $1 / 2 \frac{1}{2} \frac{1}{2} c F$ lattice complex of position $4 b$ in $P a \overline{3}$ (Fig. $\mathrm{S} 13$ ) and the result is the $\mathrm{NaCl}$ crystal structure (about lattice complexes, see section 3.4 of volume A of the International Tables for Crystallography). The same type of structure occurs in compounds with general formula MXY, which can be described by the same SPS provided the centre of mass of the X-Y dumbbell is considered (Fig. S14, S15): cobaltite, CoAsS, ullmanite, NiSbS, and gersdorffite, NiAsS, correspond to this hettotype (Fig. 22(a)). The symmetry the real structure is reduced to a subgroup of $P a \overline{3}$ because of the presence of two different types of $\mathrm{X}$ atoms (Fig. 22(b)).

Author

[Akihiro Umayahara, Massimo Nespolo*]
Title

[Derivative structures based on the sphere packing]
File Name Date

ZKrist_Special_I 12.12.2017 ssue2017_Umay ahara-Nespolorevised.odt 
The structure of fluorite, $\mathrm{CaF}_{2}$, can be described as based on edge-sharing $\mathrm{FCa}_{4}$ tetrahedra, with an SPS symbol $\mathrm{A}(11-) \mathrm{B}(-11) \mathrm{C}(1-1)$ or S-(11)D-(11) (Fig. 23(a)). The real structure coincides with the undistorted hettotype obtained from the aristotype by removing the octahedral cation and exchanging the role of cations and anions; consequently, the similarity parameters are all zero. The same structure can also be described as cation centred, with an SPS symbol $\mathrm{S}(1 / 2) \mathrm{S}(1 / 2)$, which indicates a stacking of tetragonal sheets with all the $\mathrm{X}$ atoms in $\mathrm{S}$ position and a period of two sheets (Fig. 23(b)). The cubic cavity is occupied for $1 / 2$, leading to the stoichiometry $\mathrm{MX}_{2}$. Now, the doubling of the symbol, $S(1 / 2) S(1 / 2)$ instead of $S(1 / 2)$, means an ordered distribution of cations so that each occupied cube is surrounded by empty cubes and vice versa, leading to edge sharing. A single symbol would mean a disordered distribution of the $\mathrm{M}$ atoms in the cubic cavities, leading locally to face sharing of cubes of the same type (empty or occupied), which is an energetically less favourable because of the higher repulsion between $\mathrm{M}$ atoms.

From the structure of fluorite, we obtain that of litharge, $\mathrm{PbO}$, and romarchite, $\mathrm{SnO}$, by removing a plane of anions. The basis vector transformation is $1 / 2 \mathbf{a}-1 / 2 \mathbf{b}, 1 / 2 \mathbf{a}+1 / 2 \mathbf{b}, \mathbf{c}$, origin shift $1 / 4,0,1 / 4$; this transformation, together with the removal of one plane of oxygen out of two, leads to symmetry reduction to $P 4 / \mathrm{nmn}$. The resulting structure can be interpreted as a derivative of sphere packing of cations, with anion-centred polyhedra. The SPS is S(1-)D(--) showing that one tetrahedron $\mathrm{OPb}_{4}$, or $\mathrm{OSn}_{4}$, is occupied between $\mathrm{S}$ and $\mathrm{D}$, whereas both are empty between $\mathrm{D}$ and $\mathrm{S}$. The octahedra, located in the plane of the S and D sheets, are empty (Fig. 24). The Wyckoff splitting scheme is shown in Fig. S16.

When one of the two tetrahedra is occupied, the SPS becomes S-(1-)D-(-1) or A(-1-)B(--1)C(1--) for both the cationcentred and the anion centred description. The occupation of only one tetrahedron out of two reduces the symmetry to the non-centrosymmetric subroup type $F 4 \overline{3} \mathrm{~m}$; the structure of sphalerite, $\mathrm{ZnS}-3 C$, coloradoite, $\mathrm{HgTe}$ and tiemannite, $\mathrm{HgSe}$, correspond exactly to the hettotype (Fig. 25(a) and S17). The role of the $\mathrm{X}$ and $\mathrm{T}$ atoms is interchangeable so that the anion-centred description has the same SPS as the cation-centred description (Fig. 25(b)).

A substitution derivative structure of sphalerite is obtained by an ordered distribution of cations in the tetrahedral sites. This corresponds to the structures of chalcopyrite, $\mathrm{CuFeS}_{2}$, and gallite, $\mathrm{CuGaS}_{2}$. The SPS is simply twice that of sphalerite, A(-1-)B(--1)C(1--)A(-1-)B(--1)C(1--) or S-(1-)D-(-1)S-(1-)D-(-1), where the doubling of the period along the stacking direction comes from the ordering of the T cations (Fig. 26 and S18).

The hettotype corresponding to sulvanite, $\mathrm{Cu}_{3} \mathrm{VS}_{4}$, is obtained with an unusual pattern of partial occupation of the tetrahedra. From the $c c p$ prototype the sulvanite hettotype is obtained with symmetry reduction to $P \overline{4} 3 m$, basis vectors in common but a shift of the origin $1 / 4,1 / 4,1 / 4$. Octahedra are empty; sulphur position changes from $4 b$ in the aristotype to $4 e$ in the hettotype, without splitting but with a reduction in the site-symmetry group from $m \overline{3} m$ to $.3 m$. The tetrahedral site moves from $8 c$ in the aristotype to $1 a+1 b+3 c+3 d$; position $1 a$ hosts vanadium, position $3 d$ copper, the others are empty (Fig. S19). This results in a different occupation of the tetrahedra in the two inter-sheet regions, SD and DS. Between $\mathrm{S}$ and D one of the two T1 tetrahedra is occupied, by V, the other is empty; the two tetrahedra T2 are both occupied by $\mathrm{Cu}$. On the other hand, between $\mathrm{D}$ and $\mathrm{S}$ one of the tetrahedra T2 is occupied by $\mathrm{Cu}$ whereas the other $\mathrm{T} 2$ as well as the two T1 are empty (Fig. 27). The resulting SPS is $\mathrm{S}(1 / 21) \mathrm{D}(-1 / 2)$.

A similar, although somewhat simpler situation, occurs in bornite (erubescite). $\mathrm{Cu}_{5} \mathrm{FeS}_{2}$, whose hettotype is obtained from the aristotype by reducing the symmetry to $F 23$ and keeping in common the basis vectors as well as the origin. The octahedra are empty, the tetrahedra are one fully occupied, the other half occupied, and the distribution is reversed in the two inter-sheet regions, leading to SPS $\mathrm{S}\left(1 \frac{1}{2}\right) \mathrm{D}\left(1 \frac{1}{2} 1\right)$, or $\mathrm{A}\left(1 \frac{1}{2-}\right) \mathrm{B}\left(-1 \frac{1}{2}\right) \mathrm{C}\left(1 \frac{1}{2}-1\right)$ (Fig. $\left.\mathrm{S} 20\right)$. $\mathrm{Cu}$ and $\mathrm{Fe}$ are disordered; each tetrahedron, whether fully or half occupied, hosts a $\mathrm{Cu} / \mathrm{Fe}$ ratio of $5 / 1$ (Fig. 28). If we ignore the partial occupation of half of the tetrahedra, the cation-centred structure of bornite is the same as the anion-centred structure of fluorite. Accordingly, an anion-centred description of bornite should correspond to the cation-centred description of fluorite, whose SPS is $\mathrm{S}(1 / 2) \mathrm{S}(1 / 2)$. However, because the cation sites in each plane are alternatively fully and halfoccupied, the SPS would no faithfully represent the structure.

A somewhat more complex structure, with partial occupation of both tetrahedra and octahedra, occurs in spinel and pentlandite. The spinel structure occurs in a large number of natural and synthetic crystals (Table 8 lists only a few representatives) with half occupation of the octahedra and one fourth occupation of one of the two tetrahedra, alternatively T1 and T2, in the SD stacking. The unit cell of the hettotype is obtained from that of the aristotype by Author Title

File Name Date Page 
doubling the period along the three directions, with a symmetry reduction to the klanssengeiche subgroup $F d \overline{3} m$ (Fig. $\mathrm{S} 21$ ). In each of the inter-sheet region, two of the sixteen tetrahedra are occupied, both of the same type, but alternatively of different type in neighbouring regions, with a sequence T1[1/4]T2[0] and T1[0]T2[1/4] (in square brackets the fractional occupation). The two tetrahedra out of eight of the same type occupied in a region are different from those in the next region (Fig. 29), so that the period of the structure actually encompasses two SD sequences, leading to the

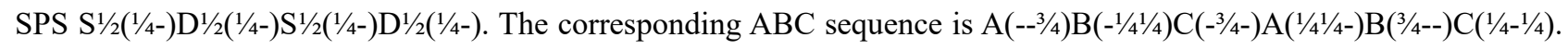
The general formula is $\mathrm{M}_{\left[4 \times^{1 / 2}\right]} \mathrm{T}_{\left[4 \times^{1 / 4}\right]} \mathrm{X}_{4}=\mathrm{M}_{2} \mathrm{TX}_{4}$.

In the case of pentlandite, the unit cell of the hettotype is obtained from that of the aristotype by doubling the period along the three directions, exactly as in the case of spinels, but the symmetry reduction is to the klassengeiche subgroup $F m \overline{3} m$ (Fig. S22). Both T1 and T2 are half occupied: four of the eight tetrahedra of each type in each of the inter-sheet region, but different from region to region, leading again to a doubling to the SPS. The octahedra are alternatively empty or occupied for one fourth (Fig. 30). This leads to the SPS S- $(1 / 21 / 2) D^{1 / 4}(1 / 21 / 2) S-(1 / 21 / 2) D^{1 / 4}(1 / 21 / 2)$. The corresponding $\mathrm{ABC}$ sequence is $\mathrm{A}\left(1 / 4^{1 / 4} \mathbf{1}^{1 / 4}\right) \mathrm{B}\left(-3 / 4^{3 / 4}\right) \mathrm{C}\left(1 / 4^{1 / 4} 4^{1 / 4}\right) \mathrm{A}\left(3 / 4^{3 / 4}-\right) \mathrm{B}\left(1 / 4^{1 / 4} 4^{1 / 4}\right) \mathrm{C}\left(3 / 4^{-3 / 4}\right)$.

\section{Structures based on different stackings}

The simplest stacking not based on an $h c p$ or $c c p$ model is that of $\mathrm{CsCl}$, whose SPS is $\mathrm{S}(1)$, representing $\mathrm{MX}_{8}$ cubes or, alternatively, $\mathrm{XM}_{8}$ cubes. The hettotype coincides with the aristotype.

Brookite is the orthorhombic polymorph of $\mathrm{TiO}_{2}$, whose structure is based on the sequence ACAB, which is known as a double-hexagonal because in the sequence ...ACABACABACAB ... the sheets $\mathrm{C}$ and $\mathrm{B}$ are surrounded by pairs of $\mathrm{A}$, leading to a local $h c p$ environment, whereas sheets A are surrounded by $\mathrm{B}$ and $\mathrm{C}$, leading to a $c c p$ environment. The hettotype corresponding to brookite is obtained from the ACBC aristotype by emptying the tetrahedral cavities and filling half of the octahedral cavities (Fig. S23). The structure is shown in Fig. 31.

Molybdenite, $\mathrm{MoS}_{2}$, has a structure based on the stacking BBCC. The hettotype has SPS B(-1)B(---)C(-1)C(---):. molybdenum takes place in trigonal prisms in the inter-sheet regions $\mathrm{BB}$ and $\mathrm{CC}$, whereas the octahedral and tetrahedral cavities in in the BC and CB inter-sheet regions do not contain metal atoms (Fig. S24 and 32). This empty inter-sheet region justifies the low hardness $\left(1-1 \frac{1}{2}\right)$; indeed, molybdenite is used as solid lubricant.

Covellite, CuS, has an unusually complex structure whose SPS is A--(--1)C-1(--1)A--(--)A--(-1-)B-1(-1-)A--(--); the splitting scheme with respect to the aristotype is shown in Fig. S25. The two triangular cavities in the plane of the first sheet (A) are empty, one of the two tetrahedra ( $\mathrm{T}^{+}$, pointing up along stacking direction) between the first two sheets (A and $C$ ) is occupied, while the other tetrahedron and the octahedron are empty. In the plane of the second sheet $(C)$ the $t_{2}$ triangular cavity is occupied and between this sheet and the third one the tetrahedron $\mathrm{T}^{-}$(pointing down the stacking direction) is occupied, so that is shares only a corner with the tetrahedron $\mathrm{T}^{+}$between the first and the second sheet. The third and fourth sheets are both of type A and between them two triangular prisms occur, which are however both unoccupied, as it is also the case of the triangular cavities in the planes of the sheets. Between the fourth (A) and the fifth (B) sheet, only the tetrahedron $\mathrm{T}^{+}$is occupied, which again shares a corner with the tetrahedron $\mathrm{T}^{-}$occupied between the fifth (B) and the sixth (A) sheet. The $t_{1}$ triangular cavity in the plane of the B sheets is also occupied. Finally, none of the cavities between the sixth and the seventh sheet, both of the type A, are occupied. The stoichiometry we can obtain from the SPS is $\mathrm{M}_{6} \mathrm{X}_{6}=\mathrm{MX}$. This structure occurs also in klockmannite, CuSe, besides covellite, CuS (Fig. 33(a)). The bonding is covalent, as one should expect from the occurrence of the AA stacking in the sequence. Further, the lack of any metal atom in the two AA portions of the sequence suggests weaker bonds in those regions, with easy cleavage and low hardness: indeed, covellite and klockmannite have Mohs hardness between $1 \frac{1 / 2}{2}$ and 2 and between 2 ans $2^{1 / 2}$ respectively, and perfect cleavage on (0001). The anion centred description is particularly interesting in this case. From the fractional atomic coordinates, the SPS is immediately obtained as A1-(---)B-1(---)A-1(---)B1(---)A1-(---)B1-(---). Only one of the two triangular cavities in the plane of the each sheet is occupied by a sulphur/selenium atom, $t_{1}$ in the sheets No. $1,4,5$ and $6, t_{2}$ in the other two sheets. In the plane of the sheets No. $1,3,4$ and 6 the occupied cavities face sulphur/selenium atoms on the two sides, whereas in the second and fifth sheet they faces copper atoms. As a consequence, in the sheets No. 1, 3, 4 and 6 the sulphur/selenium atoms moves slightly outside

Author Title File Name Date Page

[Akihiro Umayahara, [Derivative structures based on the sphere packing]

ZKrist_Special_I $12.12 .2017 \quad 9$ (17)

Massimo Nespolo*]

ssue2017_Umay

ahara-Nespolo-

revised.odt 
the plane of the copper atoms, whereas in the sheets No. 2 and 5 they are bonded to copper atoms outside the plane of the sheet, leading to a five-fold coordination (Fig. 33(b)). These deviations from the ideal coordination are clearly not taken into account in the symbol, but the undistorted hettotype obtained from the symbol suggests it is actually very close to the real structure.

\section{Discussion}

The importance of classifying crystal structures in structure types has been recognized long ago and has produced various classification schemes (see, e.g., Wells, 1984). One of the first criteria to be adopted was based on the stoichiometry: it classifies simple crystalline compounds in terms of a generalized chemical formula like $\mathrm{M}_{\mathrm{p}} \mathrm{X}_{\mathrm{r}}$ or $\mathrm{M}_{\mathrm{p}} \mathrm{M}_{\mathrm{q}}^{\prime} \mathrm{X}_{\mathrm{r}}$, The practical usefulness of such a classification scheme is limited; compounds with the same formula often have completely different structures, as we have seen for the cases of olivine and spinels, both with formula $\mathrm{M}_{2} \mathrm{TX}_{4}$. The use of coordination polyhedra is more useful as a classification criterion (see, e.g., Müller, 2007). The structure of many non-molecular crystals is based, with some degree of idealization, on simple coordination polyhedra (octahedra, tetrahedra, cubes...) which are formed by stacking dense atomic sheets that, at least in a first approximation, can be described as spheres. An upper level of classification makes use of modules (bricks, rods, layers) to identify common structural features in apparently quite diverse structures, known as modular structures (Nespolo et al., 1999; Ferraris et al., 2008).

Since long ago, attempts have been made to provide a handy, symbolic description of crystal structures as a mean to emphasise fundamental common features and to predict yet-to-be-discovered structures. For close packed structures, different symbols are widely employed in the literature (Hägg, Nabarro-Frank, Jagodzinski, Zdhanov), for instance to generate potential new polytypes (Estevez-Rams and Martinez-Mojicar, 2008). These symbols account for the topology of the sphere packing, but do not explicitly consider their stuffed derivatives, i.e. structures resulting from the various possible patterns of filling the coordination sites obtained by the stacking of spheres. The symbols introduced by Zoltai and Stout (1984) are particularly useful to describe this type of structures and superior to their predecessors. The comparison of the hettotype described by these symbols and the real structures shows how far the latter are from the former. In many cases, the similarity is striking. In some cases, the deviation is more important and the real structure can be interpreted as a derivative of sphere packing only with a certain degree of idealization. Far from being an unrealistic description, this represents a unifying model for structures which, although different, share a common aristotype. This opens therefore the possibility of algorithmically generating the possible hettotypes of a given aristotype as a function of the number of sheets and the scheme of occupation of the coordination polyhedra. The computation power today provided by crystallographic tools like the Bilbao Crystallographic Server of the ISOTROPY software suite (http://iso.byu.edu/) makes possible to endeavour such a task. The investigator needs however a solid crystallographic background because it often happens that the hettotype does not correspond to a standard setting of the space group and a black-box approach may easily fail to recognize the need of a suitable change of basis (Nespolo and Aroyo, 2016).

Despite the large number of structures we have discussed, the picture is far from being exhaustive and many other structures can be related to the same aristotype. For example, the structure of calcite can be related to the $\mathrm{NaCl}$ hettotype be replacing chlorine with a carbonate group, with a corresponding symmetry reduction from cubic to rhombohedral (Zoltai and Stout, 1984). Although some may consider this an extreme example, we believe it is a useful way of rationalizing structures apparently unrelated, and a useful didactic tool for students facing mnemonic challenges to understand and retain fundamental structure types.

Author

[Akihiro Umayahara, Massimo Nespolo*]
Title

[Derivative structures based on the sphere packing]
File Name

Date

Page

ZKrist_Special_I 12.12.2017 ssue2017_Umay ahara-Nespolorevised.odt 


\section{Captions of the figures to be printed}

Fig. 1. The hexagonal (top) and tetragonal (bottom) sheet made of spheres of equal size in contact (left: $n a / D=1$ ) or not (right: $n>$ 1).

Fig. 2. Symbolic code representing positions in the hexagonal (top) and tetragonal (bottom) with the site-symmetry group higher than 1 and a symmetry element normal to the plane of the sheet.

Fig. 3. Stacking AA and positions $\mathrm{P}_{1}$ and $\mathrm{P}_{2}$ of the trigonal prisms.

Fig. 4. Stacking $\mathrm{AB}$ and the positions $\mathrm{T}^{+}, \mathrm{T}^{-}, \mathrm{M}$ in the inter-sheet region. The same cavities are formed when two sheets corresponding to different symbols are stacked one on the top of the other.

Fig. 5. Stacking SS and the position corresponding to the centre of the cubic cavities, which is also the position of the sphere D in the SD stacking.

Fig. 6. Stacking SD and the positions of the octahedral cavity (M), in the plane of the sheet, and of the two tetrahedral cavities (T1, T2) in the inter-sheet region.

Fig. 7. Stacking $\mathrm{ABC}$ and its alternative description as $\mathrm{SD}$ as a function of the direction along which the structure is observed.

Fig. 8. The hettotype corresponding to the structure of olivine, whose SPS is $\mathrm{C}\left(1 / 2^{1 / 8} 8^{1} / 8\right) \mathrm{B}\left(1 / 2^{1} / 8^{1 / 8}\right)$, obtained from the $h c p$ hettotype by a change of basis (see Table 7). The letters indicating the the positions of the spheres are inherited from the aristotype. This and the following structural figures are drawn with Vesta (Momma and Izumi, 2011).

Fig. 9. (a). The hettotype of nickeline, NiAs, described as cation-centred. The spheres represent As atoms, whose positions correspond alternatively to $\mathrm{C}\left(1 / 3^{2} / 3 z\right)$ and $\mathrm{B}\left(2 / 3^{1} / 3 z\right)$. The NiAs 6 octahedra share their faces. The real structure differs from the hettotype for a small deviation of the $c / a$ ratio from the value $(8 / 3)^{1 / 2}$, without any displacement of the coordinates atoms. This is shown in Table 7, where two of the similarity parameters $\left(d_{\max }\right.$ and $\left.d_{a v}\right)$ are zero. (b) The hettotype of nickeline, NiAs, described as anion-centred. The spheres represent $\mathrm{Ni}$ atoms, whose positions correspond to $\mathrm{A}(00 z)$. The occupied trigonal prisms are alternatively of type $\mathrm{P}_{1}$ $(2 / 313 z)$ and $\mathrm{P}_{2}(1 / 3 / 3 z)$ so that $\mathrm{AsNi}_{6}$ trigonal prisms share their edges but not their faces.

Fig. 10.The hettotype of corundum, $\mathrm{Al}_{2} \mathrm{O}_{3}$, and hematite, $\alpha-\mathrm{Fe}_{2} \mathrm{O}_{3}$. The spheres represent oxygen atoms, whose positions correspond alternatively to $\mathrm{C}$ and $\mathrm{B}$. The octahedra share their faces along $\mathbf{c}$ and their edges in the directions perpendicular to c. Only two out of three octahedra are occupied, in a regular distribution why makes each occupied octahedra surrounded by one occupied and one empty octahedron along the c direction; the coordinates atoms are displaced from the centre of the octahedra, towards the empty cavities. This displacement reduces the repulsion and is responsible for the distortion of the real structure with respect to the hettotype. All the similarity parameters are non-zero (Table 7), but very small. The same figure can describe also the hettotype of ilmenite, $\mathrm{FeTiO}_{3}$, provided that $\mathrm{Fe}$ and $\mathrm{Ti}$ are ordered in the octahedra.

Fig. 11. The hettotype (a) and real structure (b) of marcasite, $\mathrm{FeS}_{2}$, and lollingite, $\mathrm{FeAs}_{2}$. The very significant rotation of the octahedra, resulting in a wavy distribution of the anions which no longer form a plane, is responsible for the high values of the similarity parameters (Table 7). Yet, the relation with the aristotype is clearly evident.

Fig. 12. The hettotype of rutile, $\mathrm{TiO}_{2}$, and its isotypes. The real structure (not shown because practically indistinguishable) is very close to the hettotype, as indicated by the small values of the similarity parameters (Table 7). The lack of rotation of the octahedra makes the structure of rutile more symmetric than that of marcasite, which is represented by the same SPS. In particular, the hettotype is in group-subgroup relation with the aristotype in case of marcasite, whereas for rutile the relation is through a common subgroup, which is of the same type as that of marcasite (Fig. S5).

Fig. 13. The real structure of arsenopyrite, $\mathrm{FeAsS}_{2}$, and its isotypes, to be compared with the hettotype of marcasite (Fig, 12a). The rotation of the octahedra about the $\mathbf{c}$ axis is less pronounced with respect to the sulphides; on the other hand, a significant rotation about a occurs. As a result, each plane of $\mathrm{B}$ and of $\mathrm{C}$ atoms in the hettotype is split into two planes in the real structures.

Fig. 14. The hettotype of wurtzite, $\mathrm{ZnS}-2 \mathrm{H}$, and its isotypes, described as cation-centred (a) and as anion-centred (b). The small value of the similarity parameters (Table 7) indicates that the real structure is very close to the hettotype.

Fig. 15. The hettotype of enargite, $\mathrm{Cu}_{3} \mathrm{AsS}_{4}$. $\mathrm{Cu}$ and $\mathrm{As}$ are ordered inside each pair of sheets.

Fig. 16. (a) The $h c p$ aristotype drawn in the unit cell of cubanite, with the octahedral sites removed and the tetrahedral sites separated in two types: black and white, respectively occupied and empty in cubanite. (b) The hettotype of cubanite, obtained from (a) by removing the white (unoccupied tetrahedra) and ordering $\mathrm{Cu}$ (grey) and $\mathrm{Fe}$ (black) in the occupied tetrahedra.

Fig. 17. (a). The $h c p$ aristotype drawn in the unit cell of argentopyrite, with the octahedral sites removed and the tetrahedral sites separated in two types: black and white, respectively occupied and empty in argentopyrite. (b). The hettotype of argentopyrite, obtained from Fig. (a) by removing the white (unoccupied tetrahedra) and ordering Ag (grey) and Fe (black) in the occupied tetrahedra.

Fig. 18. The hettotype of brucite, $\mathrm{Mg}(\mathrm{OH})_{2}$. The inter-sheet region is alternatively occupied by cations $(\mathrm{Mg})$ or empty.

Fig. 19. The $c c p$ aristotype, which corresponds to the structure of $\mathrm{Li}_{3} \mathrm{Bi}$.

Fig. 20. The hettotype of anatase.

Fig. 21. The real structure of pyrite. By replacing the S-S dumbbell with its centre of mass, we obtain the hettotype that corresponds to the structure of $\mathrm{NaCl}$.

Fig. 22. The hettotype (a) and real structure (b) of cobaltite (the same figure applies also to ullmanite and gersdorrfite). As in the case of pyrite and its isotypes, the real structure can be related to its hettotype by taking the centre of mass of the dumbbell, in this case As-S.

Fig. 23. The structure of fluorite described as (a) anion centred: the $\mathrm{FCa}_{4}$ tetrahedra share their edges; (b) cation centred: the $\mathrm{CaF}_{8}$ cubes share their edges.

Fig. 24. Comparison of the structure of litharge or romarchite (left) with that of fluorite (right). In the anion-centred description, the former can be obtained from the latter by a suitable change of axes (Table 8) and by removing one plane of anions.

Fig. 25. The structure of sphalerite and its isotypes, which coincides with its hettotype, in the cation-centred (a) and anion-centred (b) description. The two descriptions are in this case interchangeable.

Author

[Akihiro Umayahara, Massimo Nespolo*]
Title

[Derivative structures based on the sphere packing]
File Name

Date

Page

ZKrist_Special_I 12.12 .2017

ssue2017 Umay

ahara-Nespolo-

revised.odt 
Fig. 26. The hettotype of chalcopyrite and gallite, obtained by a suitable change of axes (Table 8) and by removing the positions that are not occupied in the real structure.

Fig. 27. The hettotype of sulvanite, obtained by a suitable change of axes (Table 8) and by removing the positions that are not occupied in the real structure. White tetrahedron: V; grey tetrahedra: $\mathrm{Cu}$.

Fig. 28. The hettotype of bornite, obtained by a suitable change of axes (Table 8) and by removing the octahedra, not occupied in the real structure. Tetrahedra are occupied for $1 / 6$ by $\mathrm{Fe}$ and $5 / 6$ by $\mathrm{Cu}$; furthermore, half of the tetrahedra are only half-occupied, with the same ratio. Black: $\mathrm{Cu}$; grey: $\mathrm{Fe}$; white: empty.

Fig. 29. The hettotype of spinels and thiospinels, obtained by a suitable change of axes (Table 8) and by removing the positions that are not occupied in the real structure.

Fig. 30. The hettotype of pentlandite, obtained by a suitable change of axes (Table 8) and by removing the positions that are not occupied in the real structure.

Fig. 31. The hettotype of brookite, obtained by a suitable change of axes (Table 9) and by removing the positions that are not occupied in the real structure.

Fig. 32. The hettotype of molybdenite, with half of the trigonal prisms occupied in the $\mathrm{BB}$ and $\mathrm{CC}$ regions, and no cation in the $\mathrm{BC}$ and $\mathrm{CB}$ regions.

Fig. 33. The hettotype of covellite and klockmannnite, described as (a) cation-centred; (b) as anion-centred.

\section{Captions of the figures to be deposited}

Fig. S1. Contracted Bärnighausen tree showing the group-subgroup relation and the corresponding Wyckoff position splitting scheme of forsterite with respect to the hcp aristotype.

Fig. S2. Contracted Bärnighausen tree showing the group-subgroup relation and the corresponding Wyckoff position splitting scheme of nickeline and its isotypes with respect to the $h c p$ aristotype.

Fig. S3. Contracted Bärnighausen tree showing the group-subgroup relation and the corresponding Wyckoff position splitting scheme of corundum and hematite with respect to the hcp aristotype.

Fig. S4. Contracted Bärnighausen tree showing the group-subgroup relation and the corresponding Wyckoff position splitting scheme of ilmenite with respect to the $h c p$ aristotype.

Fig. S5. Contracted Bärnighausen tree showing the group-subgroup relation and the corresponding Wyckoff position splitting scheme of marcasite with respect to the $h c p$ aristotype (left) and well as the path from the aristotype to the rutile hettotype through a common subgroup (right).

Fig. S6. Contracted Bärnighausen tree showing the group-subgroup relation and the corresponding Wyckoff position splitting scheme of arsenopyrite with respect to the $h c p$ aristotype.

Fig. S7. Contracted Bärnighausen tree showing the group-subgroup relation and the corresponding Wyckoff position splitting scheme of wurtzite and its isotypes with respect to the hcp aristotype.

Fig. S8. Contracted Bärnighausen tree showing the group-subgroup relation and the corresponding Wyckoff position splitting scheme of enargite with respect to the $h c p$ aristotype.

Fig. S9. Contracted Bärnighausen tree showing the group-subgroup relation and the corresponding Wyckoff position splitting scheme of cubanite with respect to the $h c p$ aristotype.

Fig. S10. Contracted Bärnighausen tree showing the group-subgroup relation and the corresponding Wyckoff position splitting scheme of argentopyrite with respect to the $h c p$ aristotype.

Fig. S11. Contracted Bärnighausen tree showing the group-subgroup relation and the corresponding Wyckoff position splitting scheme of brucite with respect to the $h c p$ aristotype.

Fig. S12. Contracted Bärnighausen tree showing the group-subgroup relation and the corresponding Wyckoff position splitting scheme of anatase with respect to the $c c p$ aristotype.

Fig. S13. Contracted Bärnighausen tree showing the group-subgroup relation and the corresponding Wyckoff position splitting scheme of pyrite and its isotypes with respect to the $c c p$ aristotype.

Fig. S14. Contracted Bärnighausen tree showing the group-subgroup relation and the corresponding Wyckoff position splitting scheme of cobaltite with respect to the $c c p$ aristotype.

Fig. S15. Contracted Bärnighausen tree showing the group-subgroup relation and the corresponding Wyckoff position splitting scheme of ullmanite and gersdorffite with respect to the $c c p$ aristotype.

Fig. S16. Contracted Bärnighausen tree showing the group-subgroup relation and the corresponding Wyckoff position splitting scheme of litharge and romarchite with respect to the $c c p$ aristotype.

Fig. S17. Contracted Bärnighausen tree showing the group-subgroup relation and the corresponding Wyckoff position splitting scheme of sphalerite and its isotypes with respect to the $c c p$ aristotype.

Fig. S18. Contracted Bärnighausen tree showing the group-subgroup relation and the corresponding Wyckoff position splitting scheme of chalcopyrite and gallite with respect to the $c c p$ aristotype.

Fig. S19. Contracted Bärnighausen tree showing the group-subgroup relation and the corresponding Wyckoff position splitting scheme of sulvanite with respect to the $c c p$ aristotype.

Fig. S20. Contracted Bärnighausen tree showing the group-subgroup relation and the corresponding Wyckoff position splitting scheme of bornite with respect to the $c c p$ aristotype.

Fig. S21. Contracted Bärnighausen tree showing the group-subgroup relation and the corresponding Wyckoff position splitting scheme of spinels and thiospinels with respect to the $c c p$ aristotype.

Fig. S22. Contracted Bärnighausen tree showing the group-subgroup relation and the corresponding Wyckoff position splitting scheme of pentlandite with respect to the $c c p$ aristotype.

Fig. S23. Contracted Bärnighausen tree showing the group-subgroup relation and the corresponding Wyckoff position splitting scheme of brookite with respect to the $\mathrm{ACAB}$ aristotype.

Author

Title

[Akihiro Umayahara,

Massimo Nespolo*]
[Derivative structures based on the sphere packing]
File Name

Date

Page

ZKrist_Special_I 12.12.2017

ssue2017 Umay

ahara-Nespolo-

revised.odt 
Fig. S24. Contracted Bärnighausen tree showing the group-subgroup relation and the corresponding Wyckoff position splitting scheme of molybdenite with respect to the BBCC aristotype.

Fig. S25. Contracted Bärnighausen tree showing the group-subgroup relation and the corresponding Wyckoff position splitting scheme of covellite and klockmannite with respect to the ACAABA aristotype.

Acknowledgements. This research has been conducted during a short term study abroad stay (AU) at Université de Lorraine, France, funded by the Tobitate Japan Scholarship Program. Critical comments from two anonymous reviewers are gratefully acknowledged.

\section{References}

S.C. Abrahams, J.L. Bernstein, Piezoelectric nonlinear optic $\mathrm{CuGaS}_{2}$ and $\mathrm{CuInS}_{2}$ crystal structure, Sublattice distortion in AIBIIIC2VI and AIIBIVC2V type chalcopyrites. J. Chem. Phys. 1973, 59, 5415-5420.

N. Alsen, Roentgenographische Untersuchungen der Kristallstrukturen von Magnetkies, Breithauptit, Pentlandit, Millerit und verwandten Verbindungen. Geol. Foer. Stock. Foerh. 1925, 47, 19-73.

M.I. Aroyo, J.M. Perez-Mato, C. Capillas, E. Kroumova, S. Ivantchev, G. Madariaga, A. Kirov, H. Wondratschek, Bilbao Crystallographic Server I: Databases and crystallographic computing programs. Z. Kristallogr. 2006, 221, 15-27.

W. Barlow, Probable Nature of the Internal Symmetry of Crystals. Nature 1883, 29, 186-188.

H. Bärnighausen, Group-Subgroup Relations between Space Groups: A Useful Tool in Crystal Chemistry. MATCH Commun. Math. Comput. Chem. 1980, 9, 139-175.

P. Bayliss, Crystal structure refinement of arsenian ullmannite approximate cubic structure. Am Mineral. 1977, 62, 369-373.

P. Bayliss, A further crystal structure refinement of cobaltite. Am Mineral. 1982, 67, 1048-1057.

G. Bergerhoff, M. Berndt, K, Brandenburg, T. Degen, Concerning inorganic crystal structure types. Acta Crystallogr. 1999, B55, 147156.

L.G. Berry, The crystal structure of covellite, CuS and klockmannite, CuSe. Am Mineral. 1954, 39, 504-509.

L. Bindi, Y. Moelo, P. Leone, M. Suchaud, M., Stoichiometric arsenopyrite, FeAsS, from La Roche-Balue Quarry, Loire-Atlantique, France, Crystal structure and Mössbauer study. Can. Mineral. 2012, 50, 471-479.

A.A. Bolzan, C. Fong, B.J. Kennedy, C. J. Howard, Structural studies of rutile-type metal dioxides. Acta Crystallogr. 1997, B53, 373-380.

M.J. Buerger, The crystal structure of gudmundite. Am Mineral. 1939, 24, 183-184.

M.J. Buerger, Derivative structures. J. Chem. Phys. 1947, 15, 1-16.

W. de Jong, Die Struktur des Tiemannit und Koloradoit. Z. Kristallogr. 1926, 63, 466-472.

G. de la Flor, D. Orobengoa, E. Tasci, J.M. Perez-Mato, M.I. Aroyo, M.I., Comparison of structures applying the tools available at the Bilbao Crystallographic Server. J. Appl. Crystallogr. 2016, 49, 653-664.

K. Dornberger-Schiff, On the nomenclature of the 80 plane groups in three dimensions. Acta Crystallogr., 1959, $12,173$.

J.W. Earley, Description and syntheses of the selenide minerals. Am Mineral. 1950, 35, 337-364.

J.-G. Eon, M. Nespolo, Charge distribution as a tool to investigate structural details. III. Extension to description in term of anioncentred polyhedra. Acta Crystallogr. 2015, B71, 34-47.

E. Estevez-Rams, R. Lora Serrano, A. Penton Madrigal, M. Nespolo, Extrinsic faulting in $3 C$ close packed crystal structures: Computational mechanics analysis. Acta Crystallogr. 2017, A73, 449-459.

E. Estevez-Rams, J. Martinez-Mojicar, The symmetry of HK codes representing close-packed structures and the efficient generation of non-equivalent polytypes of a given length. Acta Crystallogr. 2008, A64, 529-536.

Author

[Akihiro Umayahara,

Massimo Nespolo*]
Title

[Derivative structures based on the sphere packing]
File Name Date Page

ZKrist_Special_I $12.12 .2017 \quad 13$ (17) ssue2017 Umay

ahara-Nespolo-

revised.odt 
G. Ferraris E. Makovicky S. Merlino, Crystallography of modular materials. Oxford University Press, 2008, 384 pp.

H. Fjellvag, F. Gronvold, S. Stolen, B.C. Hauback, On the crystallographic and magnetic structures of nearly stoichiometric iron monoxide. J. Solid St. Chem. 1996, 124, 52-57.

A.J. Foecker, W. Jeitschko, The atomic order of the pnictogen and chalcogen atoms in equiatomic ternary compounds $\mathrm{TPnCh}(\mathrm{T}=$ $\mathrm{Ni}, \mathrm{Pd} ; \mathrm{Pn}=\mathrm{P}, \mathrm{As}, \mathrm{Sb} ; \mathrm{Ch}=\mathrm{S}, \mathrm{Se}, \mathrm{Te}) . J$. Solid St. Chem. 2001, 162, 69-78.

A. Friedrich, D.J. Wilson, E. Haussuhl, B. Winkler, W. Morgenroth, K, Refson, V. Milman, High-pressure properties of diaspore, $\mathrm{AlO}(\mathrm{OH})$. Phys. Chem. Minerals 2007, 34, 145-157.

A. Gualtieri, P. Venturelli, In situ study of the goethite-hematite phase transformation by real time synchrotron powder diffraction. Am Mineral. 1999, 84, 895-904.

C. Haavik, S. Stolen, H. Fjellvag, M. Hanfland, D. Hausermann, Equation of state of magnetite and its high-pressure modification, Thermodynamics of the Fe-O system at high pressure. Am Mineral. 2000, 85, 514-523.

R.M. Hazen, Effects of temperature and pressure on the cell dimension and X-ray temperature factors of periclase. Am Mineral.. 1976, 61, 266-271.

C.J. Howard, T.M. Sabine, F. Dickson, Structural and thermal parameters for rutile and anatase. Acta Crystallogr. 1991, B47, 462468.

International Tables for Crystallography, Volume A: space-group symmetry, edited by M.I. Aroyo. New York: Wiley, 2016, 873 pp.

International Tables for Crystallography, Volume C: Mathematical, physical and chemical tables, third edition, edited by E. Prince. Dordrecht: Kluwer Academic Press, 2004, 1000 pp.

A. Kirfel, K. Eichhorn, Accurate structure analysis with synchrotron radiation, The electron density in $\mathrm{Al}_{2} \mathrm{O}_{3}$ and $\mathrm{Cu}_{2} \mathrm{O}$. Acta Crystallogr. 1990, A46, 271-284.

E.H. Kisi, M,M, Elcombe, U parameters for the wurtzite structure of $\mathrm{ZnS}$ and $\mathrm{ZnO}$ using powder neutron diffraction. Acta Crystallogr. 1989, C45, 1867-1870.

K.S. Knight, W.G. Marshall, S,W, Zochowski, The low-temperature and high-pressure thermoelastic and structural properties of chalcopyrite, $\mathrm{CuFeS}_{2}$. Can. Mineral. 2011, 49, 1015-1034.

T. Kohler, T. Armbruster, E. Libowitzky, Hydrogen bonding and Jahn-Teller distortion in groutite, alpha-MnOOH, and manganite, gamma-MnOOH, and their relations to the manganese dioxides ramsdellite and pyrolusite. J. Solid St. Chem. 1997, 133, 486-500.

S.V. Krivovichev, Structural Crystallography of Inorganic Oxysalts. IUCr Monograph on Crystallography 22. Oxford University Press, 2009, 324 p.

E. Kroumova, J.M. Perez-Mato, and M.I. Aroyo, WYCKSPLIT: a computer program for determination of the relations of Wyckoff positions for a group-subgroup pair. J. Appl. Crystallogr. 1998, 31, 646.

D. Lundqvist, X-ray studies on the binary system Ni-S. Ark. Miner. Geol. 1947, 24, 1-12.

E.N. Maslen, V.A. Streltsov, N.R. Streltsova, N. Ishizawa, Synchrotron X-ray study of the electron density in alpha-Fe $\mathrm{O}_{3}$. Acta Crystallogr. 1994, B50, 435-441.

C.A. McCammon, Static compression of alpha-MnS at $298 \mathrm{~K}$ to 21 GPa. Phys. Chem. Minerals 1991, 17, 636-641.

C.A. McCammon, J. Zhang, R.M. Hazen, L.W. Finger,High-pressure crystal chemistry of cubanite, $\mathrm{CuFe}_{2} \mathrm{~S}_{3}$. Am Mineral. 1992, 77 , 937-944.

E.P. Meagher, G.A. Lager, Polyhedral thermal expansion in the $\mathrm{TiO}_{2}$ polymorphs, Refinement of the crystal structures of rutile and brookite at high temperature. Can. Mineral. 1979, 17, 77-85.

H.D. Megaw, Crystal Structures: a Working Approach. Philadelphia: Saunders Co., 1973, 563 pp.

Author

[Akihiro Umayahara,

Massimo Nespolo*]
Title

[Derivative structures based on the sphere packing]
File Name

Date

Page

ZKrist_Special_I 12.12.2017

ssue2017_Umay

ahara-Nespolo-

revised.odt 
K. Momma, F. Izumi, VESTA 3 for three-dimensional visualization of crystal, volumetric and morphology data. J. Appl. Crystallogr. 2011, 44, 1272-1276.

U. Müller, Inorganic Structural Chemistry. Second edition. New York: Wiley, 2007, 268 pp.

U. Müller, Symmetry Relationships between Crystal Structures. IUCr/Oxford Science Publications, 2017, 352 pp.

T. Nagai, T. Hattori, T. Yamanaka, Compression mechanism of brucite: An investigation by the structural refinement under pressure. Am Mineral. 2000, 85, 760-764.

M. Nespolo, Charge distribution as a tool to investigate structural details. IV. A new route to heteroligand polyhedra Acta Crystallogr. 2016, B72 51-66.

M. Nespolo, M.I. Aroyo, The crystallographic chameleon: when space groups change skin. Acta Crystallogr. 2016, A72, 523-538.

M. Nespolo, G. Ferraris, S. Duurovič Y. Takéuchi, Twins vs. modular crystal structures. Z. Kristallogr. 2004, 219, 773-778.

Y. Noda, K. Masumoto, S. Ohba, Y. Saito, K. Toriumi, Y. Iwata, I. Shibuya, I.: Temperature dependence of atomic thermal parameters of lead chalcogenides, PbS, PbSe and PbTe. Acta Crystallogr. 1987, C43, 1443-1445.

E. Nowack, D. Schwarzenbach, T. Hahn, Charge densities in $\mathrm{CoS}_{2}$ and $\mathrm{NiS}_{2}$ (pyrite structure). Acta Crystallogr. 1991, B47, 650-659.

P. Ondrus, I. Vavrin, R. Skala, F. Veselovsky, Low-temperature Ni-rich lollingite from Haje, Pibram, Czech Republic, Rietveld crystal structure refinement. N. Jahr. Min. Monatsh. 2001, 4, 169-185.

R.E.G. Pacalo, E.K. Graham, Pressure and temperature dependence of the elastic properties of synthetic MnO. Phys. Chem. Minerals 1991, $18,69-80$.

L. Pauling, The principles determining the structure of complex ionic crystals. J. Am. Chem. Soc. 1929, 51, 1010-1026.

A.D. Pearson, M.J. Buerger, Confirmation of the crystal structure of pentlandite. Am Mineral. 1956, 41, 804-805.

W. Petruk, D.C. Harris, J.M. Stewart, Langisite, a new mineral, and the rare minerals cobalt pentlandite, siegenite, parkerite, and bravoite from the Langis Mine, Cobalt-Gowganda area, Ontario. Can. Mineral. 1969, 9, 597-616.

A. Pfitzner, T. Bernert, The system $\mathrm{Cu}_{3} \mathrm{AsS}--\mathrm{Cu}_{3} \mathrm{SbS}_{4}$ and investigations on normal tetrahedral structures. Z. Kristallogr. 2004, 219 , 20-26.

M. Rieder, J.C. Crelling, O. Sustai, M. Drabek, Z. Weiss, M. Klementova, Arsenic in iron disulfides in a brown coal from the North Bohemian Basin, Czech Republic. Int. J. Coal Geol. 2007, 71, 115-121.

W. RostokerObservations on the lattice parameters of the alpha and Ti O phases in the titanium-oxygen system. Trans. Am. Inst. Min. Metal. Petr. Eng. 1952, 194, 981-982.

B. Schonfeld, J.J. Huang, S.C. Moss, S. C.: Anisotropic mean-square displacements (MSD) in single crystals of $2 H$-and $3 R$-MoS . Acta Crystallogr. 1983, B39, 404-407.

B.J. Skinner, Unit-cell edges of natural and synthetic sphalerites. Am Mineral. 1961, 46, 1399-1411.

B.J. Skinner, R.C. Erd, F.S. Grimaldi, Greigite, the thio-spinel of iron, a new mineral. Am Mineral. 1964, 49, 543-555.

J.R. Smyth, R.M. Hazen, The crystal structures of forsterite and hortonolite at several temperatures. Am Mineral. 1973, 58, 588-593.

H. Sowa, H. Ahsbahs, W. Schmitz, X-ray diffraction studies of millerite Ni S under non-ambient conditions. Phys. Chem. Minerals 2004, 31, 321-327.

W.N. Stassen, R.D. Heyding, Crystal structures of $\mathrm{RuSe}_{2}, \mathrm{OsSe}_{2}, \mathrm{PtAs}_{2}$, and alpha-NiAss. Can. J. Chem. 1968, 46, $2159-2163$.

F.J. Trojer, Refinement of the structure of sulvanite. Am Mineral. 1966, 51, 890-894.

G. Tunell, C.E. Adams, On the symmetry and crystal structure of bornite. Am Mineral. 1949, 34, 824-829.

Author

[Akihiro Umayahara,

Massimo Nespolo*]
Title

[Derivative structures based on the sphere packing]
File Name

ZKrist_Special_I ssue2017_Umay ahara-Nespolorevised.odt
Date Page

$12.12 .2017 \quad 15(17)$ 
D.J. Vaughan, J.R. Craig, The crystal chemistry of iron-nickel thiospinels. Am Mineral. 1985, 70, 1036-1043.

B.W. Wechsler, C.T. Prewitt, Crystal structure of ilmenite $\left(\mathrm{FeTiO}_{3}\right)$ at high temperature and high pressure. Am Mineral. 1984, 69, 176-185.

A.F. Wells, Structural Inorganic Chemistry. Fifth edition. Oxford: Clarendon Press, 1984, 1416 pp.

H. Wondratschek, Splitting of Wyckoff positions (orbits). Min. Petr. 1993, 48, 87-96.

R.W.G. Wyckoff, Second edition. Interscience Publishers, New York, New York rocksalt structure. Crystal Structures. 1963a, 1, 85237.

R.W.G. Wyckoff, Second edition. Interscience Publishers, New York, New York rocksalt structure. Crystal Structures. 1963b, 1, 239444.

Y.N. Xu, W.Y. Ching, Electronic, optical, and structural properties of some wurtzite crystals. Phy. Rev. 1993, B48, 4335-4351.

H. Yang, W.W. Pinch, R.T. Downs, Crystal structure of argentopyrite, $\mathrm{AgFe}_{2} \mathrm{~S}_{3}$, and its relationship with cubanite. Am Mineral. 2009, 94, 1727-1730.

J. Zhang, Room temperature compressibilities of $\mathrm{MnO}$ and $\mathrm{CdO}$, further examination of the role of cation type in bulk modulus systematics. Phys. Chem. Minerals 1999, 26, 644-648.

E. Zintl, G. Brauer, Konstitution der Lithium-Wismut Legierungen. Z. Elektrochemie 193541 297-303.

T. Zoltai, J.H. Stout, Mineralogy. Concepts and Principles. Minneapolis: Burgess, 1984, 505 pp.

Table 1. Packing efficiency of the hexagonal and tetragonal sheets as a function of the parameter $n=a / \mathrm{D}$ (after Zoltai \& Stout, 1984).

\begin{tabular}{|c|c|c|}
\cline { 2 - 3 } \multicolumn{1}{c|}{} & \multicolumn{2}{c|}{ packing efficiency (PE) } \\
\hline$n$ & hexagonal sheet & tetragonal sheet \\
\hline 1 & $90.69 \%$ & $78.54 \%$ \\
\hline$(4 / 3)^{1 / 2}$ & $68.02 \%$ & $58.90 \%$ \\
\hline$(3 / 2)^{1 / 2}$ & $40.46 \%$ & $52.36 \%$ \\
\hline $2^{1 / 2}$ & $45.34 \%$ & $39.27 \%$ \\
\hline$(8 / 3)^{1 / 2}$ & $34.01 \%$ & $29.45 \%$ \\
\hline
\end{tabular}

Table 2. Site-symmetry group and fractional coordinates of the special positions in the hexagonal and tetragonal sheets

\begin{tabular}{|c|c|c|c|c|c|}
\hline \multirow[b]{2}{*}{ Sheet } & \multirow[b]{2}{*}{ site } & \multicolumn{2}{|c|}{ site-symmetry group } & \multirow[b]{2}{*}{$x$} & \multirow[b]{2}{*}{$y$} \\
\hline & & $2 \mathrm{D}$ & $3 \mathrm{D}$ & & \\
\hline \multirow{6}{*}{ Hexagonal } & A & 6. & $6 / \mathrm{mmm}$ & 0 & 0 \\
\hline & $\mathrm{B}$ & $3 .$. & $\overline{6} m 2$ & $2 / 3$ & $1 / 3$ \\
\hline & $\mathrm{C}$ & $3 .$. & $\overline{6} m 2$ & $1 / 3$ & $2 / 3$ \\
\hline & $\mathrm{D}$ & $2 .$. & $2 \mathrm{~mm}$ & $1 / 2$ & $1 / 2$ \\
\hline & $\mathrm{E}$ & $2 .$. & $2 \mathrm{~mm}$ & $1 / 2$ & 0 \\
\hline & $\mathrm{F}$ & $2 .$. & $2 \mathrm{~mm}$ & 0 & $1 / 2$ \\
\hline \multirow{4}{*}{$\begin{array}{c}\text { Tetragonal, } \\
t I \text { cell }\end{array}$} & $\mathrm{S}$ & $4 .$. & $4 / \mathrm{mmm}$ & 0 & 0 \\
\hline & $\mathrm{D}$ & $4 .$. & $4 / \mathrm{mmm}$ & $1 / 2$ & $1 / 2$ \\
\hline & $\mathrm{E}$ & $2 .$. & mmm. & $1 / 2$ & 0 \\
\hline & $\mathrm{F}$ & $2 .$. & $m m m$. & 0 & $1 / 2$ \\
\hline \multirow{4}{*}{$\begin{array}{c}\text { Tetragonal, } \\
c F \text { cell }\end{array}$} & $\mathrm{S}$ & $4 .$. & $4 / \mathrm{mmm}$ & 0 & 0 \\
\hline & $\mathrm{D}$ & $4 .$. & $4 / \mathrm{mmm}$ & 0 & $1 / 2$ \\
\hline & $\mathrm{E}$ & $2 .$. & $m m m$. & $1 / 4$ & $1 / 4$ \\
\hline & $\mathrm{F}$ & $2 .$. & mmm. & $3 / 4$ & $1 / 4$ \\
\hline
\end{tabular}


Table 3. Symmetric Packing Index (SPI) of the main types of stacking for the hexagonal and the tetragonal sheet. hcp: hexagonal close packing; $c c p$ : cubic close packing; sh: simply hexagonal: sc: simple cubic; bcc: body-centred cubic. $2 H$ and $3 \mathrm{C}$ are the polytype symbols of $h c p$ and $c c p$ respectively (after Zoltai and Stout, 1984).

\begin{tabular}{|l|c|c|c|c|}
\hline Sheet & $\boldsymbol{n}$ & stacking & Type of lattice & SPI \\
\hline \multirow{4}{*}{ Hexagonal } & 1 & $\mathrm{AB}: h c p 2 H$ & $h P$ & $74,05 \%$ \\
\cline { 2 - 5 } & 1 & $\mathrm{ABC}(\equiv \mathrm{SD}): c c p 3 C$ & $h R \alpha=60^{\circ} \equiv c F$ & $74,05 \%$ \\
\cline { 2 - 5 } & 1 & $\mathrm{~A}(\equiv \mathrm{SE}): s h$ & $h P$ & $60,46 \%$ \\
\cline { 2 - 5 } & $2^{1 / 2}$ & $2^{1 / 2} \mathrm{ABC}(\equiv \mathrm{S}): s c$ & $c P$ & $52,36 \%$ \\
\cline { 2 - 5 } Tetragonal & $(8 / 3)^{1 / 2}$ & $(8 / 3)^{1 / 2} \mathrm{ABC}\left[\equiv(4 / 3)^{1 / 2} \mathrm{SD}\right]: b c c$ & $c I$ & $68,02 \%$ \\
\hline & 1 & $\mathrm{SD}(\equiv \mathrm{ABC}): c c p$ ou $3 C$ & $c F$ & $74,05 \%$ \\
\cline { 2 - 5 } & 1 & $\mathrm{SE}(\equiv \mathrm{A}): s h$ & $h P$ & $60,46 \%$ \\
\cline { 2 - 5 } & $(4 / 3)^{1 / 2}$ & $(4 / 3)^{1 / 2} \mathrm{SD}\left[\equiv(8 / 3)^{1 / 2} \mathrm{ABC}\right]: b c c$ & $c I$ & $68,02 \%$ \\
\hline
\end{tabular}

Table 4. Site-symmetry group and fractional coordinates in the (001) plane of the special positions in the hexagonal sheet.

\begin{tabular}{|c|c|c|c|c|c|c|c|c|c|c|c|}
\hline Sheet & $\mathbf{t}_{1}$ & $\mathbf{t}_{2}$ & Pair of sheets & $\mathbf{P}_{1}$ & $\mathbf{P}_{2}$ & $\mathbf{T}^{-}$ & $\mathbf{T}^{+}$ & $\mathbf{O}$ & 0,0 & $2 / 3,1 / 3$ & $1 / 3,2 / 3$ \\
\hline $\mathrm{A}$ & $2 / 3,1 / 3$ & $1 / 3,2 / 3$ & $\mathrm{AA}$ & $2 / 3,1 / 3$ & $1 / 3,2 / 3$ & --- & --- & --- & --- & $\mathbf{t}_{1}, \mathbf{P}_{1}$ & $\mathbf{t}_{2}, \mathbf{P}_{2}$ \\
\hline $\mathrm{B}$ & $1 / 3,2 / 3$ & 0,0 & $\mathrm{BB}$ & $1 / 3,2 / 3$ & 0,0 & --- & --- & --- & $\mathbf{t}_{2}, \mathbf{P}_{2}$ & --- & $\mathbf{t}_{1}, \mathbf{P}_{1}$ \\
\hline $\mathrm{C}$ & 0,0 & $2 / 3,1 / 3$ & $\mathrm{CC}$ & 0,0 & $2 / 3,1 / 3$ & --- & --- & --- & $\mathbf{t}_{1}, \mathbf{P}_{1}$ & $\mathbf{t}_{2}, \mathbf{P}_{2}$ & --- \\
\hline & & & $\mathrm{AB}$ & --- & --- & 0,0 & $2 / 3,1 / 3$ & $1 / 3,2 / 3$ & $\mathbf{T}^{-}$ & $\mathbf{t}_{\mathbf{1}}, \mathbf{T}^{+}$ & $\mathbf{t}_{2}, \mathbf{O}$ \\
\hline & & & $\mathrm{BC}$ & --- & --- & $2 / 3,1 / 3$ & $1 / 3,2 / 3$ & 0,0 & $\mathbf{t}_{2}, \mathbf{O}$ & $\mathbf{T}^{-}$ & $\mathbf{t}_{1}, \mathbf{T}^{+}$ \\
\hline & & & $\mathrm{CA}$ & --- & --- & $1 / 3,2 / 3$ & 0,0 & $2 / 3,1 / 3$ & $\mathbf{t}_{\mathbf{1}}, \mathbf{T}^{+}$ & $\mathbf{t}_{2}, \mathbf{O}$ & $\mathbf{T}^{-}$ \\
\hline & & & $\mathrm{BA}$ & --- & --- & $2 / 3,1 / 3$ & 0,0 & $1 / 3,2 / 3$ & $\mathbf{t}_{2}, \mathbf{T}^{+}$ & $\mathbf{T}^{-}$ & $\mathbf{t}_{1}, \mathbf{O}$ \\
\hline & & & $\mathrm{CB}$ & --- & --- & $1 / 3,2 / 3$ & $2 / 3,1 / 3$ & 0,0 & $\mathbf{t}_{1}, \mathbf{O}$ & $\mathbf{t}_{2}, \mathbf{T}^{+}$ & $\mathbf{T}^{-}$ \\
\hline & & & $\mathrm{AC}$ & --- & --- & 0,0 & $1 / 3,2 / 3$ & $2 / 3,1 / 3$ & $\mathbf{T}^{-}$ & $\mathbf{t}_{1}, \mathbf{O}$ & $\mathbf{t}_{2}, \mathbf{T}^{+}$ \\
\hline
\end{tabular}

Table 5. Site-symmetry group and fractional coordinates in the (001) plane of the special positions in the tetragonal sheet.

\begin{tabular}{|c|c|c|c|c|c|c|c|c|c|c|c|}
\hline \multicolumn{6}{|c|}{$t I$ unit cell } & \multicolumn{6}{|c|}{$c F$ unit cell } \\
\hline Sheet & $\mathbf{s}$ & $\begin{array}{c}\text { Pair of } \\
\text { sheets }\end{array}$ & T1 & $\mathbf{T 2}$ & $\mathbf{O}$ & Sheet & $\mathbf{s}$ & $\begin{array}{c}\text { Pair of } \\
\text { sheets }\end{array}$ & T1 & T2 & $\mathbf{O}$ \\
\hline $\mathrm{S}$ & $1 / 2,1 / 2$ & SD & $1 / 2,0$ & $0,1 / 2$ & $1 / 2,1 / 2$ & $\mathrm{~S}$ & $1 / 2,1 / 2$ & $\mathrm{SD}$ & $1 / 4,1 / 4 ; 3 / 4,3 / 4$ & $1 / 4,3 / 4 ; 3 / 4,1 / 4$ & $1 / 2,0 ; 0,1 / 2$ \\
\hline $\mathrm{D}$ & 0,0 & DS & $0,1 / 2$ & $1 / 2,0$ & $1 / 2,1 / 2$ & $\mathrm{D}$ & 0,0 & $\mathrm{DS}$ & $1 / 4,3 / 4 ; 3 / 4,1 / 4$ & $1 / 4,1 / 4 ; 3 / 4,3 / 4$ & $1 / 2,0 ; 0,1 / 2$ \\
\hline
\end{tabular}

Table 6. Atomic fractional coordinates in the $h c p$ aristotype

\begin{tabular}{|c|c|c|c|c|c|c|c|c|}
\hline Site & $\mathbf{C}$ & $\mathbf{B}$ & $\mathbf{T}^{+}$ & $\mathbf{T}^{+}$ & $\mathbf{T}^{-}$ & $\mathbf{T}^{-}$ & $\mathbf{O}$ & $\mathbf{O}$ \\
\hline $\boldsymbol{x}$ & $1 / 3$ & $2 / 3$ & $2 / 3$ & $1 / 3$ & $2 / 3$ & $1 / 3$ & 0 & 0 \\
\hline $\boldsymbol{y}$ & $2 / 3$ & $1 / 3$ & $1 / 3$ & $2 / 3$ & $1 / 3$ & $2 / 3$ & 0 & 0 \\
\hline $\boldsymbol{z}$ & $1 / 4$ & $3 / 4$ & $3 / 8$ & $7 / 8$ & $1 / 8$ & $5 / 8$ & 0 & $1 / 2$ \\
\hline
\end{tabular}


Table 7. Derivative structures of the $h c p$ aristotype

\begin{tabular}{|c|c|c|c|c|c|c|c|c|}
\hline $\begin{array}{c}\text { Hettotype, cation } \\
\text { centred }\end{array}$ & $\begin{array}{c}\text { Hettotype, anion } \\
\text { centred }\end{array}$ & Compound & $\begin{array}{c}\text { Space-group } \\
\text { type }\end{array}$ & $\begin{array}{c}\text { Basis vector } \\
\text { transformation }\end{array}$ & $\mathbf{S}$ & $\mathbf{d}_{\max }$ & $\mathbf{d}_{\mathrm{av}}$ & $\Delta$ \\
\hline $\mathrm{C}\left(1 / 2^{1} / 8^{1 / 8}\right) \mathrm{B}\left(1 / 21 / 8^{1} / 8\right)$ & --- & forsterite $\mathrm{Mg}_{2} \mathrm{SiO}_{4}$ & Pnma & $2 \mathbf{a}-2 \mathbf{b},-2 \mathbf{a}-2 \mathbf{b},-\mathbf{c} ; 1,-1,-1 / 2$ & 0.0062 & 0.3417 & 0.2119 & 0.049 \\
\hline \multirow{4}{*}{$\mathrm{C}(1--) \mathrm{B}(1--)$} & \multirow{4}{*}{$\mathrm{A}(-1) \mathrm{A}(1-)$} & troilite $\mathrm{FeS}$ & $\mathrm{P6}_{3} / m m c$ & $\mathbf{a , b}, \mathbf{c} ; 0,0,0$ & 0.0091 & 0 & 0 & 0.034 \\
\hline & & nickeline NiAs & $P 6_{3} / m m c$ & $\mathbf{a , b}, \mathbf{c} ; 0,0,0$ & 0.0418 & 0 & 0 & 0.174 \\
\hline & & breithauptite NiSb & $\mathrm{Pb}_{3} / \mathrm{mmc}$ & $\mathbf{a , b}, \mathbf{c} ; 0,0,0$ & 0.0575 & 0 & 0 & 0.252 \\
\hline & & millerite NiS & $P 6_{3} / m m c$ & $\mathbf{a , b}, \mathbf{c} ; 0,0,0$ & 0.0120 & 0 & 0 & 0.046 \\
\hline \multirow[t]{3}{*}{$\mathrm{C}(2 / 3--) \mathrm{B}(2 / 3--)$} & \multirow[t]{3}{*}{$\begin{array}{ll}-- \\
\end{array}$} & corundum $\mathrm{Al}_{2} \mathrm{O}_{3}$ & $R \overline{3} c$ & $\mathbf{a}-\mathbf{b}, \mathbf{a}+2 \mathbf{b}, 3 \mathbf{c} ; 0,0,3 / 2$ & 0.0097 & 0.2448 & 0.1752 & 0.071 \\
\hline & & hematite $\mathrm{Fe}_{2} \mathrm{O}_{3}$ & $R \overline{3} c$ & $\mathbf{a}-\mathbf{b}, \mathbf{a}+2 \mathbf{b}, 3 \mathbf{c} ; 0,0,0$ & 0.0095 & 0.3081 & 0.2047 & 0.073 \\
\hline & & ilmenite $\mathrm{FeTiO}_{3}$ & $R \overline{3}$ & $\mathbf{a}-\mathbf{b}, \mathbf{a}+2 \mathbf{b}, 3 \mathbf{c} ; 0,0,0$ & 0.0058 & 0.3149 & 0.2328 & 0.059 \\
\hline \multirow[t]{12}{*}{$\mathrm{C}(1 / 2--) \mathrm{B}(1 / 2--)$} & \multirow[t]{12}{*}{--} & marcasite $\mathrm{FeS}_{2}$ & Pnnm & $\mathbf{a}-\mathbf{b}, \mathbf{c}, \mathbf{- a}-\mathbf{b} ; 0,0,0$ & 0.0683 & 0.9563 & 0.6375 & 1.006 \\
\hline & & lollingite $\mathrm{FeSAs}_{2}$ & Pnnm & $\mathbf{a}-\mathbf{b}, \mathbf{c},-\mathbf{a}-\mathbf{b} ; 0,0,0$ & 0.0583 & 1.0464 & 0.6976 & 0.406 \\
\hline & & rutile $\mathrm{TiO}_{2}$ & $P 4_{2} / n m n$ & $\mathbf{a}-\mathbf{b}, \mathbf{c},-\mathbf{a}-\mathbf{b} ; 0,0,0$ & 0.0258 & 0.0887 & 0.0591 & 0.204 \\
\hline & & cassiterite $\mathrm{SnO}_{2}$ & $P 4_{2} / n m n$ & $\mathbf{a - b}, \mathbf{c},-\mathbf{a}-\mathbf{b} ; 0,0,0$ & 0.0372 & 0.0975 & 0.065 & 0.259 \\
\hline & & pyrolusite $\mathrm{MnO}_{2}$ & $P 4_{2} / n m n$ & $\mathbf{a}-\mathbf{b}, \mathbf{c}, \mathbf{- a}-\mathbf{b} ; 0,0,0$ & 0.0293 & 0.0663 & 0.0442 & 0.216 \\
\hline & & plattnerite $\mathrm{PbO}_{2}$ & $P 4_{2} / n m n$ & $\mathbf{a - b}, \mathbf{c},-\mathbf{a}-\mathbf{b} ; 0,0,0$ & 0.0416 & 0.1142 & 0.0761 & 0.281 \\
\hline & & arsenopyrite FeAsS & $P 2_{1} / c$ & $2 \mathbf{a}+2 \mathbf{b},-\mathbf{c},-2 \mathbf{a} ;-1 / 2,0,-1 / 2$ & 0.0597 & 1.3630 & 1.2518 & 0.598 \\
\hline & & gudmundite FeSbS & $P 2_{1} / c$ & $-2 \mathbf{a}-2 \mathbf{b}, \mathbf{c},-2 \mathbf{a} ;-3 / 2,0,1 / 2$ & 0.0582 & 1.3495 & 1.2769 & 0.584 \\
\hline & & manganite $\mathrm{MnO}(\mathrm{OH})$ & $P 2_{1} / c$ & $2 \mathbf{a}+2 \mathbf{b},-\mathbf{c},-2 \mathbf{a} ; 1 / 2,1,0$ & 0.0543 & 1.2677 & 1.2413 & 0.638 \\
\hline & & $\begin{array}{ll}\text { diaspore } & \alpha- \\
\mathrm{AlO}(\mathrm{OH}) & \end{array}$ & Pnma & $2 \mathbf{a}-2 \mathbf{b},-\mathbf{a}-\mathbf{b},-\mathbf{c} ; 1 / 2,-2,-1 / 2$ & 0.0137 & 0.2676 & 0.2365 & 0.102 \\
\hline & & $\begin{array}{ll}\text { goethite } & \alpha- \\
\mathrm{FeO}(\mathrm{OH}) & \end{array}$ & Pnma & $2 \mathbf{a}-2 \mathbf{b},-\mathbf{a}-\mathbf{b},-\mathbf{c} ; 1,-3 / 2,-1 / 2$ & 0.0171 & 0.3041 & 0.2519 & 0.102 \\
\hline & & $\begin{array}{l}\text { columbite }(\mathrm{Fe}, \mathrm{Mn}) \\
(\mathrm{Nb}, \mathrm{Ta})_{2} \mathrm{O}_{6}\end{array}$ & Pbcn & $3 \mathbf{c},-2 \mathbf{a}-2 \mathbf{b}, \mathbf{a}-\mathbf{b} ;-1 / 2-2,0$ & 0.0047 & 0.3256 & 0.1952 & 0.058 \\
\hline \multirow[t]{5}{*}{$\mathrm{C}(-1-) \mathrm{B}(--1)$} & \multirow[t]{5}{*}{$\mathrm{A}(1--) \mathrm{B}(-1-)$} & zincite $\mathrm{ZnO}$ & $P 6_{3} m c$ & $\mathbf{a}, \mathbf{b}, \mathbf{c} ; 0,0,0$ & 0.0057 & 0.0781 & 0.0781 & 0.042 \\
\hline & & bromellite $\mathrm{BeO}$ & $P 6_{3} m c$ & $\mathbf{a , b}, \mathbf{b} ; 0,0,0$ & 0.0016 & 0.0066 & 0.0066 & 0.008 \\
\hline & & wurtzite- $2 H \mathrm{ZnS}$ & $P 6_{3} m c$ & $\mathbf{a , b}, \mathbf{c} ; 0,0,0$ & 0.0008 & 0.0066 & 0.0066 & 0.003 \\
\hline & & greenockite CdS & $P 6_{3} m c$ & $\mathbf{a , b}, \mathbf{b} ; 0,0,0$ & 0.0017 & 0 & 0 & 0.006 \\
\hline & & enargite $\mathrm{Cu}_{3} \mathrm{AsS}$ & $P m n 2_{1}$ & $2 \mathbf{a}+2 \mathbf{b}, \mathbf{a}-\mathbf{b},-\mathbf{c} ;-1 / 2,-1 / 2,-1 / 2$ & 0.0043 & 0.1344 & 0.0779 & 0.038 \\
\hline \multirow[t]{2}{*}{$\mathrm{C}(-1 / 21 / 2) \mathrm{B}\left(-1 / 22^{1 / 2}\right)$} & \multirow[t]{2}{*}{---} & cubanite $\mathrm{CuFe}_{2} \mathrm{~S}_{3}$ & Pnma & $\mathbf{c},-3 \mathbf{a}-3 \mathbf{b}, \mathbf{a}-\mathbf{b} ; 0, \overline{1} / 2,0$ & 0.0071 & 0.1101 & 0.0752 & 0.069 \\
\hline & & argentopyrite $\mathrm{AgFe}_{2} \mathrm{~S}_{3}$ & $P 2_{1} / c$ & $-2 \mathbf{c}-\mathbf{b},-\mathbf{c}, 2 \mathbf{a}-2 \mathbf{b} ; 0,1 / 2,0$ & 0.0084 & 0.2405 & 0.128 & 0.037 \\
\hline $\mathrm{B}(1--) \mathrm{C}(---)$ & --- & brucite $\mathrm{Mg}(\mathrm{OH})_{2}$ & $P \overline{3} m 1$ & $\mathbf{a , b}, \mathbf{c} ; 0,0,0$ & 0.0203 & 0.1493 & 0.0995 & 0.110 \\
\hline
\end{tabular}


Table 8. Derivative structures of the ccp aristotype

\begin{tabular}{|c|c|c|c|c|c|c|c|c|}
\hline $\begin{array}{c}\text { Hettotype, cation } \\
\text { centred }\end{array}$ & $\begin{array}{c}\begin{array}{c}\text { Hettotype, anion } \\
\text { centred }\end{array} \\
\end{array}$ & Compound & $\begin{array}{c}\text { Space- } \\
\text { group type }\end{array}$ & $\begin{array}{c}\text { Basis vector } \\
\text { transformation }\end{array}$ & $\mathbf{S}$ & $\mathbf{d}_{\max }$ & $\mathbf{d}_{\mathrm{av}}$ & $\Delta$ \\
\hline $\begin{array}{c}\mathrm{S} 1(11) \mathrm{D} 1(11) / \\
\mathrm{A}(111) \mathrm{B}(111) \mathrm{C}(111)\end{array}$ & $\begin{array}{ll}-- \\
-1\end{array}$ & $\mathrm{Li}_{3} \mathrm{Bi}$ & $F m \overline{3} m$ & $\mathbf{a}, \mathbf{b}, \mathbf{c} ; 0,0,0$ & 0 & 0 & 0 & 0 \\
\hline $\mathrm{S}(1 / 2) \mathrm{S}(1 / 2)$ & $\begin{array}{c}\mathrm{A}(11-) \mathrm{B}(-11) \mathrm{C}(1-1) / \mathrm{S}- \\
(11) \mathrm{D}-(11)\end{array}$ & fluorite $\mathrm{CaF}_{2}$ & $F m \overline{3} m$ & $\mathbf{a}, \mathbf{b}, \mathbf{c} ; 0,0,0$ & 0 & 0 & 0 & 0 \\
\hline \multirow{3}{*}{$\begin{array}{c}\mathrm{S}-(1-) \mathrm{D}-(-1) / \mathrm{A}(-1-) \mathrm{B}(-- \\
1) \mathrm{C}(1--)\end{array}$} & \multirow{3}{*}{$\begin{array}{c}\mathrm{S}-(1-) \mathrm{D}-(-1) / \mathrm{A}(-1-) \mathrm{B}(-- \\
1) \mathrm{C}(1--)\end{array}$} & sphalerite $\mathrm{ZnS}-3 C$ & $F \overline{4} 3 m$ & $\mathbf{a}, \mathbf{b}, \mathbf{c} ; 1 / 4,1 / 4,1 / 4$ & 0 & 0 & 0 & 0 \\
\hline & & coloradoite $\mathrm{HgTe}$ & $F \overline{4} 3 m$ & $\mathbf{a}, \mathbf{b}, \mathbf{c} ; 1 / 4,1 / 4,1 / 4$ & 0 & 0 & 0 & 0 \\
\hline & & tiemannite $\mathrm{HgSe}$ & $F \overline{4} 3 m$ & $\mathbf{a}, \mathbf{b}, \mathbf{c} ; 1 / 4,1 / 4,1 / 4$ & 0 & 0 & 0 & 0 \\
\hline \multirow{4}{*}{$\begin{array}{c}\text { S-(-1)D-(1-)S-(-1)D-(1-) } \\
/ \mathrm{A}(1--) \mathrm{B}(-1-) \mathrm{C}(-- \\
1) \mathrm{A}(1--) \mathrm{B}(-1-) \mathrm{C}(--1) \\
\end{array}$} & \multirow{2}{*}{$\begin{array}{c}\text { S-(-1)D-(1-)S-(-1)D-(1-) } \\
\text { / A(1--)B(-1-)C(-- } \\
\text { 1)A(1--)B(-1-)C(--1) }\end{array}$} & chalcopyrite $\mathrm{CuFeS}_{2}$ & $I \overline{4} 2 d$ & $-\mathbf{b}, \mathbf{a}, 2 \mathbf{c} ; 1 / 4,1 / 4,3 / 4$ & 0.0041 & 0.0547 & 0.0273 & 0.023 \\
\hline & & gallite $\mathrm{CuGaS}_{2}$ & $I \overline{4} 2 d$ & $-\mathbf{b}, \mathbf{a}, 2 \mathbf{c} ; 1 / 4,1 / 4,3 / 4$ & 0.0056 & 0.0204 & 0.0102 & 0.024 \\
\hline & $\mathrm{S}(1-) \mathrm{D}(--)$ & litharge $\mathrm{PbO}$ & $P 4 / n m n$ & $1 / 2 \mathbf{a}-1 / 2 \mathbf{b}, 1 / 2 \mathbf{a}+1 / 2 \mathbf{b}, \mathbf{c} ; 1 / 4,0,1 / 4$ & 0.0303 & 0.0712 & 0.0356 & 0.133 \\
\hline & $\mathrm{S}(1-) \mathrm{D}(--)$ & romarchite $\mathrm{SnO}$ & $P 4 / n m n$ & $1 / 2 \mathbf{a}-1 / 2 \mathbf{b}, 1 / 2 \mathbf{a}+1 / 2 \mathbf{b}, \mathbf{c} ; 1 / 4,0,1 / 4$ & 0.0279 & 0.0607 & 0.0303 & 0.121 \\
\hline $\begin{array}{c}\mathrm{S}\left(1 \frac{1}{2}\right) \mathrm{D}(1 / 21) / \\
\mathrm{A}\left(1 \frac{1}{2}-\right) \mathrm{B}\left(-1 \frac{1}{2}\right) \mathrm{C}(1 / 2-1)\end{array}$ & --- & $\begin{array}{l}\text { bornite (erubescite) } \\
\mathrm{Cu}_{5} \mathrm{FeS}_{2}\end{array}$ & $F 23$ & $\mathbf{a}, \mathbf{b}, \mathbf{c} ; 1 / 2,1 / 2,1 / 2$ & 0 & 0 & 0 & 0 \\
\hline $\begin{array}{c}\mathrm{S}(1 / 21) \mathrm{D}(-1 / 2) / \\
\mathrm{A}(11-) \mathrm{B}(--1) \mathrm{C}(---)\end{array}$ & --- & sulvanite $\mathrm{Cu}_{3} \mathrm{VS}_{4}$ & $P \overline{4} 3 m$ & $\mathbf{a}, \mathbf{b}, \mathbf{c}, 1 / 4,1 / 4,1 / 4$ & 0 & 0.1195 & 0.0597 & 0.016 \\
\hline $\begin{array}{l}\mathrm{S} 1(--) \mathrm{D} 1(--) / \mathrm{A}(-- \\
1) \mathrm{B}(1--) \mathrm{C}(-1-)\end{array}$ & $\begin{array}{l}\text { S1(--)D1(--) / A(-- } \\
\text { 1)B(1--)C(-1-) }\end{array}$ & $\begin{array}{l}\text { halite } \mathrm{NaCl} \\
\text { periclase } \mathrm{MgO} \\
\text { manganosite } \mathrm{MnO} \\
\text { wüstite } \mathrm{FeO} \\
\text { bunsenite } \mathrm{NiO} \\
\text { monteponite } \mathrm{CdO} \\
\text { hongquiite } \mathrm{HgO} \\
\text { lime } \mathrm{CaO} \\
\text { galena } \mathrm{PbS} \\
\text { alabandite } \mathrm{MnS} \\
\end{array}$ & $F m \overline{3} m$ & $\mathbf{a}, \mathbf{b}, \mathbf{c} ; 0,0,0$ & 0 & 0 & 0 & 0 \\
\hline \multirow[t]{6}{*}{$\begin{array}{l}\mathrm{S}^{1} / 2(--) \mathrm{D} 1 / 2(--) / \mathrm{A}(-- \\
1 / 2) \mathrm{B}(1 / 2--) \mathrm{C}(-1 / 2-)^{1}\end{array}$} & \multirow[t]{5}{*}{---} & $\begin{array}{l}\text { pyrite } \mathrm{FeS}_{2} \\
\text { sperrylite } \mathrm{PtS}_{2} \\
\text { vaesite } \mathrm{NiS}_{2} \\
\text { bravoite }\left(\mathrm{Ni}_{0.5} \mathrm{Fe}_{0.5}\right) \mathrm{S}_{2}\end{array}$ & $P a \overline{3}$ & $-\mathbf{b}, \mathbf{a}, \mathbf{c} ; 1 / 2,1 / 2,0$ & 0 & 0 & 0 & 0 \\
\hline & & ulmannite NiSbS & $P 2,3$ & $\mathbf{a}, \mathbf{b}, \mathbf{c} ; 0,0,0$ & 0 & 0.1743 & 0.1058 & 0.025 \\
\hline & & gersdorffite NiAsS & $P 2_{1} \overline{3}$ & $\mathbf{a}, \mathbf{b}, \mathbf{c} ; 0,0,0$ & 0 & 0.0552 & 0.0352 & 0.009 \\
\hline & & cobaltite CoAsS & $P c a 2_{1}$ & $-\mathbf{a},-\mathbf{b}, \mathbf{c} ; 1 / 2,-1 / 4,0$ & 0.0011 & 0.0593 & 0.0355 & 0.014 \\
\hline & & anatase $\mathrm{TiO}_{2}$ & I4 $1 /$ amd & $-\mathbf{b}, \mathbf{a}, 2 \mathbf{c} ; 3 / 4,1 / 2,3 / 4$ & 0.0585 & 0.3990 & 0.2660 & 0.307 \\
\hline & --- & magnetite $\mathrm{Fe}_{3} \mathrm{O}_{4}$ & $F d \overline{3} m$ & $2 \mathbf{a}, 2 \mathbf{b}, 2 \mathbf{c} ; 0,0,0$ & 0 & 0.7130 & 0.0407 & 0.007 \\
\hline
\end{tabular}

1 The structure of these compounds can be interpreted as a derivative of the $c c p$ aristotype by replacing the $\mathrm{S}_{2}$ dumbbell with its centre of gravity. See text for details. 


\begin{tabular}{|c|c|c|c|c|c|c|c|}
\hline \multirow{3}{*}{$\begin{array}{c}\mathrm{S}^{1 / 2(1 / 4-)} \mathrm{D}^{1 / 2(1 / 4-)} \mathrm{S}^{1 / 2(1 / 4-)} \\
\mathrm{D}^{1 / 2(1 / 4-)} / \\
\mathrm{A}(--3 / 4) \mathrm{B}\left(-1 / 4^{1 / 4}\right) \mathrm{C}(- \\
\left.3 / 4^{-}\right) \mathrm{A}\left(1 / 4^{1 / 4-}\right) \mathrm{B}\left(3 / 4^{--}\right) \mathrm{C}(1 / 4- \\
1 / 4) \\
\end{array}$} & violarite $\mathrm{FeNi}_{2} \mathrm{~S}_{4}$ & $F d \overline{3} m$ & $2 \mathbf{a}, 2 \mathbf{b}, 2 \mathbf{c} ; 0,0,0$ & 0 & 0.1475 & 0.0843 & 0.013 \\
\hline & polydymite $\mathrm{Ni}_{3} \mathrm{~S}_{4}$ & $F d \overline{3} m$ & $2 \mathbf{a}, 2 \mathbf{b}, 2 \mathbf{c} ; 0,0,0$ & 0 & 0.1638 & 0.0936 & 0.014 \\
\hline & greigite $\quad \mathrm{Fe}_{3} \mathrm{~S}_{4}$ & $F d \overline{3} m$ & $2 \mathbf{a}, 2 \mathbf{b}, 2 \mathbf{c} ; 0,0,0$ & 0 & 0.0086 & 0.0049 & 0.001 \\
\hline 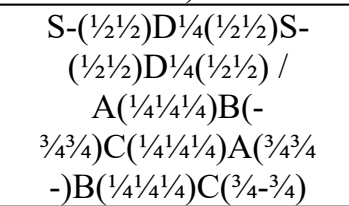 & Pentlandite $(\mathrm{Fe}, \mathrm{Ni})_{9} \mathrm{~S}_{8}$ & $F m \overline{3} m$ & $2 \mathbf{a}, 2 \mathbf{b}, 2 \mathbf{c} ; 0,0,0$ & 0 & 0 & 0 & 0 \\
\hline
\end{tabular}

Table 9. Derivative structures of other aristotypes

\begin{tabular}{|c|c|c|c|c|c|c|c|c|}
\hline Aristotype & Hettotype & Compound & $\begin{array}{c}\text { Space-group } \\
\text { type }\end{array}$ & $\begin{array}{c}\text { Basis vector } \\
\text { transformation }\end{array}$ & $\mathbf{S}$ & $\mathbf{d}_{\max }$ & $d_{a v}$ & $\Delta$ \\
\hline $\mathrm{S}(1)$ & $\mathrm{S}(1)$ & $\begin{array}{l}\mathrm{CsCl} \text { (both cation- and } \\
\text { anion-centred) }\end{array}$ & $P m \overline{3} m$ & $\mathbf{a}, \mathbf{b}, \mathbf{c} ; 0,0,0$ & 0 & 0 & 0 & 0 \\
\hline \multirow{2}{*}{$\begin{array}{l}\text { A11(111)C11(111)A11(1 } \\
\text { 1)A11(111)B11(111)A1 } \\
\text { 1(11) }\end{array}$} & \multirow{2}{*}{$\begin{array}{c}\text { A--(--1)C-1(--1)A-- } \\
(--) \mathrm{A}--(-1-) \mathrm{B}-1(-1-) \mathrm{A}-- \\
(--)\end{array}$} & $\begin{array}{l}\text { covellite CuS, cation } \\
\text { centred }\end{array}$ & $P 6_{3} / m m c$ & $\mathbf{a}, \mathbf{b}, \mathbf{c} ; 0,0,0$ & 0.0336 & 0.3444 & 0.2217 & 0.157 \\
\hline & & $\begin{array}{l}\text { klockmannite CuSe, } \\
\text { cation centred }\end{array}$ & $P 6_{3} / m m c$ & $\mathbf{a}, \mathbf{b}, \mathbf{c} ; 0,0,0$ & 0.0294 & 0.3345 & 0.2189 & 0.137 \\
\hline \multirow[t]{2}{*}{ A11(111)B11(111) } & \multirow{2}{*}{$\begin{array}{l}\text { A1-(---)B-1(---)A- } \\
\text { 1(---)B1-(---)A1- } \\
\text { (---)B1-(---) }\end{array}$} & $\begin{array}{l}\text { covellite CuS, anion } \\
\text { centred }\end{array}$ & $P 6_{3} / m m c$ & $\mathbf{a}, \mathbf{b}, \mathbf{c} ; 0,0,0$ & 0.0336 & 0.3444 & 0.2217 & 0.157 \\
\hline & & $\begin{array}{l}\text { klockmannite CuSe, } \\
\text { anion centred }\end{array}$ & $P 6_{3} / m m c$ & $\mathbf{a}, \mathbf{b}, \mathbf{c} ; 0,0,0$ & 0.0294 & 0.3345 & 0.2189 & 0.137 \\
\hline $\mathrm{B}(11) \mathrm{B}(111) \mathrm{C}(11) \mathrm{C}(111$ & $\mathrm{B}(1-) \mathrm{B}(---) \mathrm{C}(1-) \mathrm{C}(---)$ & molybdenite $\mathrm{MoS}_{2}$ & $P 6_{3} / m m c$ & $\mathbf{a , b}, \mathbf{c} ; \mathbf{0 , 0 , 0}$ & 0.0453 & 0.0307 & 0.0205 & 0.194 \\
\hline $\begin{array}{c}\mathrm{A}(111) \mathrm{B}(111) \mathrm{C}(111) \mathrm{B}(1 \\
11)\end{array}$ & $\begin{array}{c}\mathrm{A}(--1 / 2) \mathrm{B}(1 / 2--) \mathrm{C}(1 / 2--) \mathrm{B}(-- \\
1 / 2)\end{array}$ & brookite $\mathrm{TiO}_{2}$ & $P b c a$ & $\mathbf{c}, 2 \mathbf{b},-2 \mathbf{a}-\mathbf{b} ; \overline{1} / 2,0,0$ & 0.0206 & 0.3643 & 0.3237 & 0.113 \\
\hline
\end{tabular}



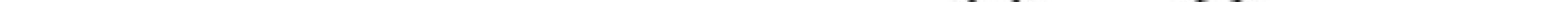

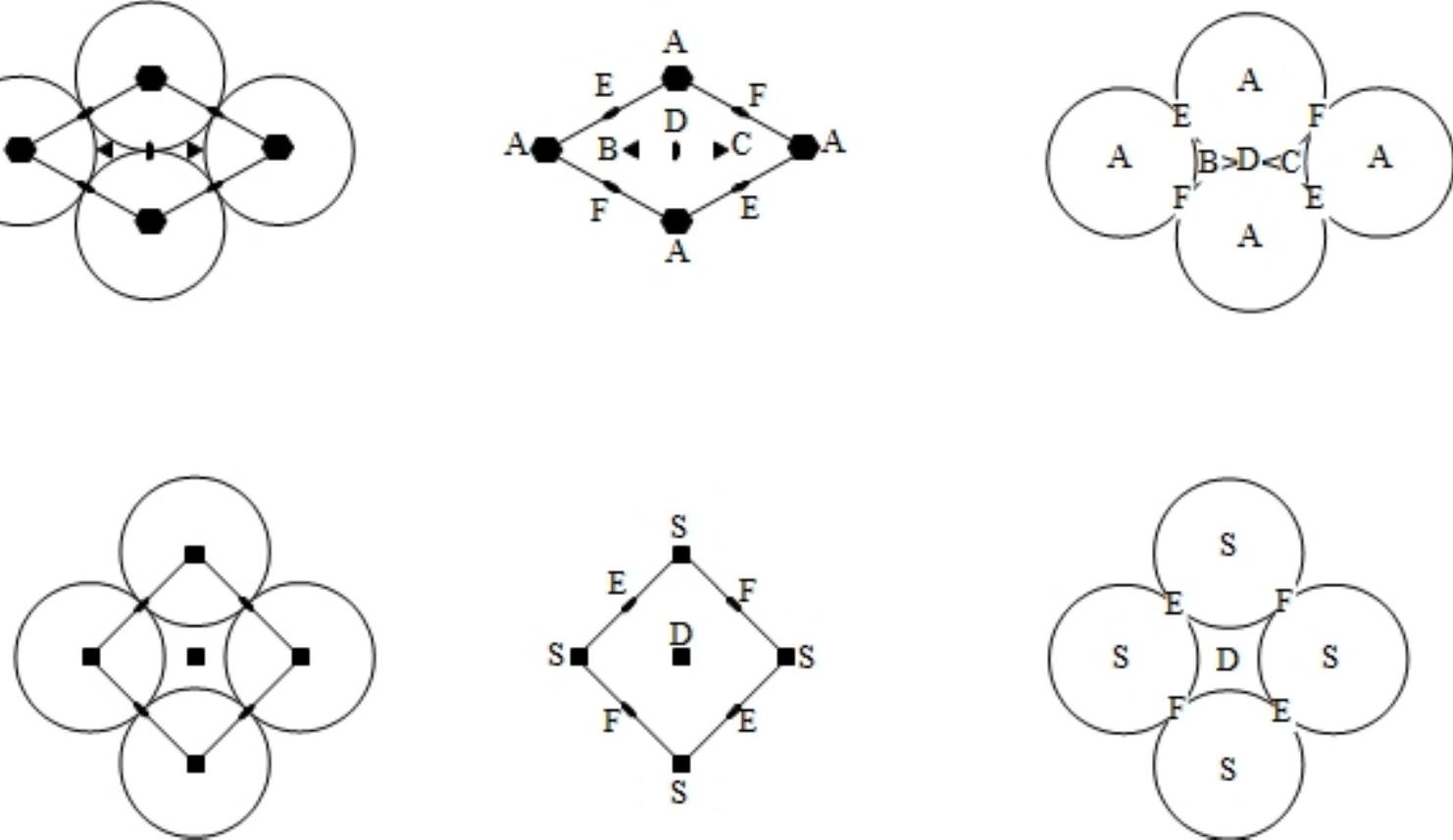


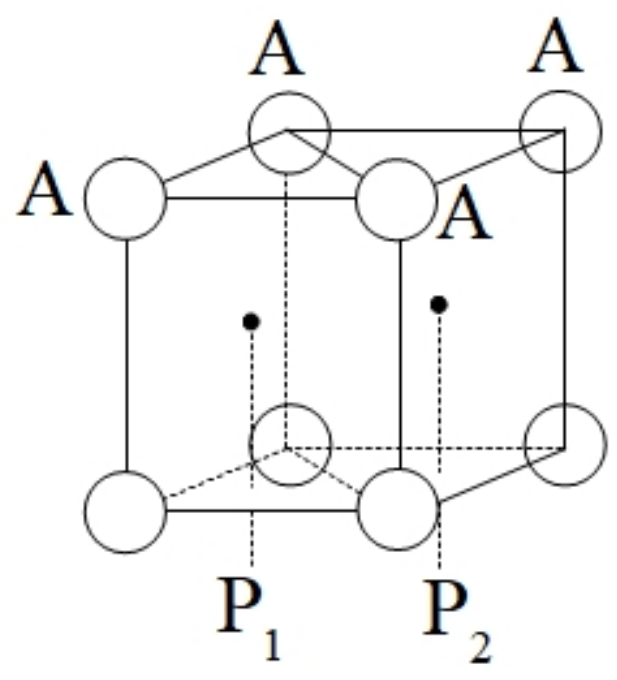








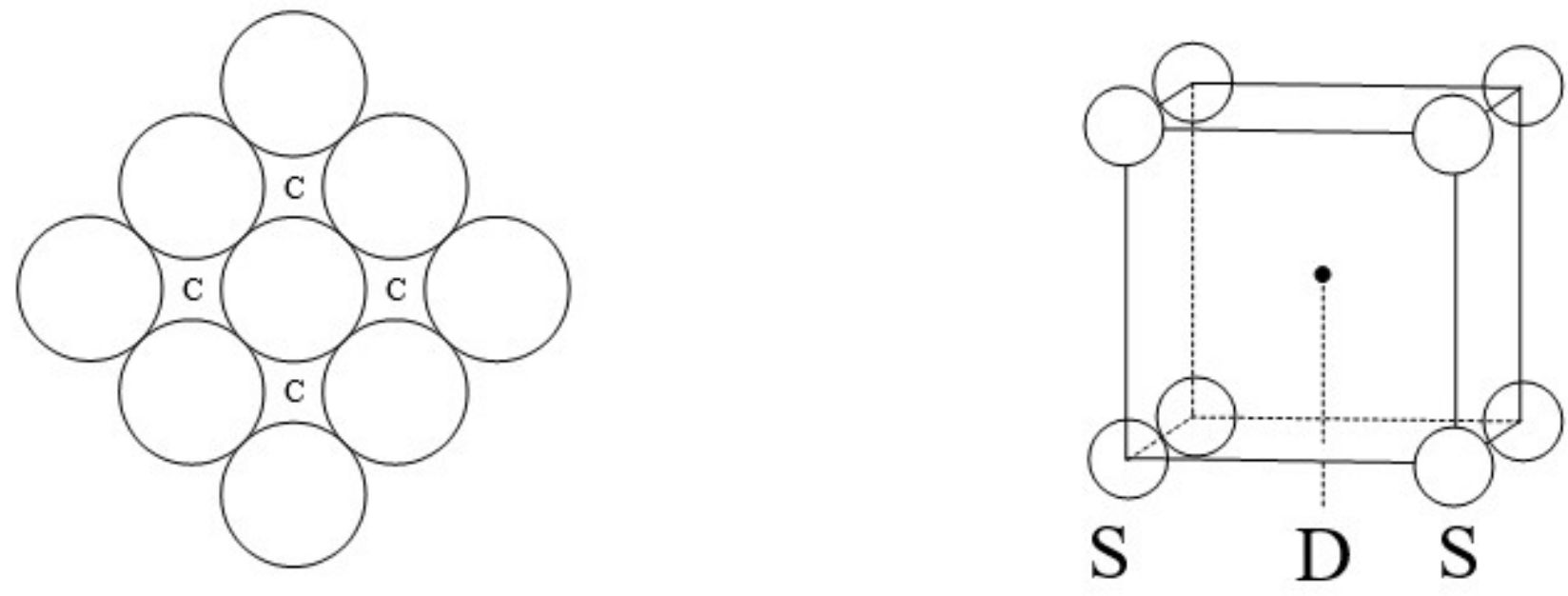

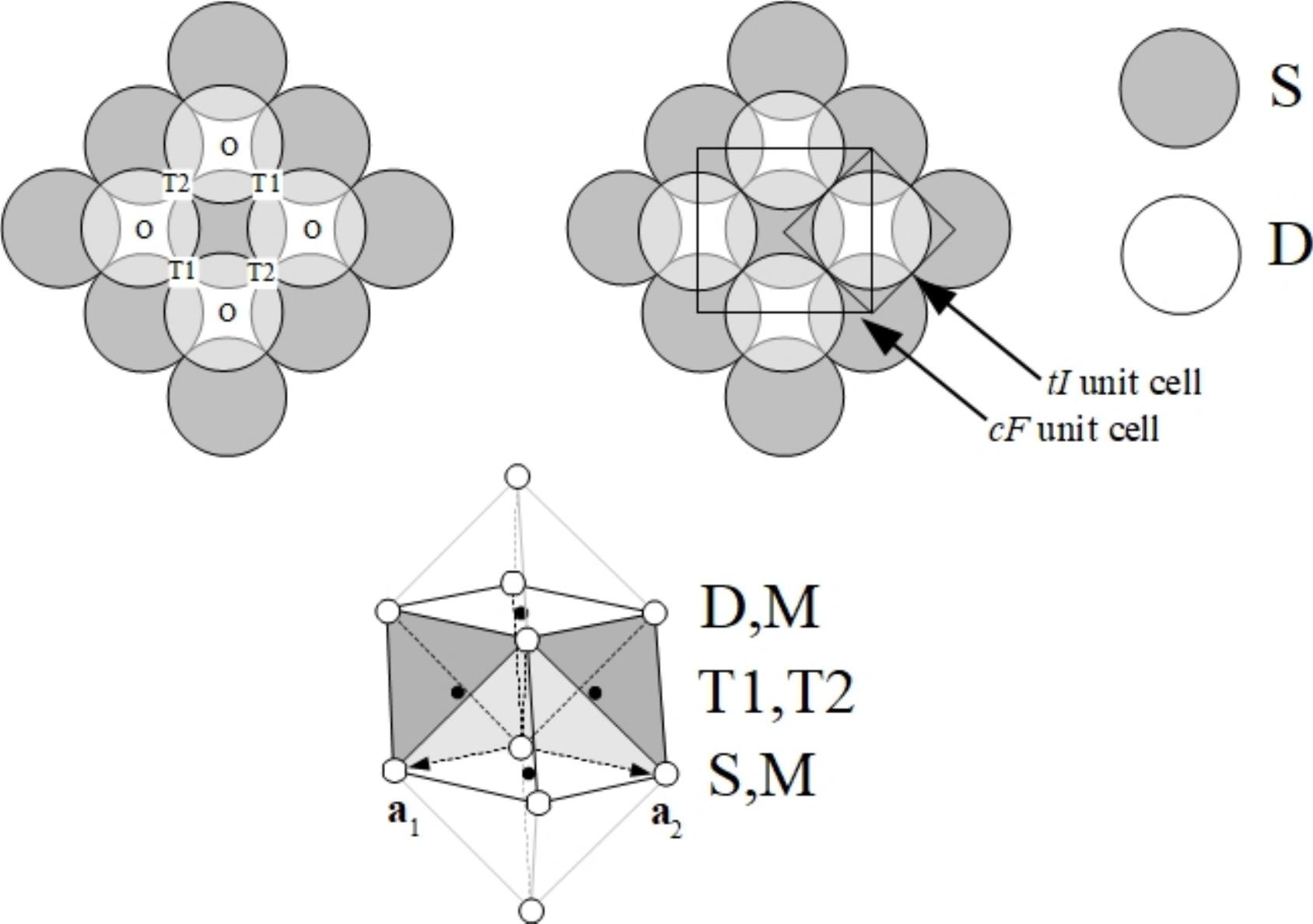







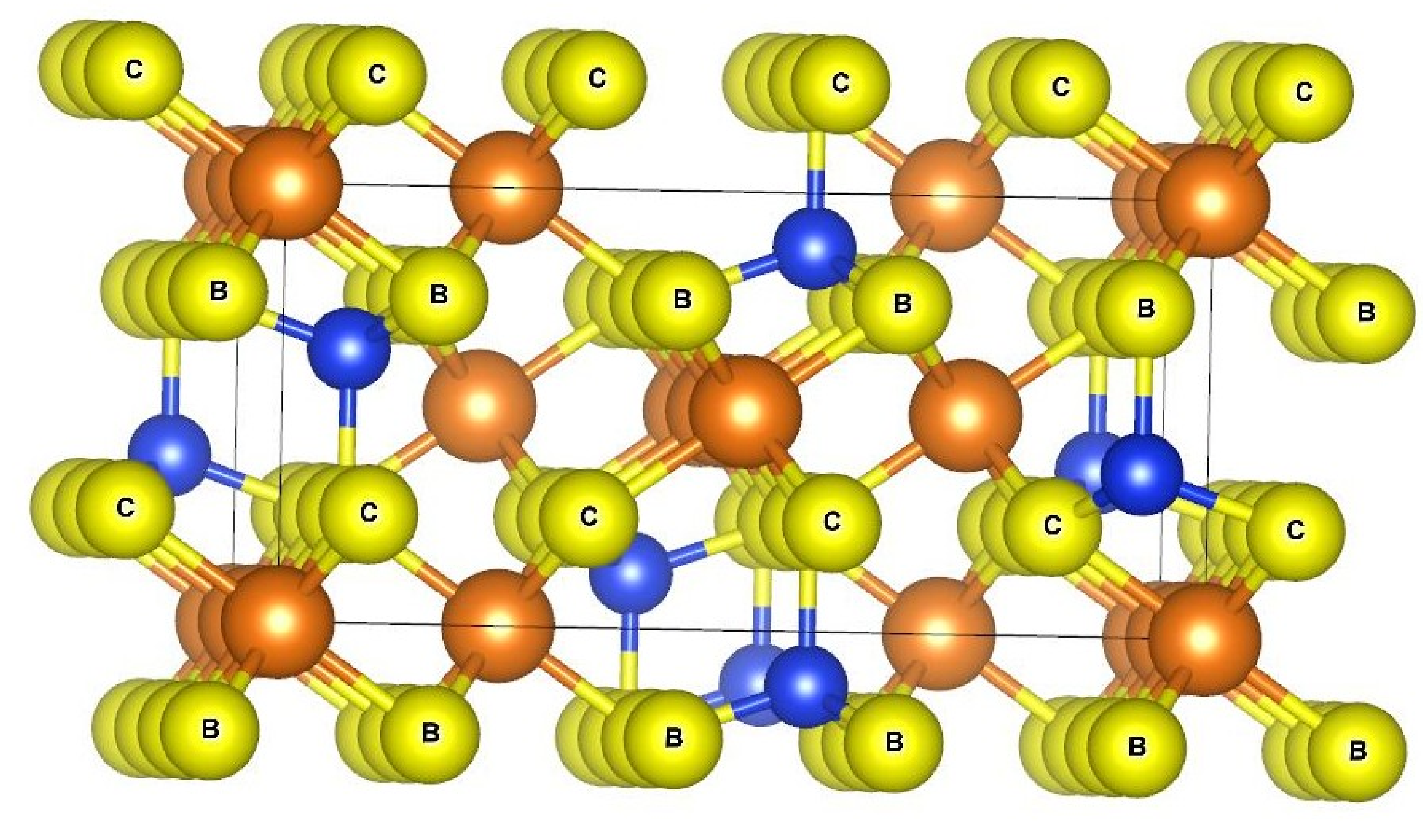




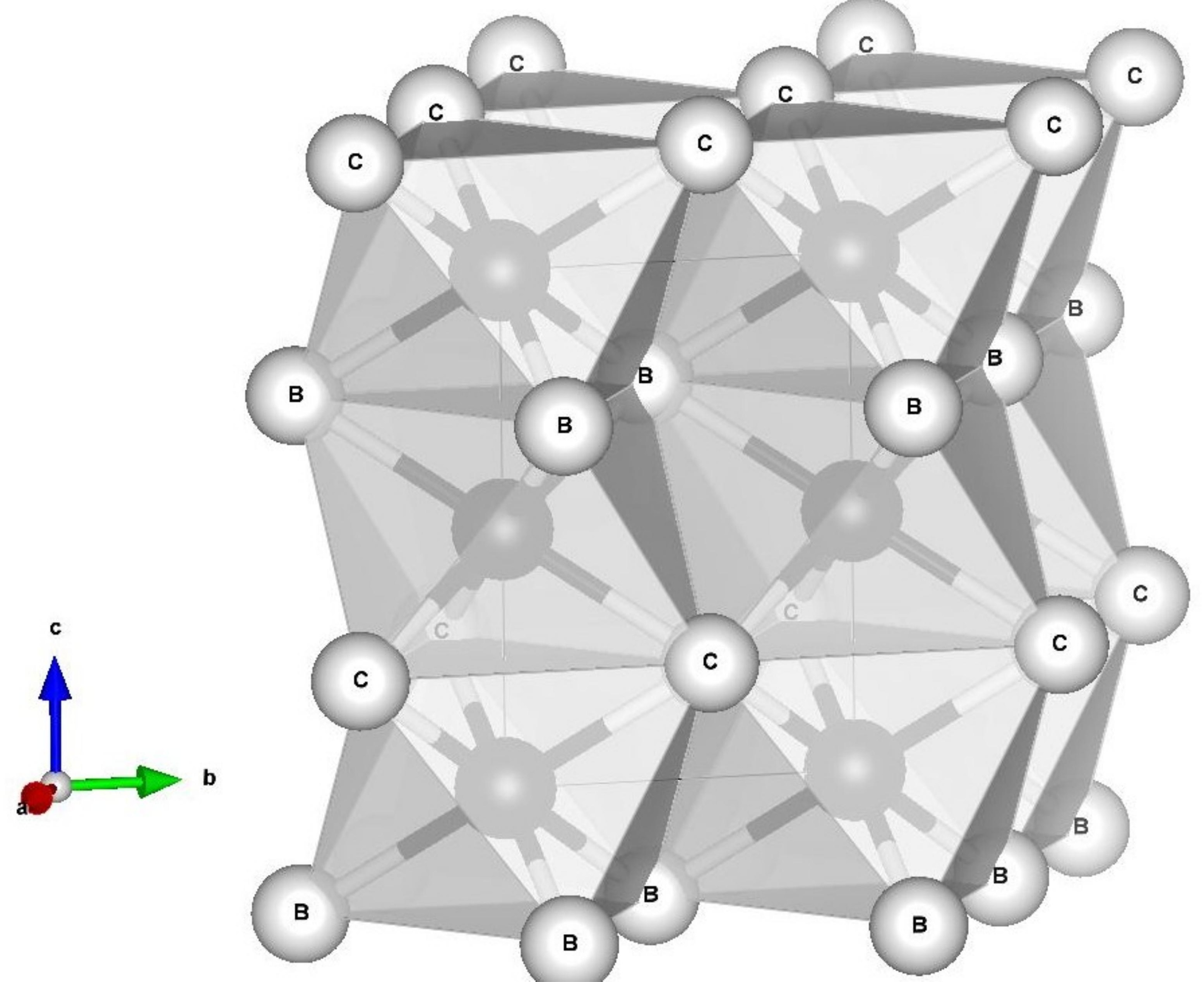





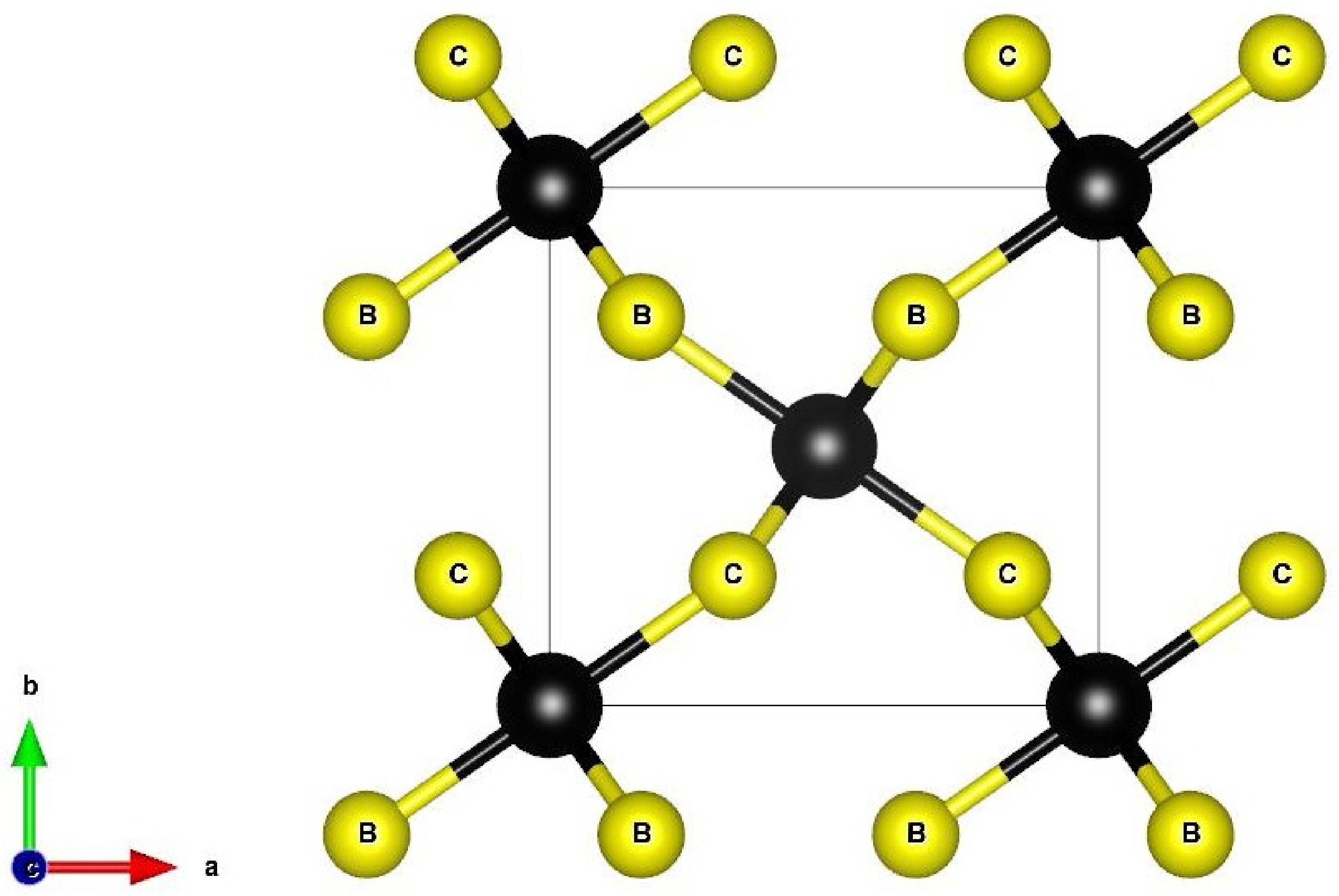

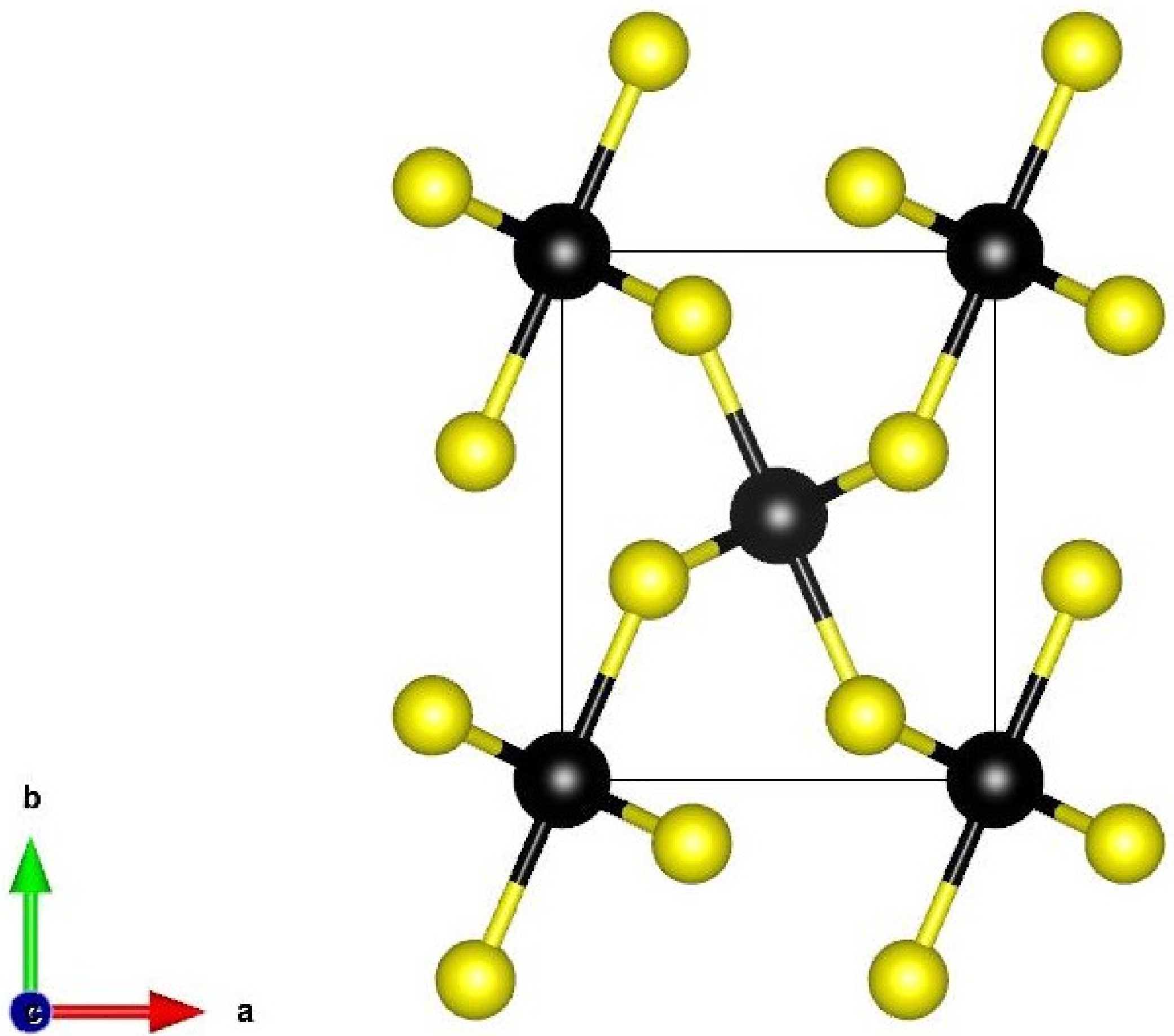



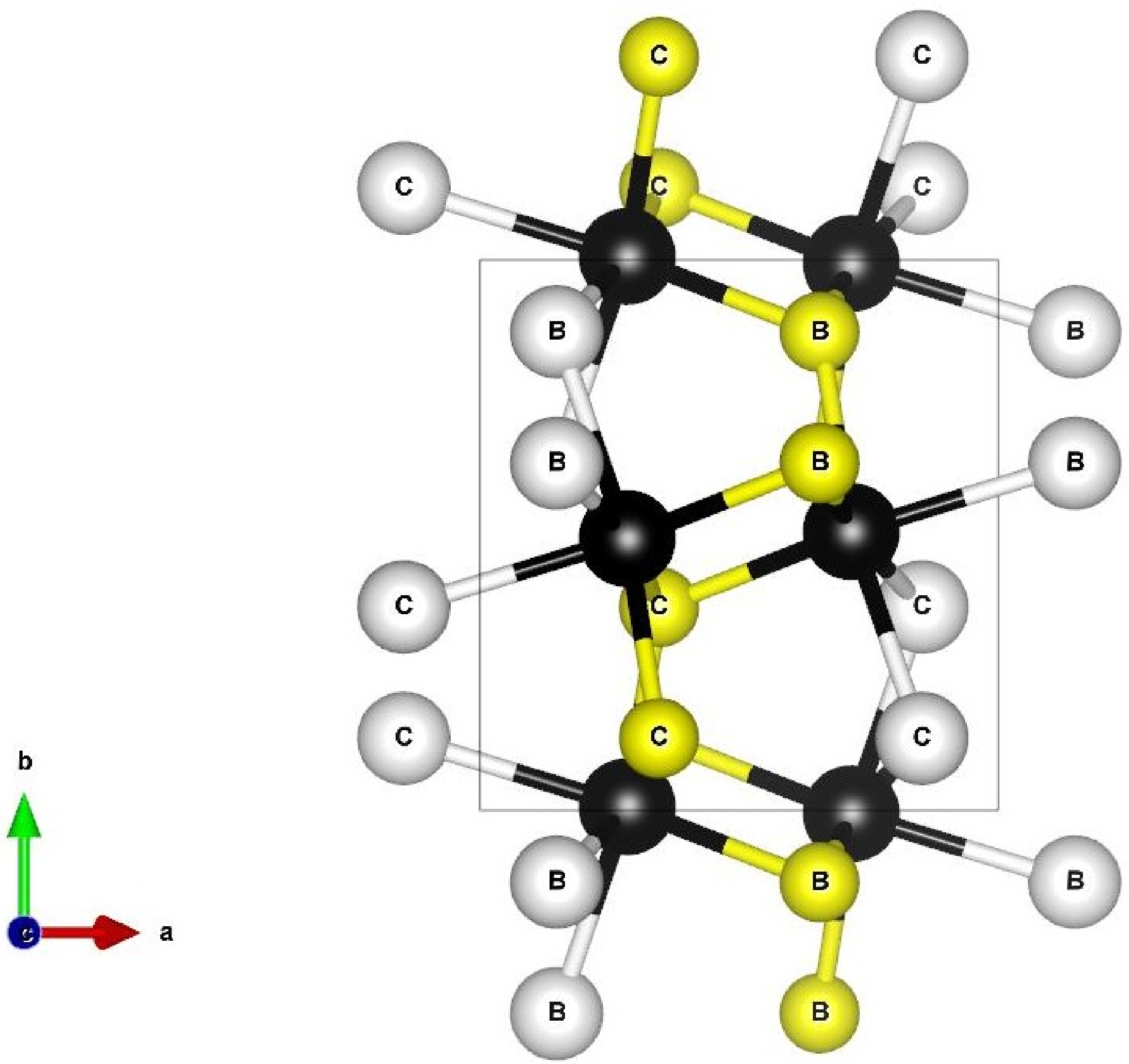


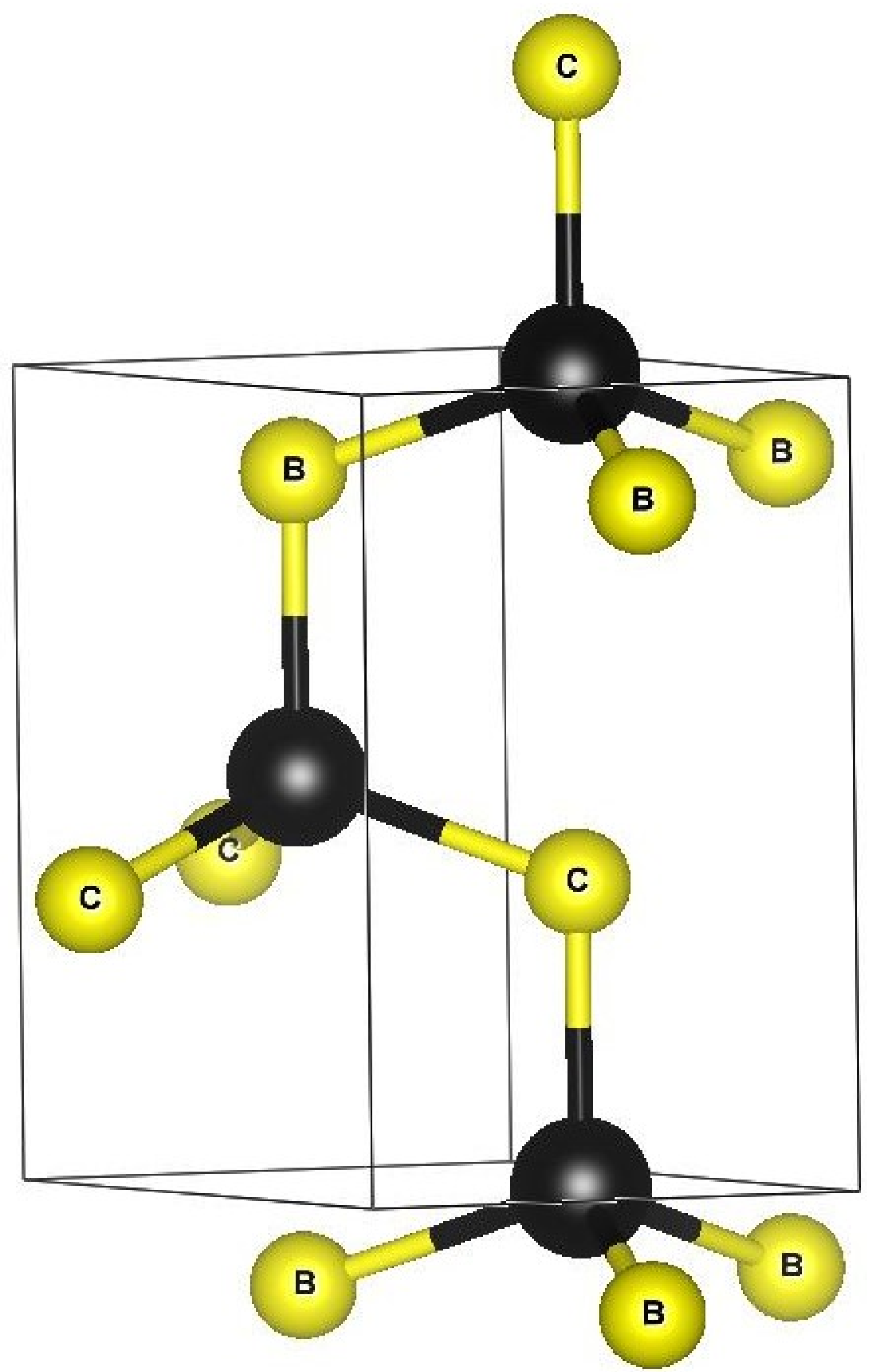



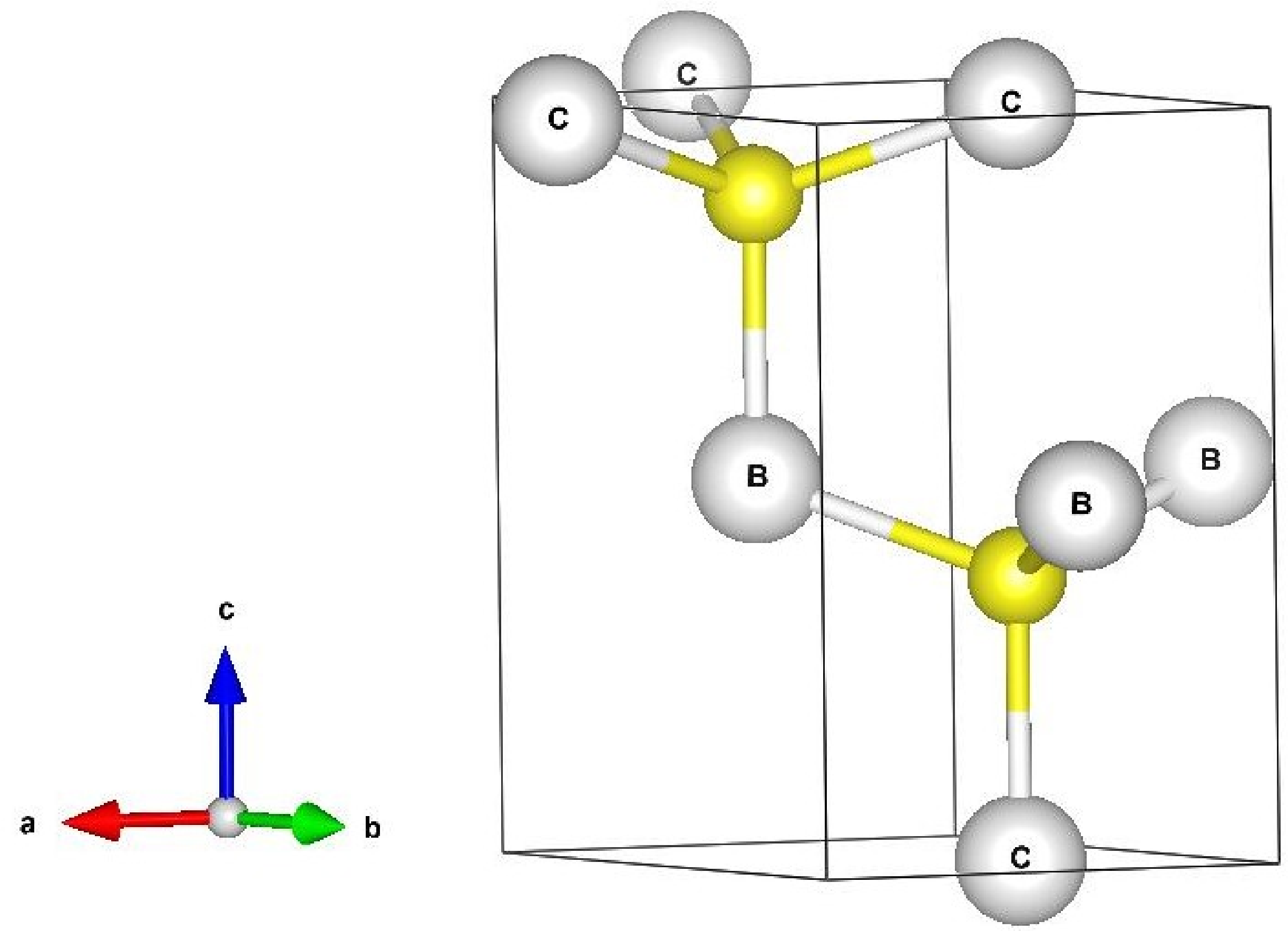




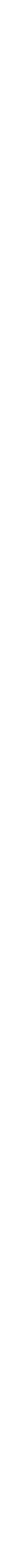




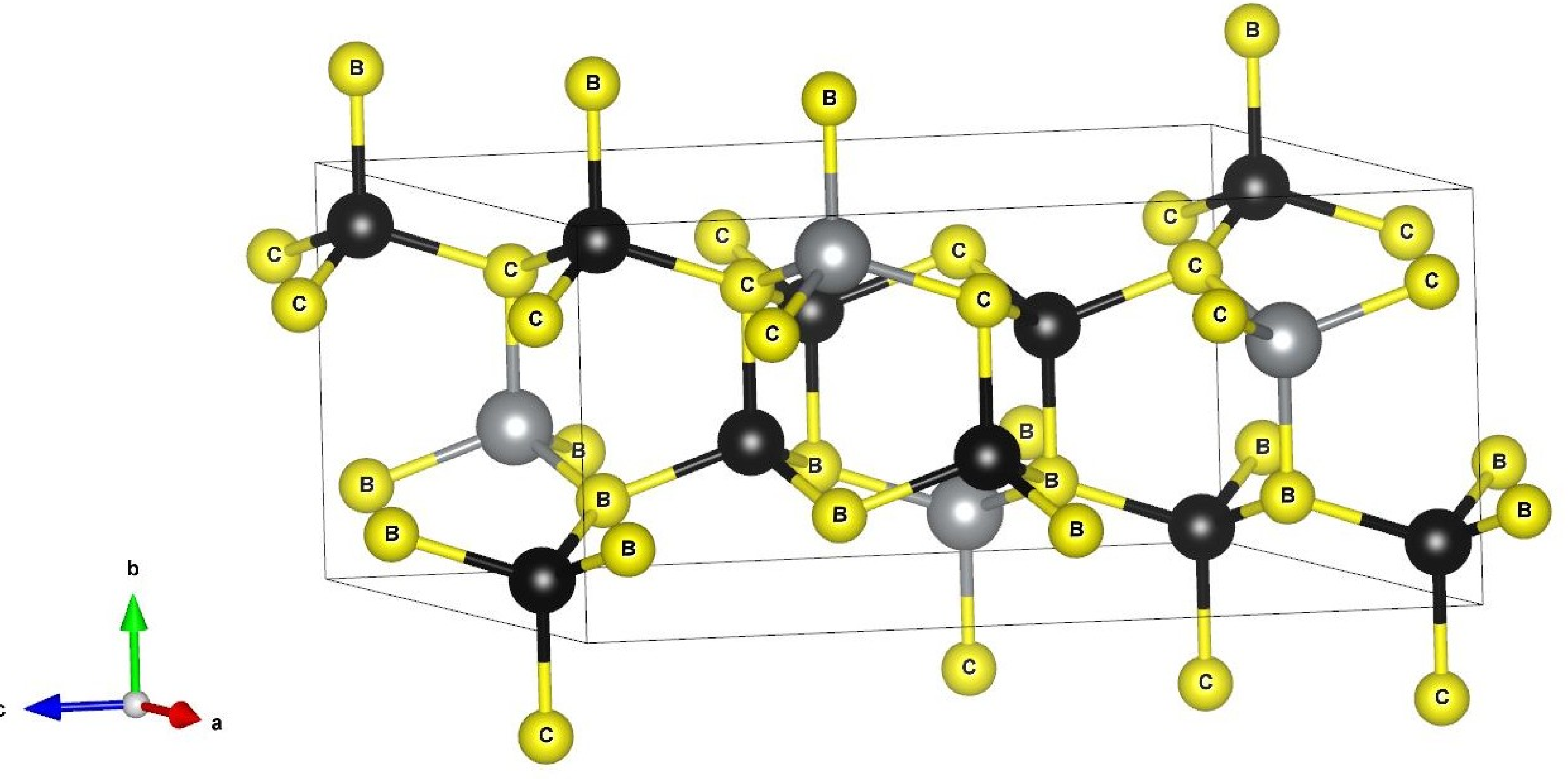



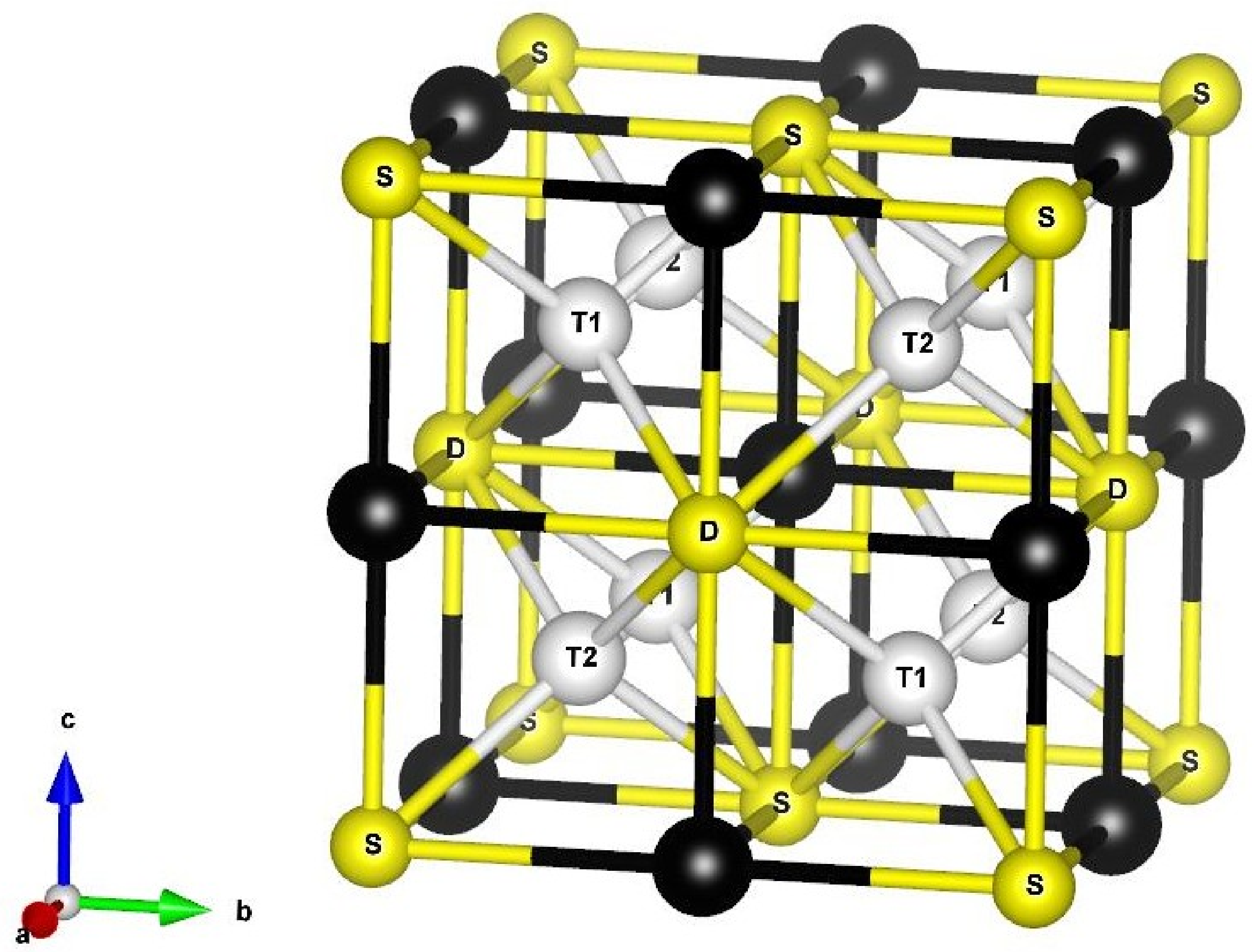

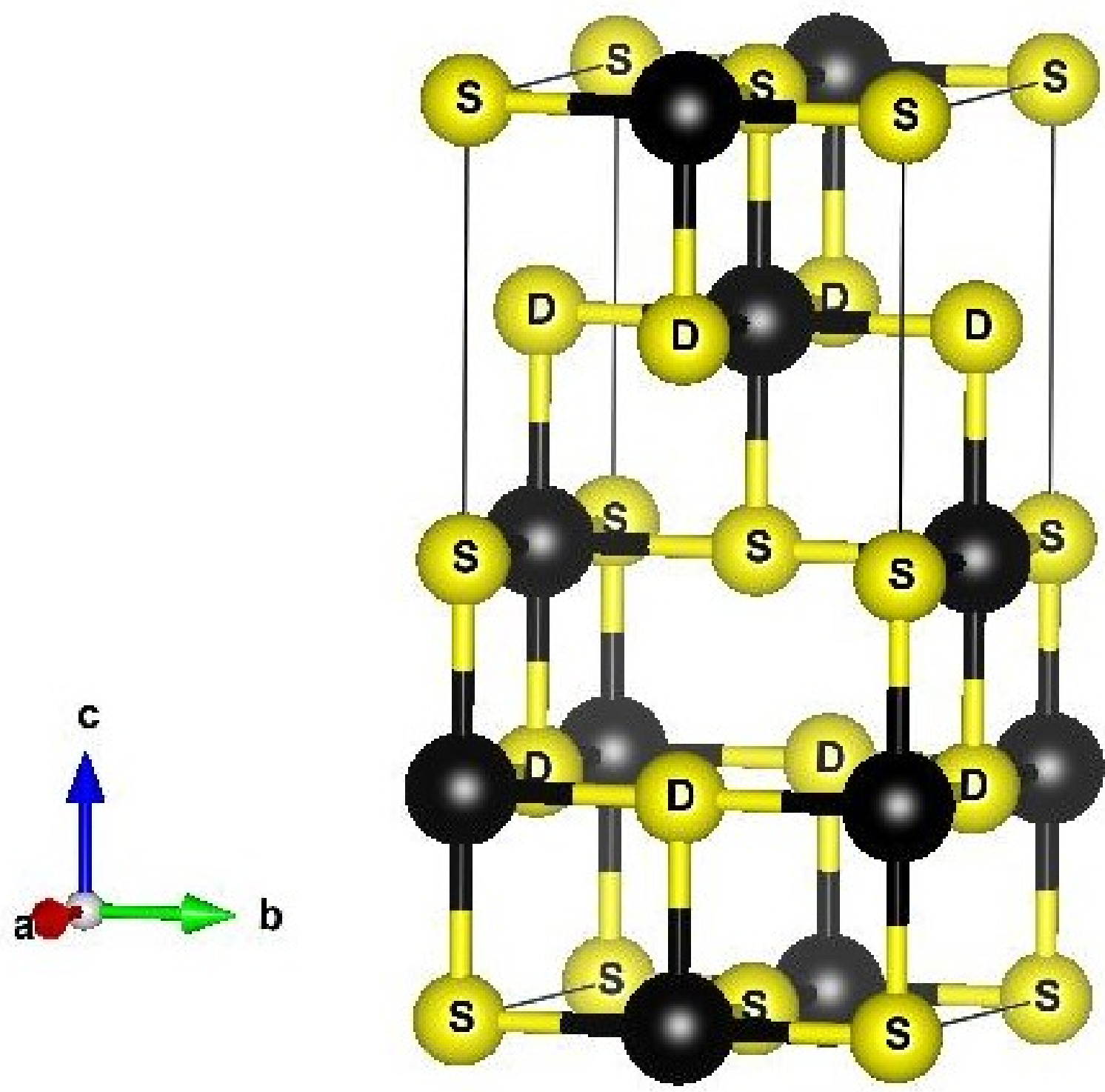

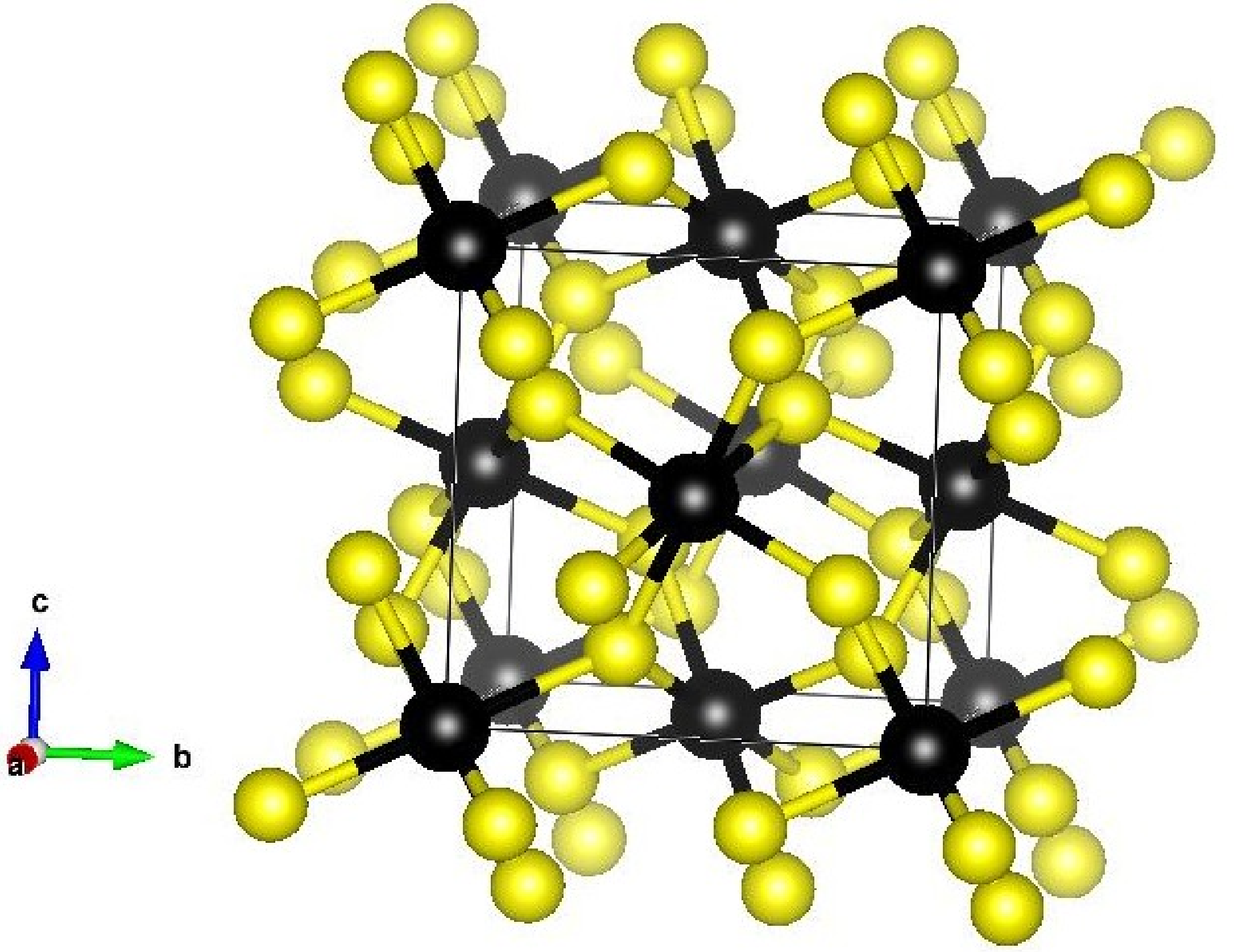


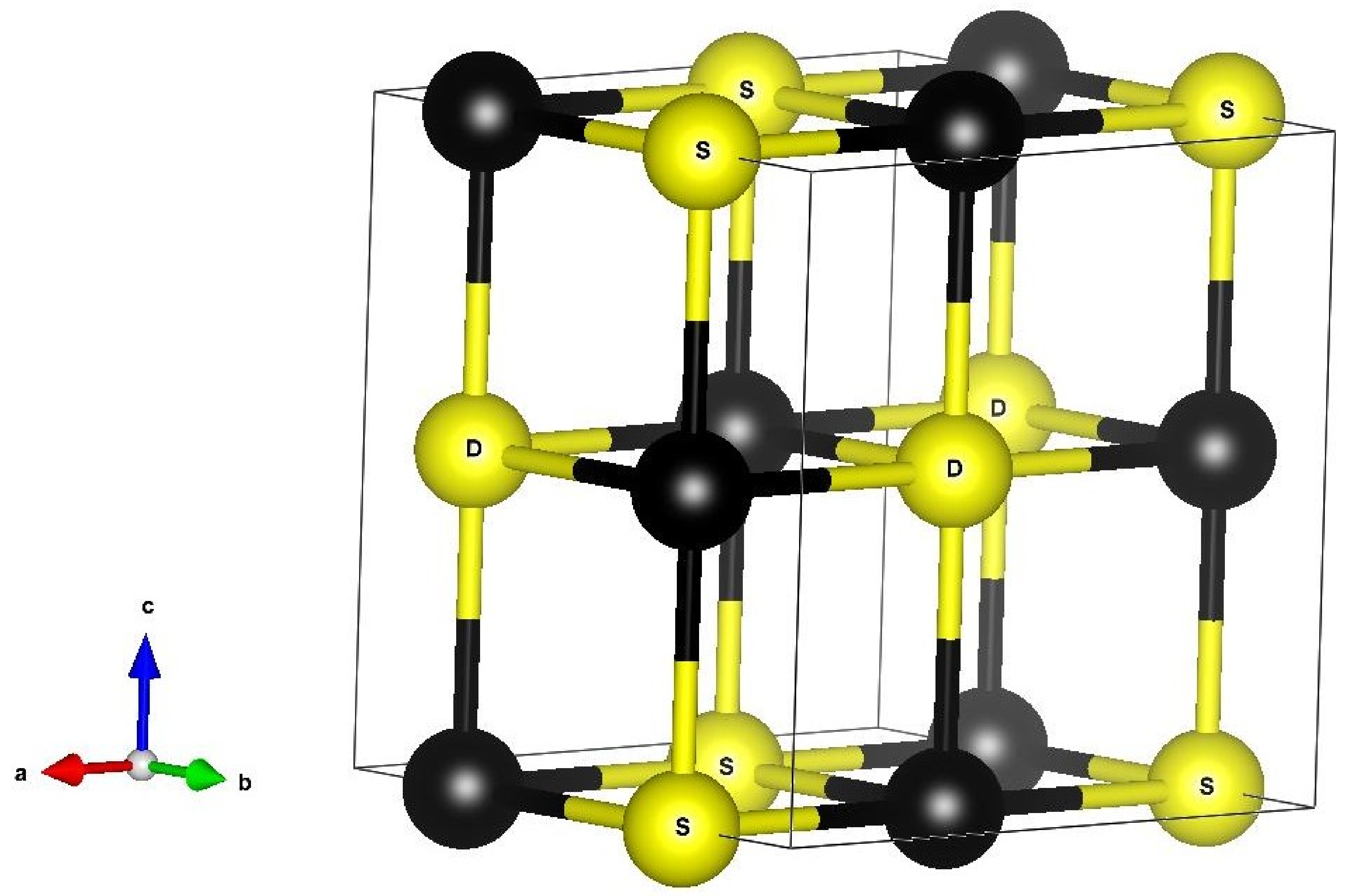




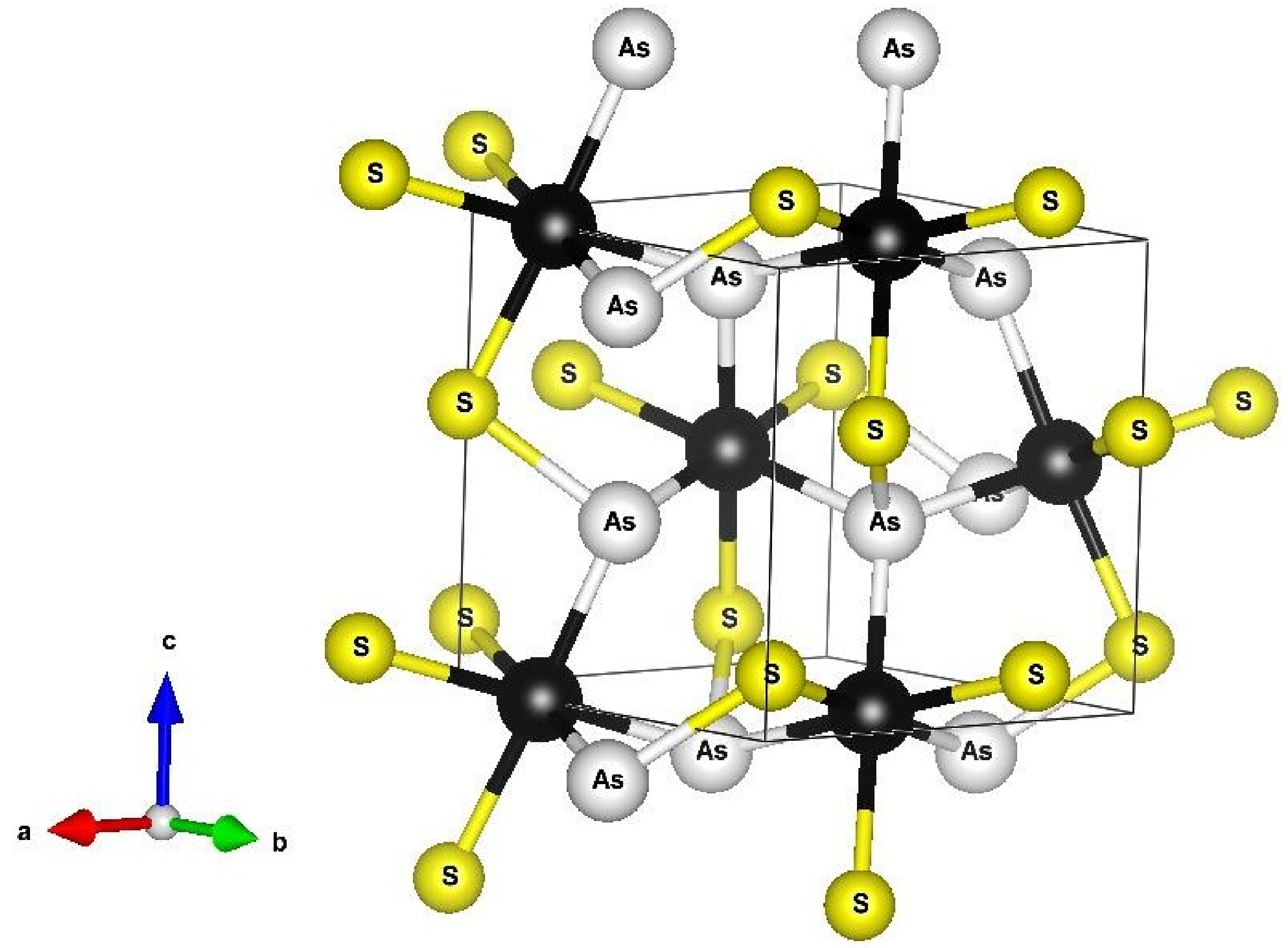




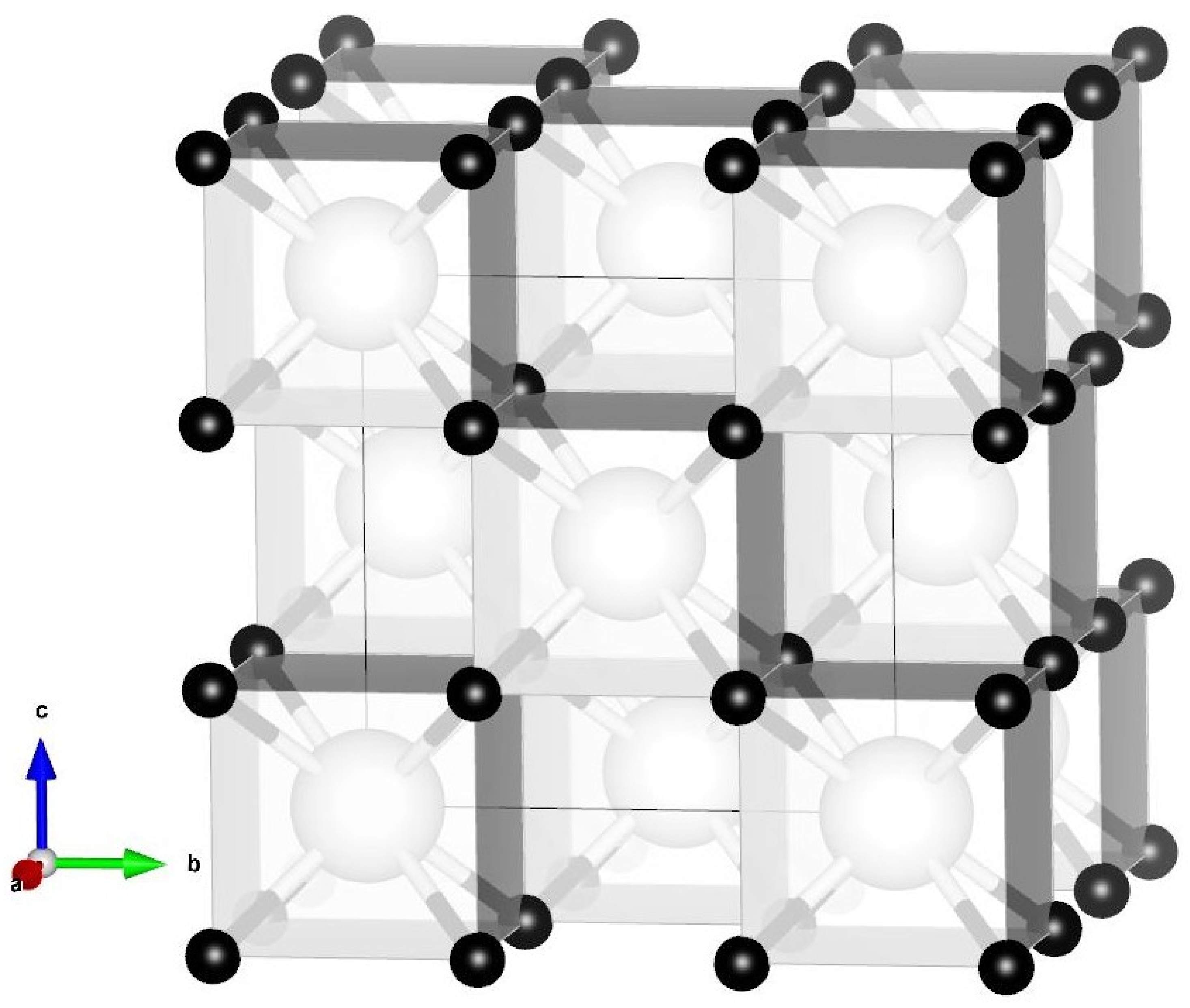




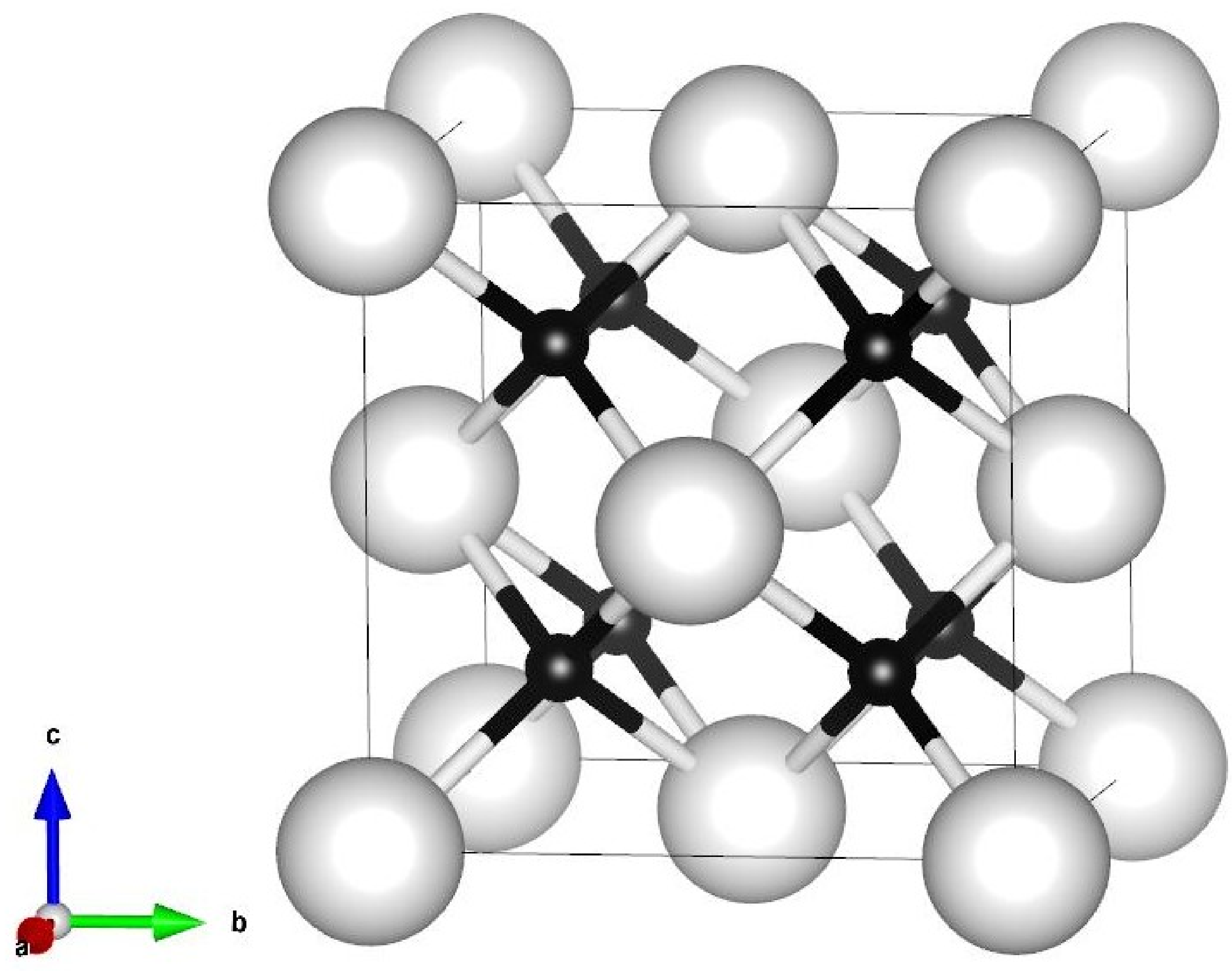



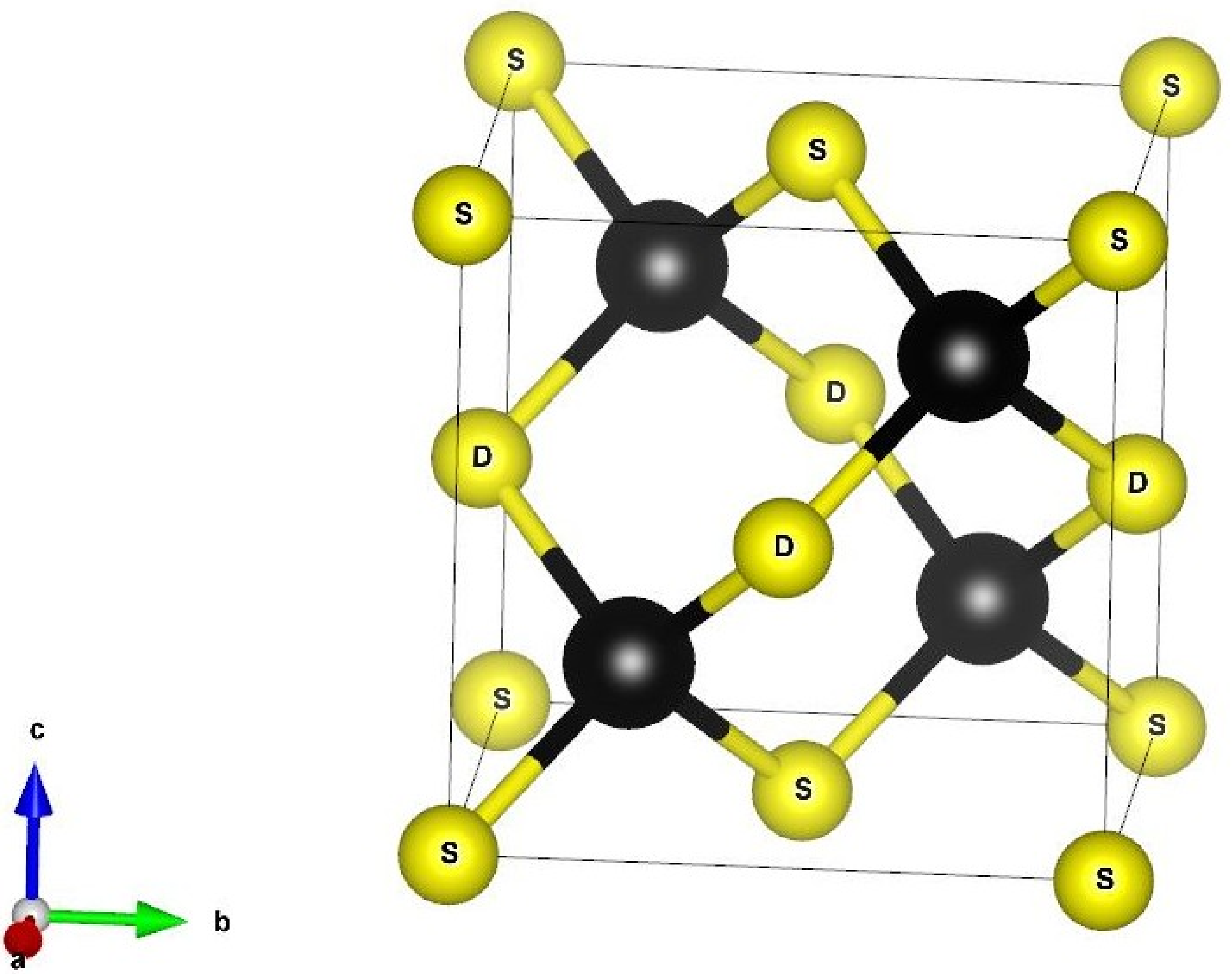

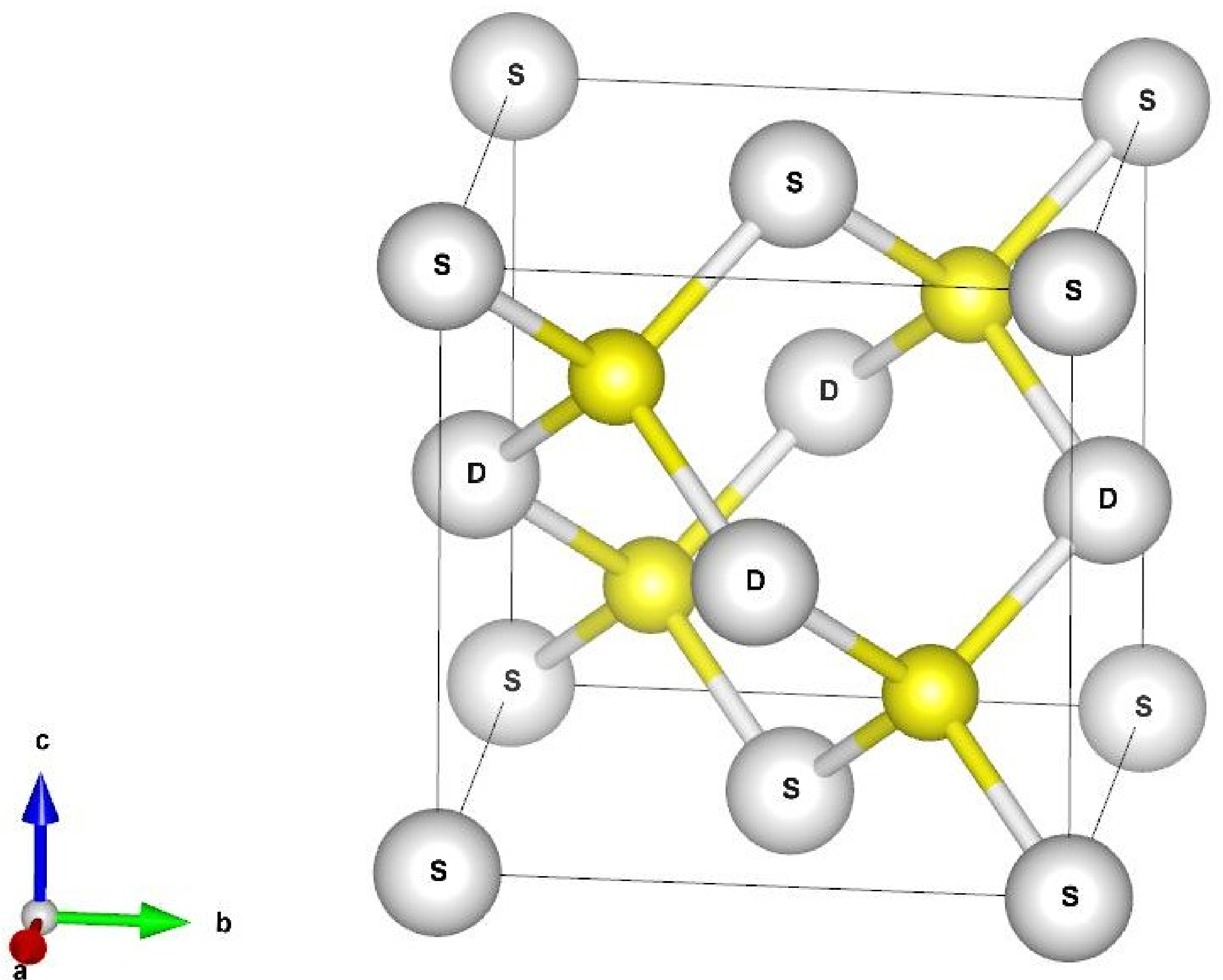

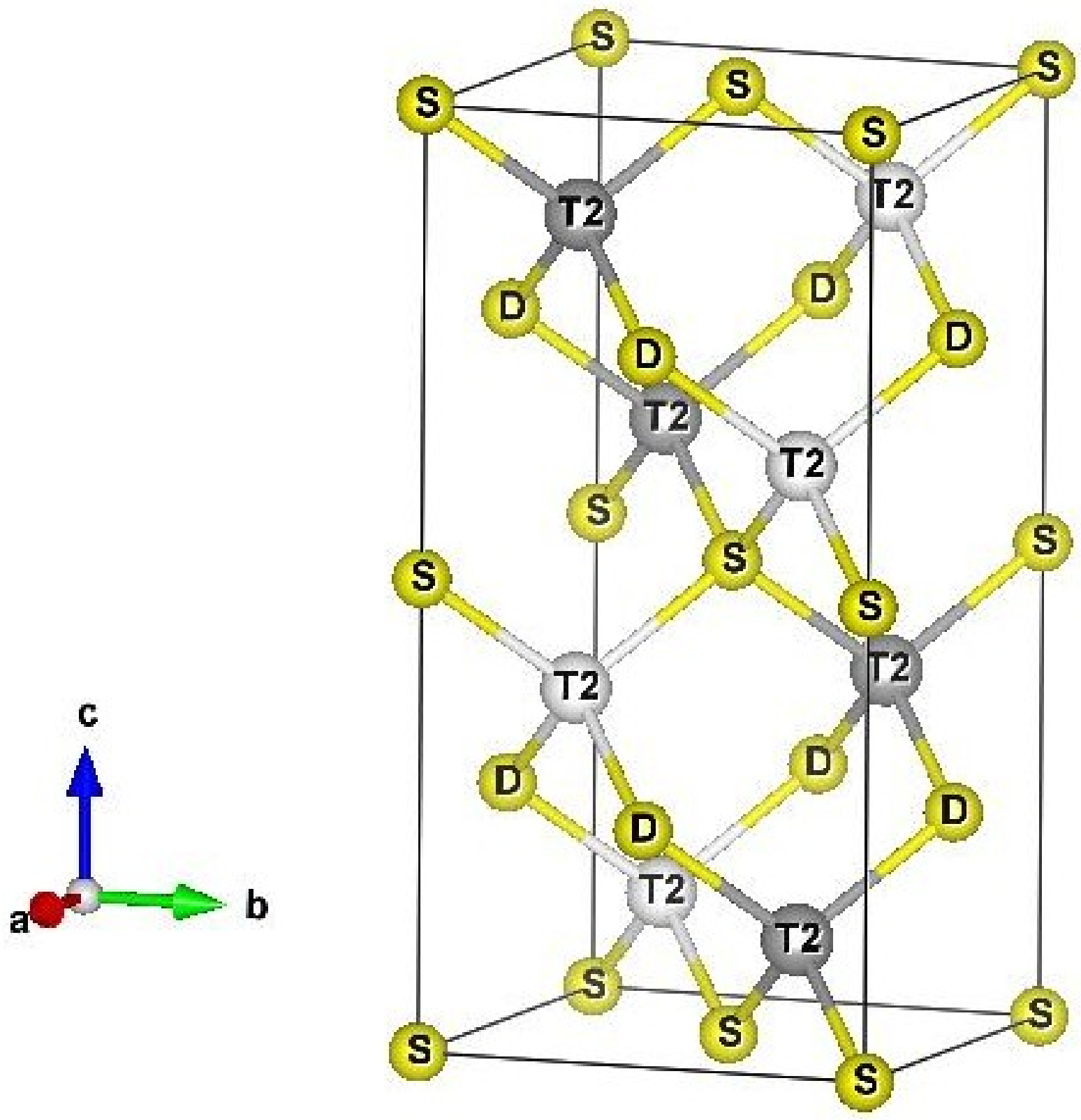


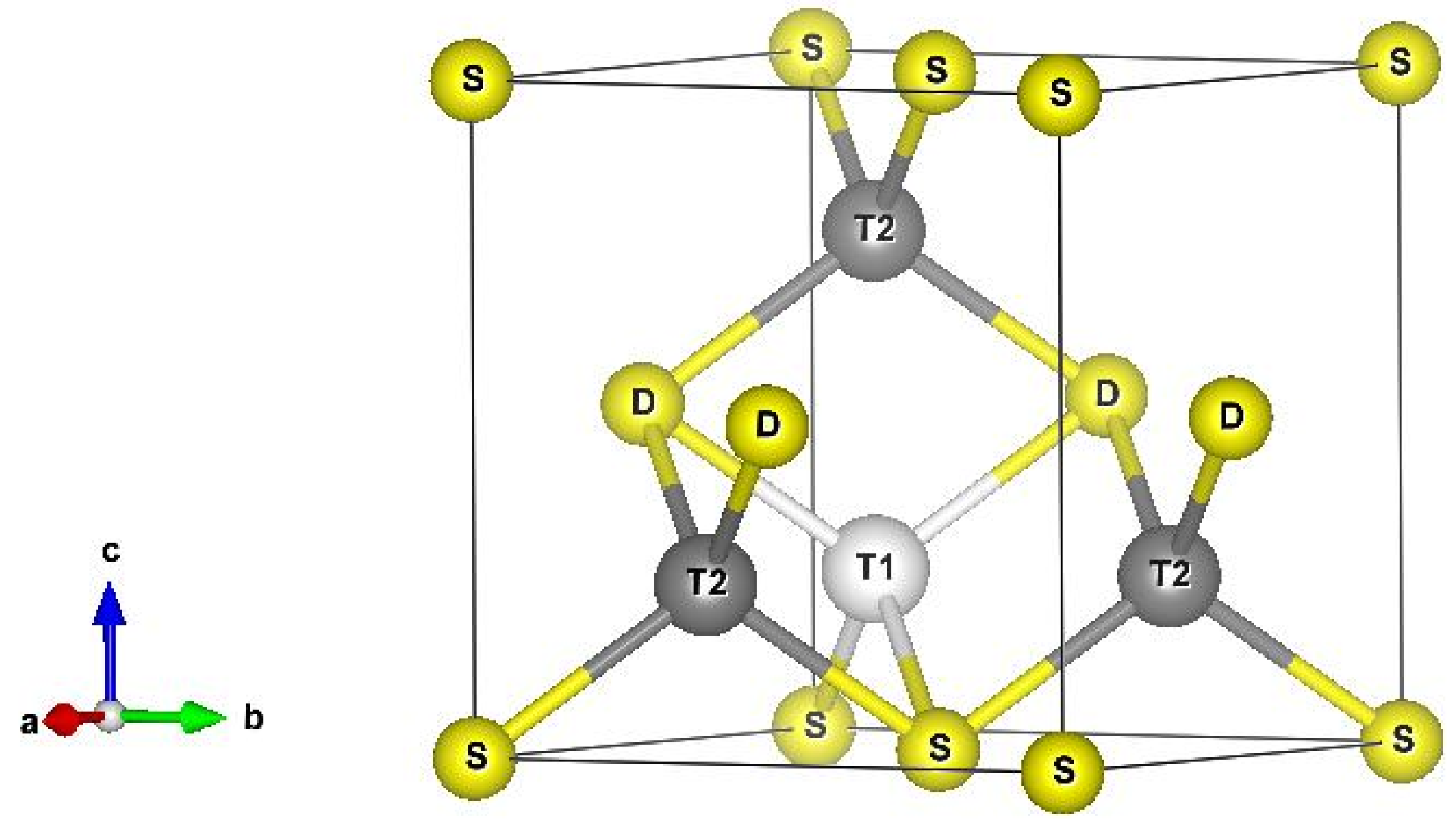



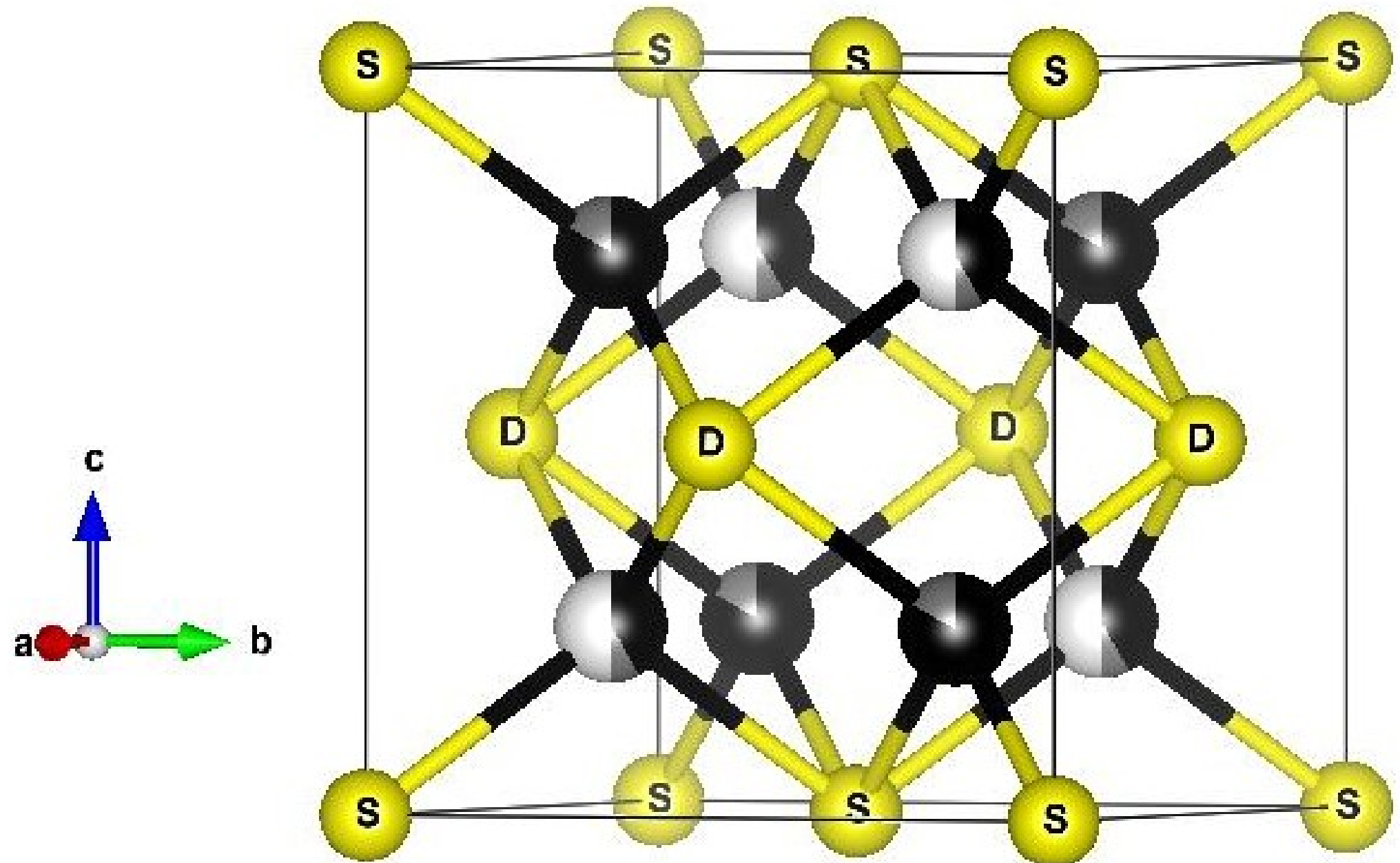


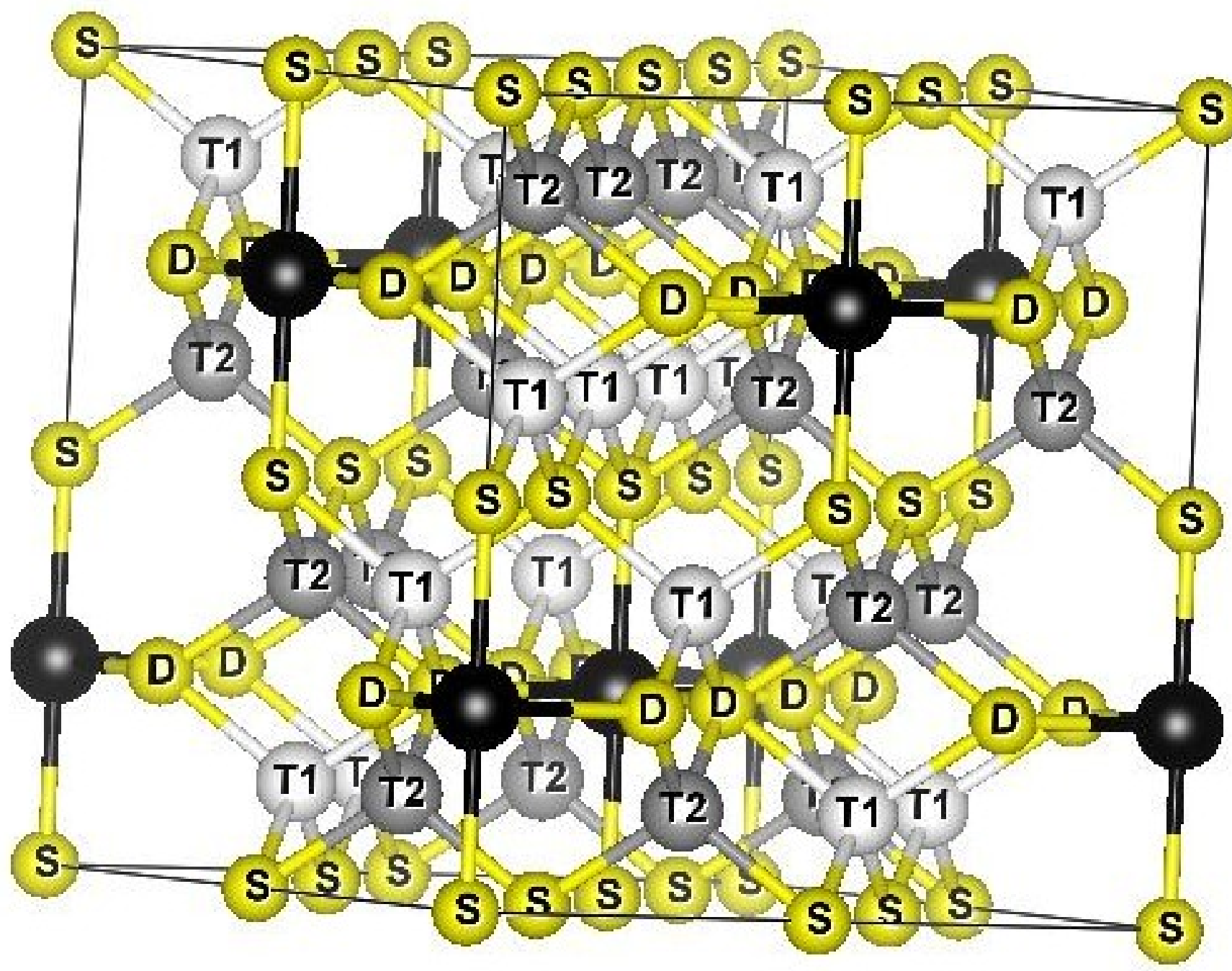




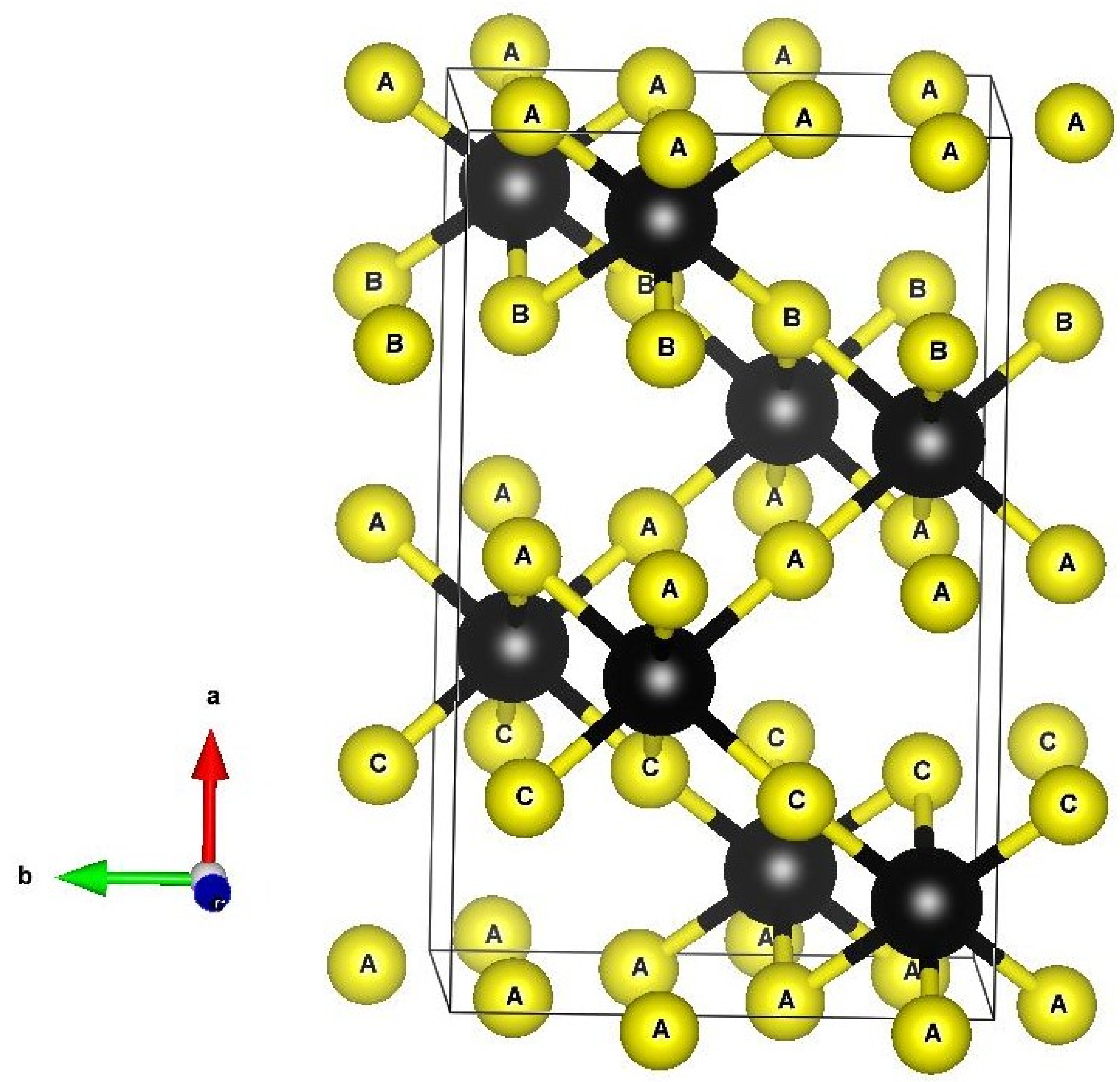



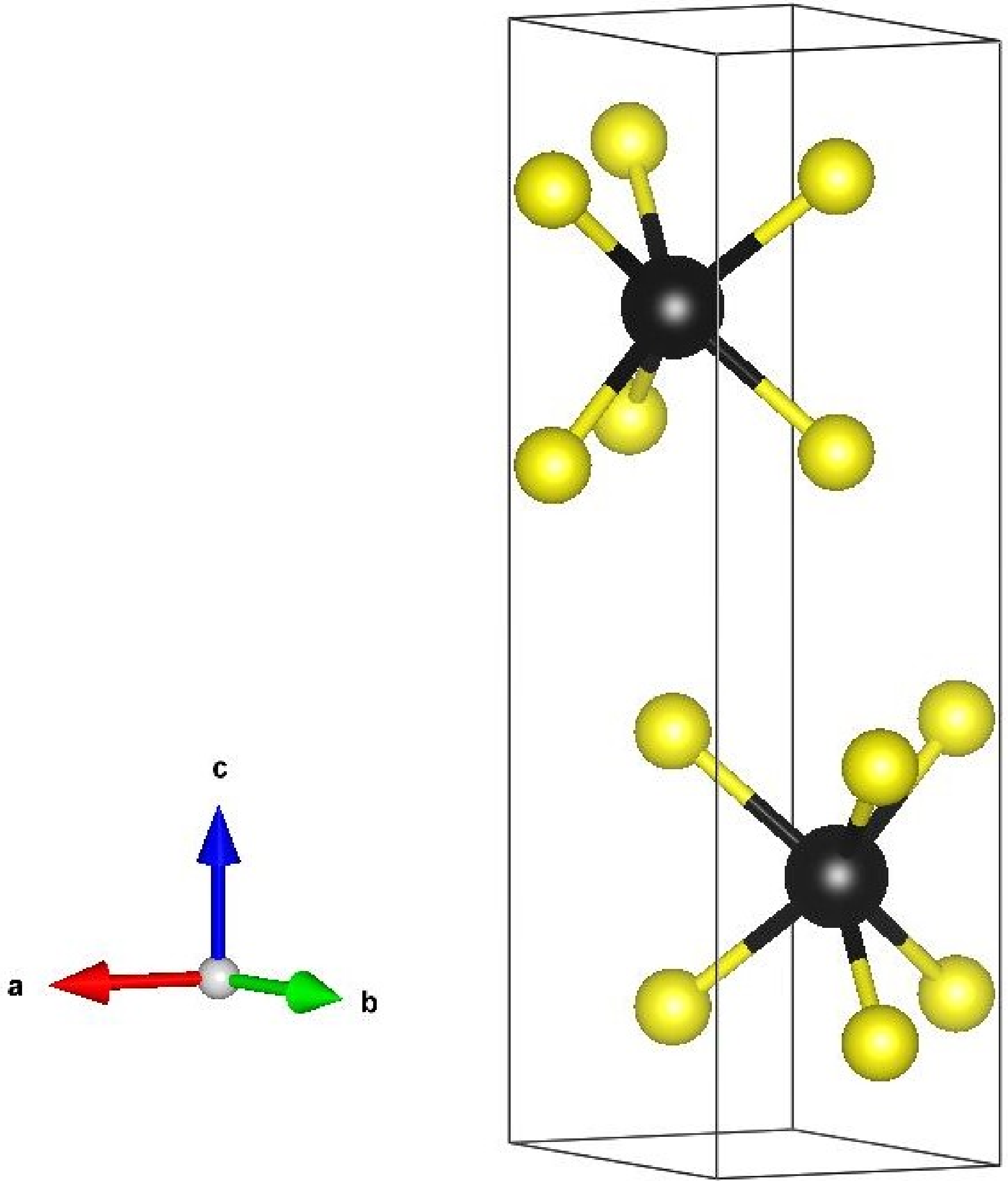

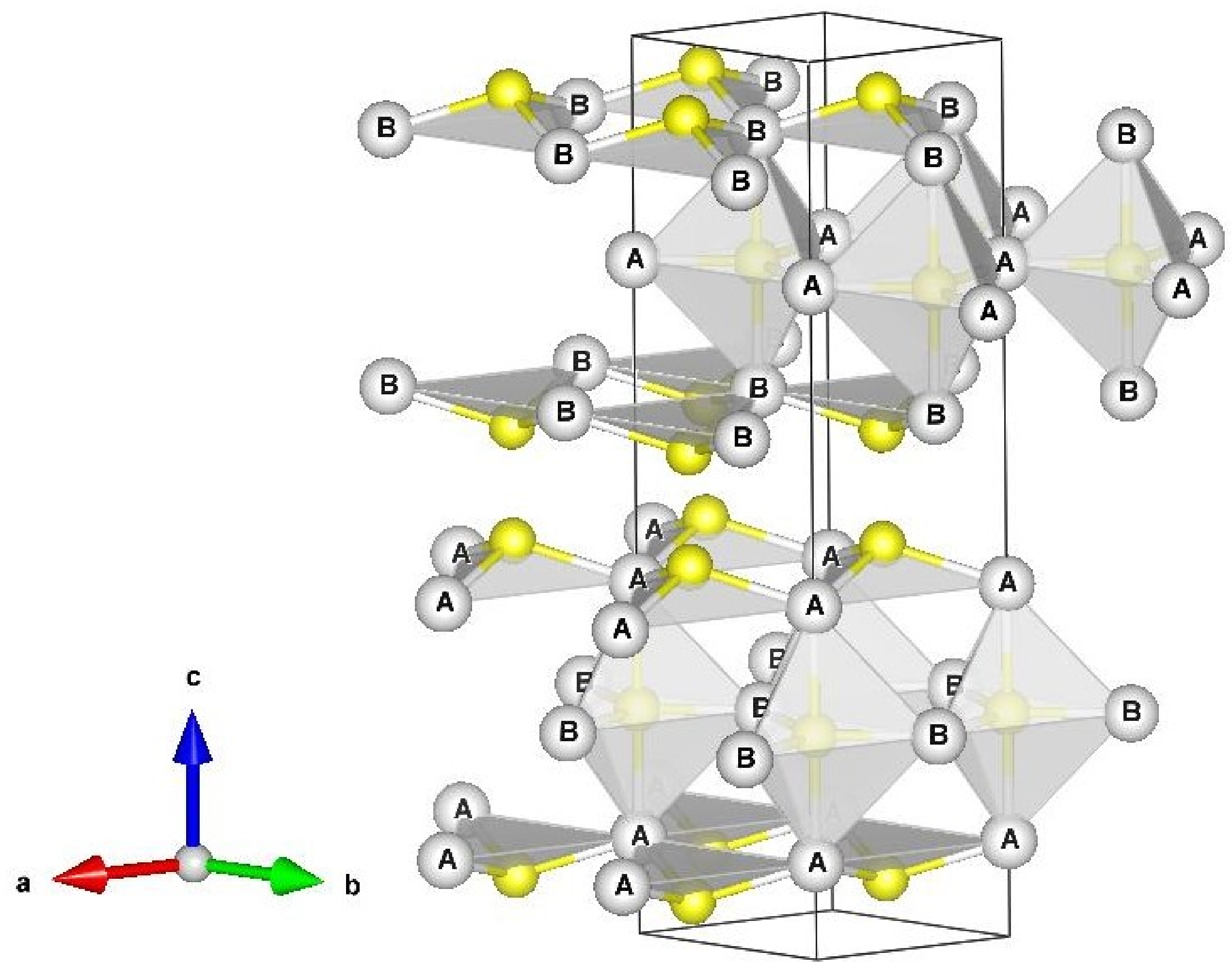


\section{aristotype}

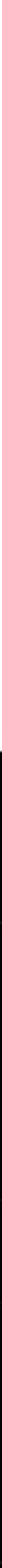


$\mathrm{PG}_{3} / m m c$

\section{aristotype}



$\mathrm{P6}_{3} / \mathrm{mmc}$

\section{hettotype}

Nickeline

$\mathrm{FeS}$

Troilite

NiAs

Breithauptite

$\mathrm{NiSb}$

Millerite

NiS

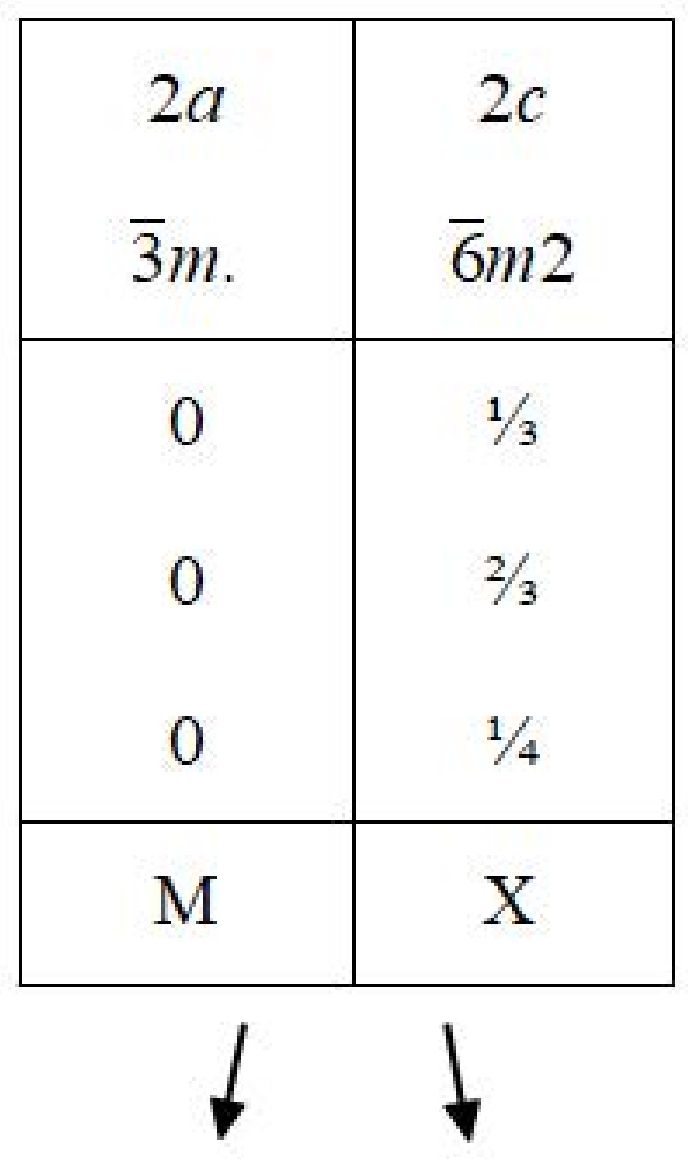

$2 c$

$\overline{6} m 2$

$1 / 3$

$2 / 3$

$1 / 4$

$\mathrm{O}$

$1 / 3$

0

$\mathrm{Fe}$

$\begin{array}{ll}0 & 2 / 3\end{array}$

0 
$\mathrm{P6}_{3} / \mathrm{mmc}$

\section{aristotype}

\section{hettotype}

Ilmenite $\mathrm{FeTiO}_{3}$

\begin{tabular}{|cccc|c|}
\hline $\begin{array}{c}3 a \\
\overline{3} .\end{array}$ & $3 b$ & $6 c$ & $6 c$ & $18 f$ \\
\hline 0 & $\overline{3}$. & 3. & 3. & 1 \\
\hline 0 & 0 & 0 & 0 & 0.3333 \\
0 & $1 / 2$ & 0.3333 & 0.1667 & 0.2500 \\
\hline$\square$ & $\square$ & $\mathrm{Fe}$ & $\mathrm{Ti}$ & $\mathrm{O}$ \\
\hline- & - & 0 & 0 & 0.3174 \\
- & - & 0 & 0 & 0.0233 \\
- & - & 0.3554 & 0.1464 & 0.2451 \\
\hline
\end{tabular}


$\mathrm{PG}_{3} / \mathrm{mmc}$

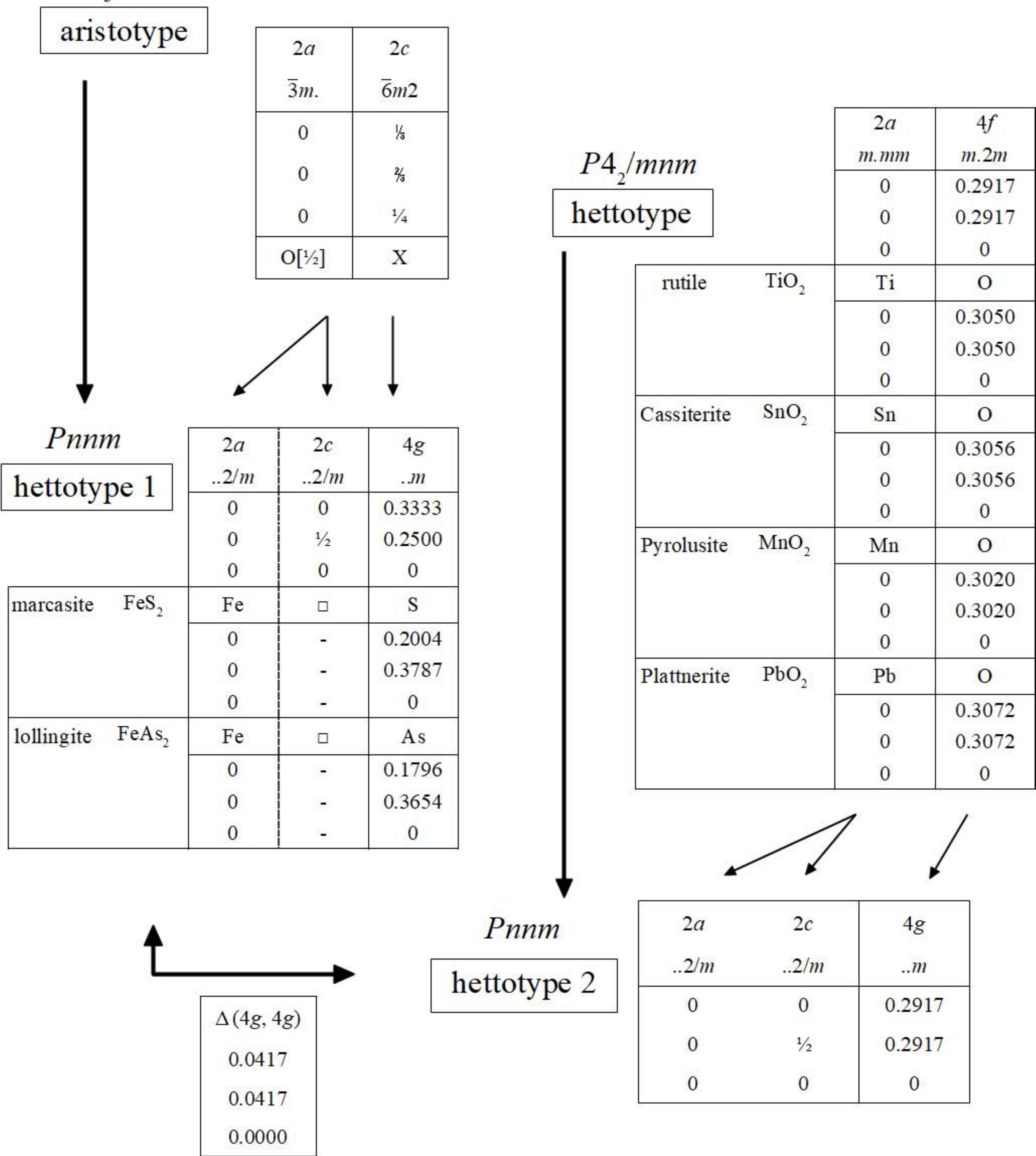


$\mathrm{PG}_{3} / m m c$

\section{aristotype}

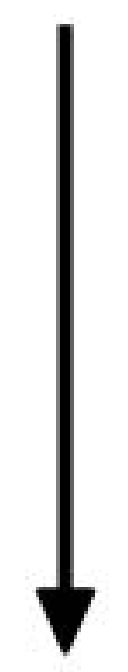

$P 2_{1} / c$

hettotype

\begin{tabular}{|c|c|}
\hline $2 a$ & $2 c$ \\
$\overline{3} m$ & $\overline{6} m 2$ \\
\hline 0 & $1 / 3$ \\
0 & $2 / 3$ \\
0 & $1 / 4$ \\
\hline $\mathrm{M}[1 / 2]$ & $\mathrm{X}$ \\
\hline
\end{tabular}

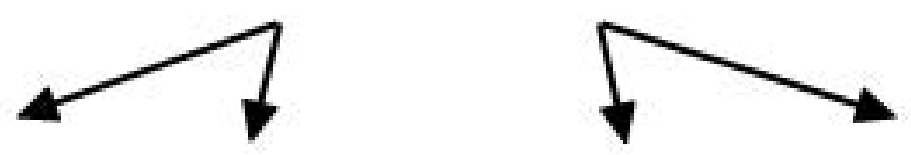

\begin{tabular}{|c|ccc|cc|}
\cline { 2 - 5 } \multicolumn{1}{c|}{} & \multicolumn{1}{c|}{$P 2_{1} / c$} & $4 e$ & $4 e$ & $4 e$ \\
\hline \multicolumn{1}{c|}{ hettotype } & 1 & 1 & 1 & 1 \\
\cline { 3 - 6 } & 0.0000 & 0.5000 & 0.3333 & 0.8333 \\
& 0.0000 & 0.0000 & 0.2500 & 0.2500 \\
\hline \multirow{3}{*}{ Arsenopyrite FeAsS } & 0.2500 & 0.2500 & 0.9167 & 0.4167 \\
\cline { 3 - 6 } & - & $\mathrm{Fe}$ & $\mathrm{As}$ & $\mathrm{S}$ \\
\cline { 2 - 6 } & - & 0.2835 & 0.1475 & 0.6551 \\
& - & 0.9936 & 0.1306 & 0.1311 \\
& - & 0.2943 & 0.8694 & 0.3211 \\
\hline
\end{tabular}


$\mathrm{PG}_{3} / \mathrm{mmc}$

\section{aristotype}

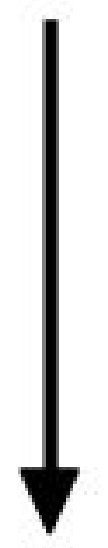

$P 2 / c$

hettotype

\begin{tabular}{|c|c|}
\hline $2 a$ & $2 c$ \\
$\overline{3} m$. & $\overline{6} m 2$ \\
\hline 0 & $1 / 6$ \\
0 & $2 / 6$ \\
0 & $1 / 4$ \\
\hline $\mathrm{M}[1 / 2]$ & $\mathrm{X}$ \\
\hline
\end{tabular}
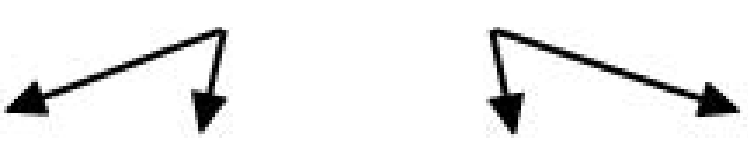

\begin{tabular}{|c|cc|cc|}
\cline { 2 - 5 } \multicolumn{1}{c|}{$P 2_{1} / c$} & $4 e$ & $4 e$ & $4 e$ & $4 e$ \\
\cline { 3 - 6 } hettotype & 1 & 1 & 1 & 1 \\
\cline { 3 - 6 } & 0.5000 & 0.0000 & 0.8333 & 0.3333 \\
\cline { 3 - 6 } \multicolumn{1}{c|}{ Gudmundite FeSbS } & 0.0000 & 0.0000 & 0.2500 & 0.2500 \\
& 0.2500 & 0.2500 & 0.0833 & 0.5833 \\
\cline { 2 - 6 } & - & 0.2000 & 0.6490 & 0.1440 \\
& - & 0.0150 & 0.1310 & 0.1450 \\
& - & 0.3000 & 0.1320 & 0.6670 \\
\hline
\end{tabular}


$\mathrm{P}_{3} / m m c$

\section{aristotype}

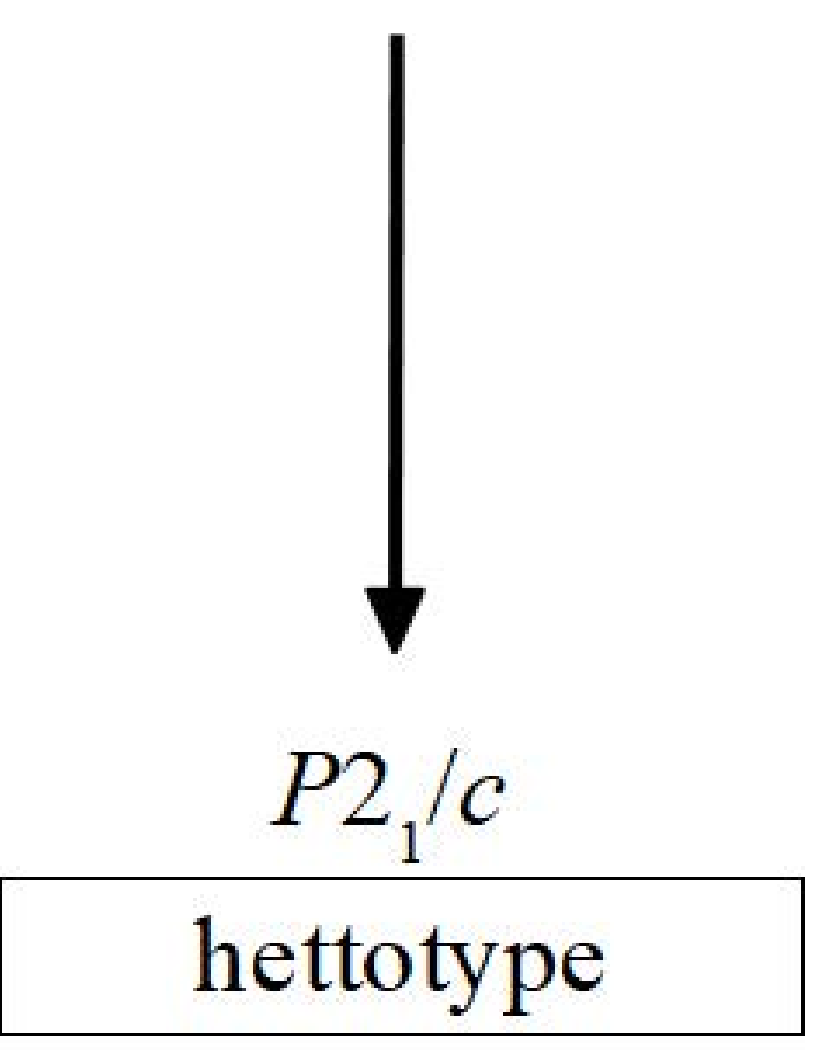

\begin{tabular}{|cc|cc|}
\hline $4 e$ & $4 e$ & $4 e$ & $4 e$ \\
1 & 1 & 1 & 1 \\
\hline 0.0000 & 0.5000 & 0.6667 & 0.1667 \\
0.0000 & 0.0000 & 0.2500 & 0.2500 \\
0.7500 & 0.7500 & 0.0833 & 0.5833 \\
\hline $\mathrm{Mn}$ & $\square$ & $\mathrm{O}$ & $\mathrm{OH}$ \\
\hline 0.7632 & - & 0.8752 & 0.3749 \\
0.0103 & - & 0.1256 & 0.1238 \\
0.7546 & - & 0.1206 & 0.6279 \\
\hline
\end{tabular}


$\mathrm{P6}_{3} / \mathrm{mmc}$

\section{aris totype}

\begin{tabular}{|c|c|}
\hline $4 f$ & $2 c$ \\
$3 m$. & $6 m 2$ \\
\hline $1 / 3$ & $1 / 3$ \\
$2 / 3$ & $2 / 3$ \\
0.625 & $1 / 4$ \\
\hline $\mathrm{T}[1 / 2]$ & $\mathrm{X}$ \\
\hline
\end{tabular}

$\mathrm{Pb}_{3} m c$

hettotype

\begin{tabular}{|c|c|c|c|c|}
\hline & & 73 & $1 / 3$ & $1 / 3$ \\
\hline & & 0.6250 & 0.3750 & 0.7500 \\
\hline Zincite & $\mathrm{ZnO}$ & ㅁ & $\mathrm{Zn}$ & $\mathrm{O}$ \\
\hline & & - & 0.6667 & 0.6667 \\
\hline & & - & 0.3333 & 0.3333 \\
\hline & & - & 0.4050 & 0.7500 \\
\hline Bromellite & $\mathrm{BeO}$ & $\square$ & $\mathrm{Be}$ & $\mathrm{O}$ \\
\hline & & - & 0.6667 & 0.6667 \\
\hline & & - & 0.3333 & 0.3333 \\
\hline & & - & 0.3720 & 0.7500 \\
\hline wurtzite & $\mathrm{ZnS}$ & 口 & $\mathrm{Zn}$ & $\mathrm{s}$ \\
\hline & & - & 0.6667 & 0.6667 \\
\hline & & - & 0.3333 & 0.3333 \\
\hline & & - & 0.3752 & 0.7500 \\
\hline greeenockite & $\mathrm{CdS}$ & $\square$ & $\mathrm{Cd}$ & $\mathrm{S}$ \\
\hline & & - & 0.6667 & 0.6667 \\
\hline & & - & 0.3333 & 0.3333 \\
\hline & & - & 0.3750 & 0.7500 \\
\hline
\end{tabular}


$\mathrm{Pb}_{3} / \mathrm{mmc}$

\section{aristotype}

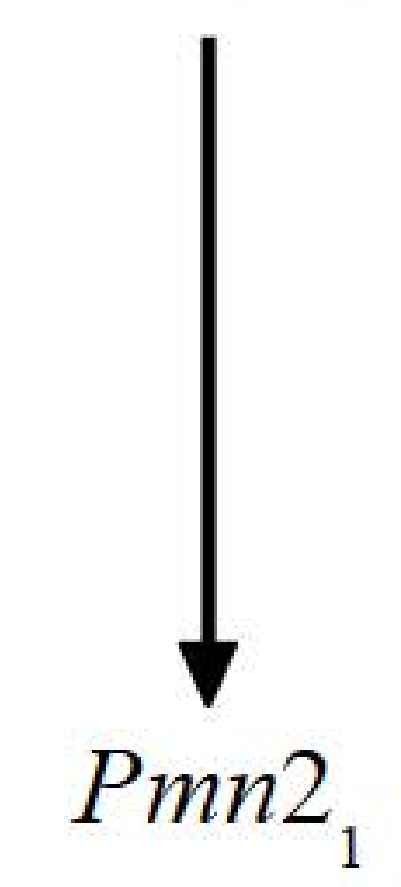

\section{hettotype}

\begin{tabular}{|c|cccccc|cccc}
\hline \multicolumn{1}{c|}{} & 0.1667 & 0.8333 & 0.8333 & 0.1667 & 0.6667 & 0.6667 & 0.1667 & 0.8333 & 0.6667 \\
\hline \multirow{2}{*}{ Enargite $\mathrm{Cu}_{3} \mathrm{AsS}_{4}$} & 0.3762 & 0.8762 & 0.6238 & 0.1238 & 0.3762 & 0.3762 & 0.7512 & 0.2512 & 0.7512 \\
\cline { 2 - 10 } & $\mathrm{As}$ & $\mathrm{Cu}$ & $\square$ & $\square$ & $\mathrm{Cu}$ & $\square$ & $\mathrm{S}$ & $\mathrm{S}$ & $\mathrm{S}$ \\
\cline { 2 - 10 } & 0 & 0 & - & - & 0.7523 & - & 0 & 0 & 0.7436 \\
& 0.1726 & 0.8467 & - & - & 0.6745 & - & 0.1777 & 0.8517 & 0.6648 \\
& 0.3751 & 0.8753 & - & - & 0.3834 & - & 0.7326 & 0.25 & 0.7548 \\
\hline
\end{tabular}


$\mathrm{P6}_{3} / \mathrm{mmc}$

\section{aristotype}

\begin{tabular}{|c|c|c|c|c|c|c|}
\hline $\mid$ & & & $\begin{array}{c}2 / 2 \\
0.625\end{array}$ & $\begin{array}{l}2 / 6 \\
1 / 4\end{array}$ & & \\
\hline & & & $\mathrm{T}[1 / 2]$ & $\mathrm{X}$ & & \\
\hline & $4 c$ & $4 c$ & $8 d$ & $8 d$ & $4 c$ & $8 d$ \\
\hline 1 тита & $m$. &.$m$. & 1 & 1 &.$m$ & 1 \\
\hline nettotype & 0.1250 & 0.1250 & 0.6250 & 0.6250 & 0.7500 & 0.2500 \\
\hline & $3 / 4$ & $1 / 4$ & 0.5833 & 0.4167 & $1 / 4$ & 0.4167 \\
\hline & 0.9167 & 0.4167 & 0.0833 & 0.5833 & 0.41667 & 0.5833 \\
\hline cubanite $\mathrm{CuFe}_{2} \mathrm{~S}_{3}$ & $\square$ & $\mathrm{Cu}$ & $\square$ & $\mathrm{Fe}$ & $\mathrm{S}$ & $\mathrm{S}$ \\
\hline & - & 0.1227 & - & 0.6366 & 0.7577 & 0.2670 \\
\hline & - & $1 / 4$ & - & 0.4129 & $1 / 4$ & 0.4155 \\
\hline & - & 0.4164 & - & 0.5852 & 0.4143 & 0.5884 \\
\hline
\end{tabular}


$\mathrm{P6}_{3} / \mathrm{mmc}$

\section{aristotype}

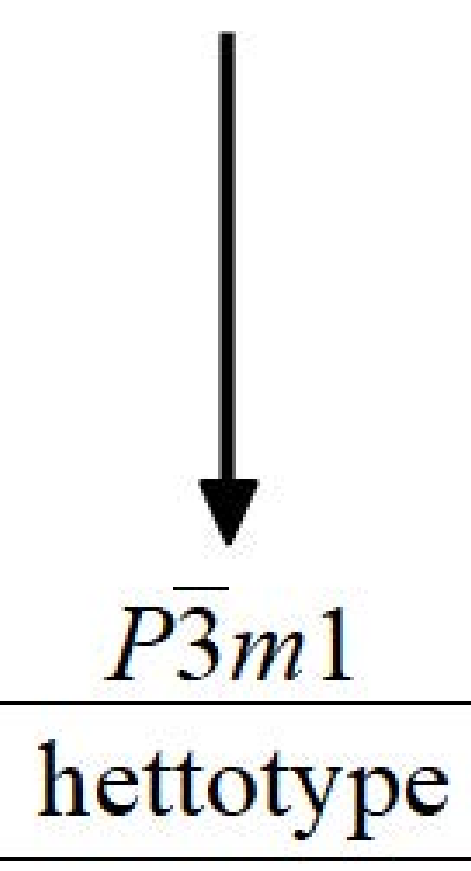

Brucite $\mathrm{Mg}(\mathrm{OH})_{2}$

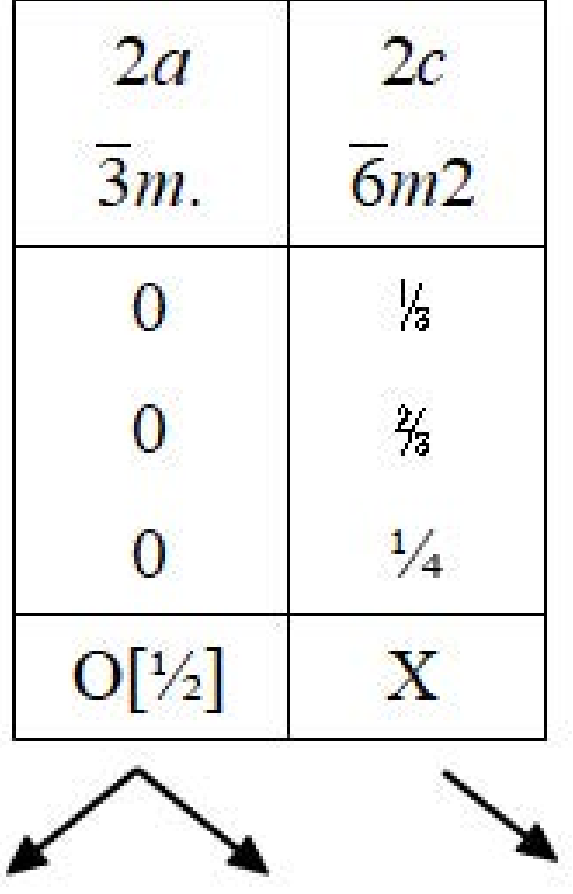

$P \overline{3} m 1$

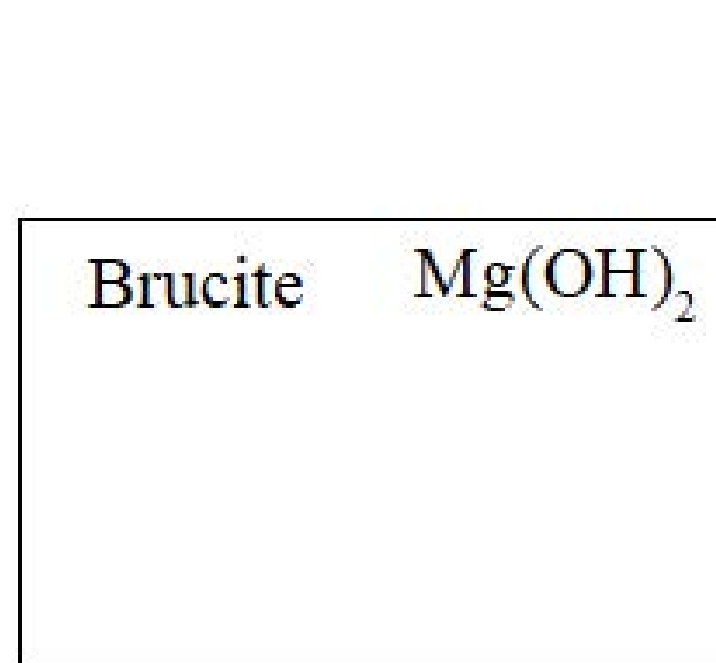

\begin{tabular}{|cc|c|}
\hline $\begin{array}{c}1 a \\
\overline{3} m .\end{array}$ & $\begin{array}{c}1 b \\
\overline{3} m .\end{array}$ & $\begin{array}{c}2 d \\
3 m .\end{array}$ \\
\hline 0 & 0 & $1 / 3$ \\
0 & 0 & $2 / 3$ \\
0 & $1 / 2$ & 0.2500 \\
\hline $\mathrm{Mg}$ & $\square$ & $\mathrm{OH}$ \\
\hline 0 & - & $1 / 3$ \\
0 & - & $2 / 3$ \\
0 & - & 0.2200 \\
\hline
\end{tabular}




\section{$F m \overline{3} m$ \\ aristotype}

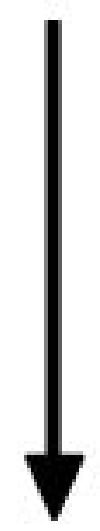

I4 / / amd

hettotype

anatase

\begin{tabular}{|c|c|}
\hline $4 a$ & $4 b$ \\
$m \overline{3} m$ & $m \overline{3} m$ \\
\hline 0 & $1 / 2$ \\
0 & $1 / 2$ \\
0 & $1 / 2$ \\
\hline $\mathrm{M}[1 / 2]$ & $\mathrm{X}$ \\
\hline
\end{tabular}



\begin{tabular}{|cc|c|}
\hline $4 a$ & $4 b$ & $8 e$ \\
$\overline{4} m 2$ & $\overline{4} m 2$ & $2 m m$ \\
\hline 0 & 0 & 0 \\
$1 / 4$ & $1 / 4$ & $1 / 4$ \\
78 & $* 8$ & 0.1250 \\
\hline $\mathrm{Ti}$ & $\square$ & $\mathrm{O}$ \\
\hline 0 & - & 0 \\
$1 / 4$ & - & $1 / 4$ \\
$7 \%$ & - & 0.0831 \\
\hline
\end{tabular}




\section{$F m \overline{3} m$ \\ aristotype}

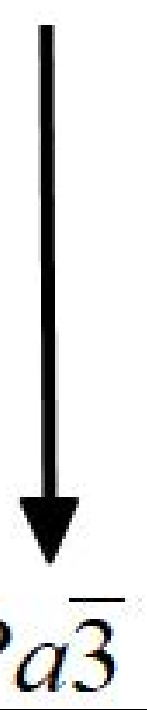

\section{hettotype \\ $P a \overline{3}$}

\begin{tabular}{|c|c|}
\hline $4 a$ & $4 b$ \\
$m \overline{3} m$ & $m \overline{3} m$ \\
\hline 0 & $1 / 2$ \\
0 & $1 / 2$ \\
0 & $1 / 2$ \\
\hline $\mathrm{M}$ & $\mathrm{X}$ \\
\hline
\end{tabular}

$\swarrow \quad \searrow$

\begin{tabular}{|cc|c|c|}
\hline Pyrite & $\mathrm{FeS}_{2}$ & $\mathrm{M}$ & $\mathrm{X}-\mathrm{X}$ \\
\cline { 3 - 4 } Sperrylite & $\mathrm{PtAs}_{2}$ & 0 & $1 / 2$ \\
Vasesite & $\mathrm{NiS}_{2}$ & 0 & $1 / 2$ \\
& & 0 & $1 / 2$ \\
\hline \multirow{2}{*}{ Bravoite } & $(\mathrm{Ni}, \mathrm{Fe}) \mathrm{S}_{2}$ & $\mathrm{Fe}\left[\frac{1}{2}\right], \mathrm{Ni}\left[\frac{1}{2}\right]$ & $\mathrm{S}-\mathrm{S}$ \\
\cline { 3 - 4 } & & 0 & $1 / 2$ \\
& & 0 & $1 / 2$ \\
& & 0 & $1 / 2$ \\
\hline
\end{tabular}




\section{$F m \overline{3} m$ \\ aristotype}

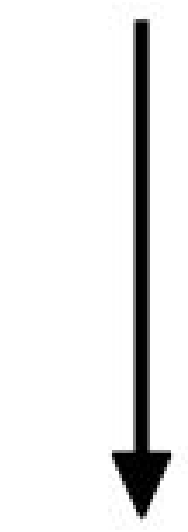

hettotype

\section{Cobaltite CoAsS}

\begin{tabular}{|c|c|}
\hline $\begin{array}{c}4 a \\
\overline{3} m\end{array}$ & $\begin{array}{c}4 b \\
\overline{3}\end{array}$ \\
\hline 0 & $1 / 2$ \\
0 & $1 / 2$ \\
0 & $1 / 2$ \\
\hline $\mathrm{M}$ & $\mathrm{X}$ \\
\hline & \\
\hline
\end{tabular}

\section{$\mathrm{Pca}_{1}$}

\begin{tabular}{c|c}
$4 a$ & $4 a$ \\
1 & 1 \\
\hline 0.0000 & 0.0000 \\
0.2500 & 0.2500 \\
0.9994 & 0.4994
\end{tabular}

\begin{tabular}{c|c} 
Co & S-As \\
\hline 0.9955 & 0.0020 \\
0.2596 & 0.2496 \\
0.0000 & 0.4989
\end{tabular}




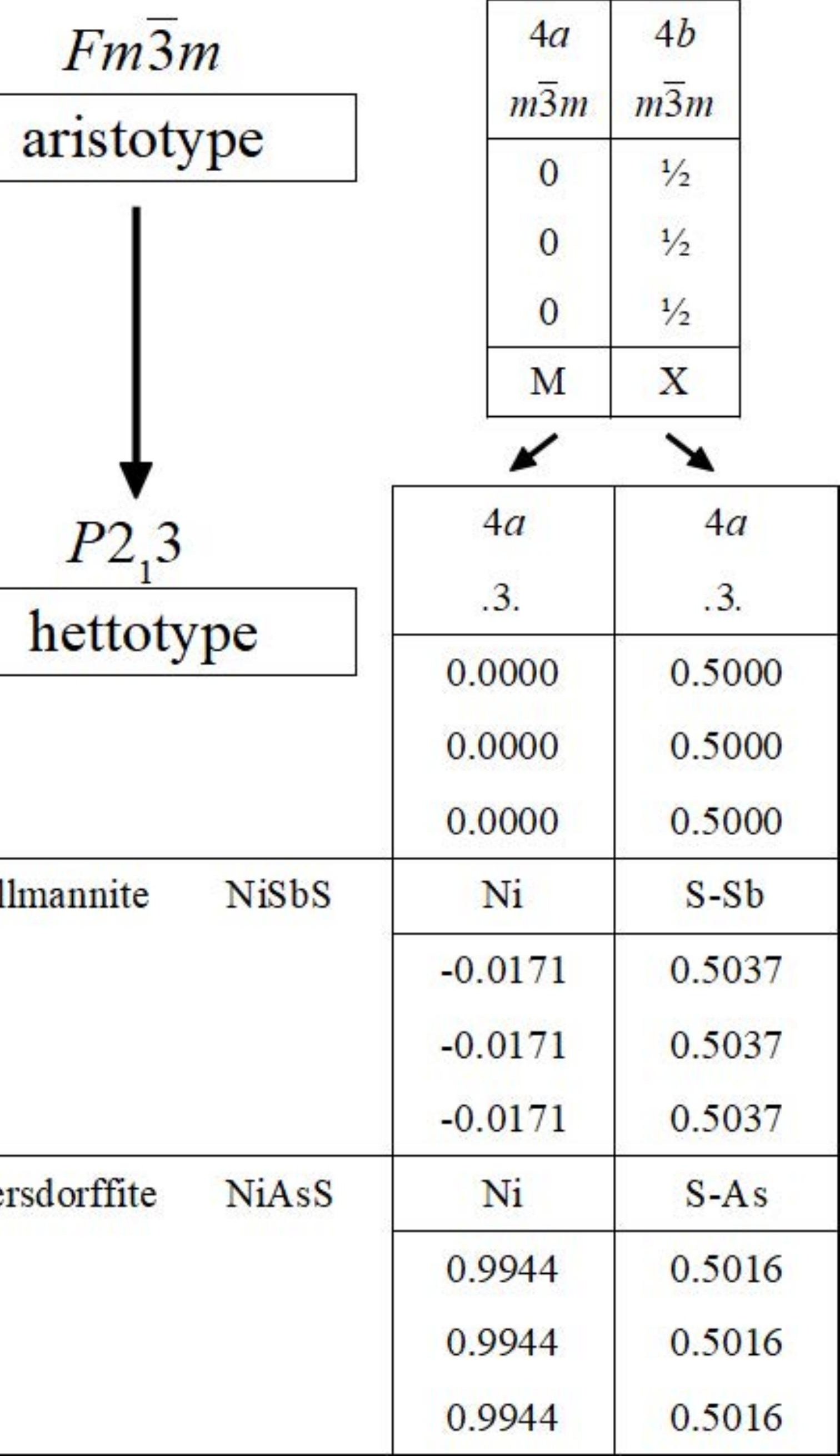




\section{$F m \overline{3} m$ \\ aristotype}

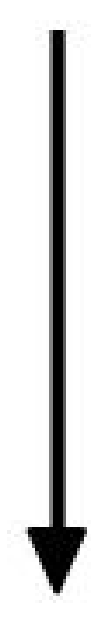

P4/nmn

\section{hettotype}

\begin{tabular}{|c|c|}
\hline $8 c$ & $4 b$ \\
$\overline{4} 3 m$ & $m \overline{3} m$ \\
\hline $1 / 4$ & $1 / 2$ \\
$1 / 4$ & $1 / 2$ \\
0 & $1 / 2$ \\
\hline $\mathrm{X}[1 / 2]$ & $\mathrm{T}$ \\
\hline
\end{tabular}




\section{$F m \overline{3} m$ aristotype}

\begin{tabular}{|c|c|}
\hline $8 c$ & $4 b$ \\
$\overline{4} 3 m$ & $m \overline{3} m$ \\
\hline $1 / 4$ & $1 / 2$ \\
$1 / 4$ & $1 / 2$ \\
$1 / 4$ & $1 / 2$ \\
\hline $\mathrm{T}[1 / 2]$ & $\mathrm{X}$ \\
\hline
\end{tabular}

\section{$F \overline{4} 3 m$ \\ hettotype}

\begin{tabular}{|cc}
\hline Sphalerite & $\mathrm{ZnS}$ \\
Coloradoite & $\mathrm{HgTe}$ \\
Tiemannite & $\mathrm{HgSe}$
\end{tabular}




\begin{tabular}{|c|c|c|c|c|}
\hline 1 & & $\begin{array}{l}1 / 4 \\
1 / 4\end{array}$ & $\begin{array}{l}1 / 2 \\
1 / 2\end{array}$ & \\
\hline & & $\mathrm{T}[1 / 2]$ & $\mathrm{X}$ & \\
\hline $142 d$ & $4 a$ & $4 b$ & $8 c$ & $8 d$ \\
\hline hettotype & $\overline{4} .$. & $\overline{4} .$. & 2. & 2. \\
\hline & 0 & 0 & 0 & 0.2500 \\
\hline & 0 & 0 & 0 & $1 / 4$ \\
\hline & 0 & $1 / 2$ & 0.1250 & $1 / 8$ \\
\hline Chalcopyrite $\quad \mathrm{CuFeS}_{2}$ & $\mathrm{Cu}$ & $\mathrm{Fe}$ & $\square$ & $\mathrm{S}$ \\
\hline & 0 & 0 & - & 0.2604 \\
\hline & 0 & 0 & - & $1 / 4$ \\
\hline & 0 & $1 / 2$ & - & $1 / 8$ \\
\hline Gallite $\quad \mathrm{CuGaS}_{2}$ & $\mathrm{Cu}$ & $\mathrm{Ga}$ & $\square$ & $\mathrm{S}$ \\
\hline & 0 & 0 & - & 0.2539 \\
\hline & 0 & 0 & - & $1 / 4$ \\
\hline & 0 & $1 / 2$ & - & $1 / 8$ \\
\hline
\end{tabular}




\section{aristotype}
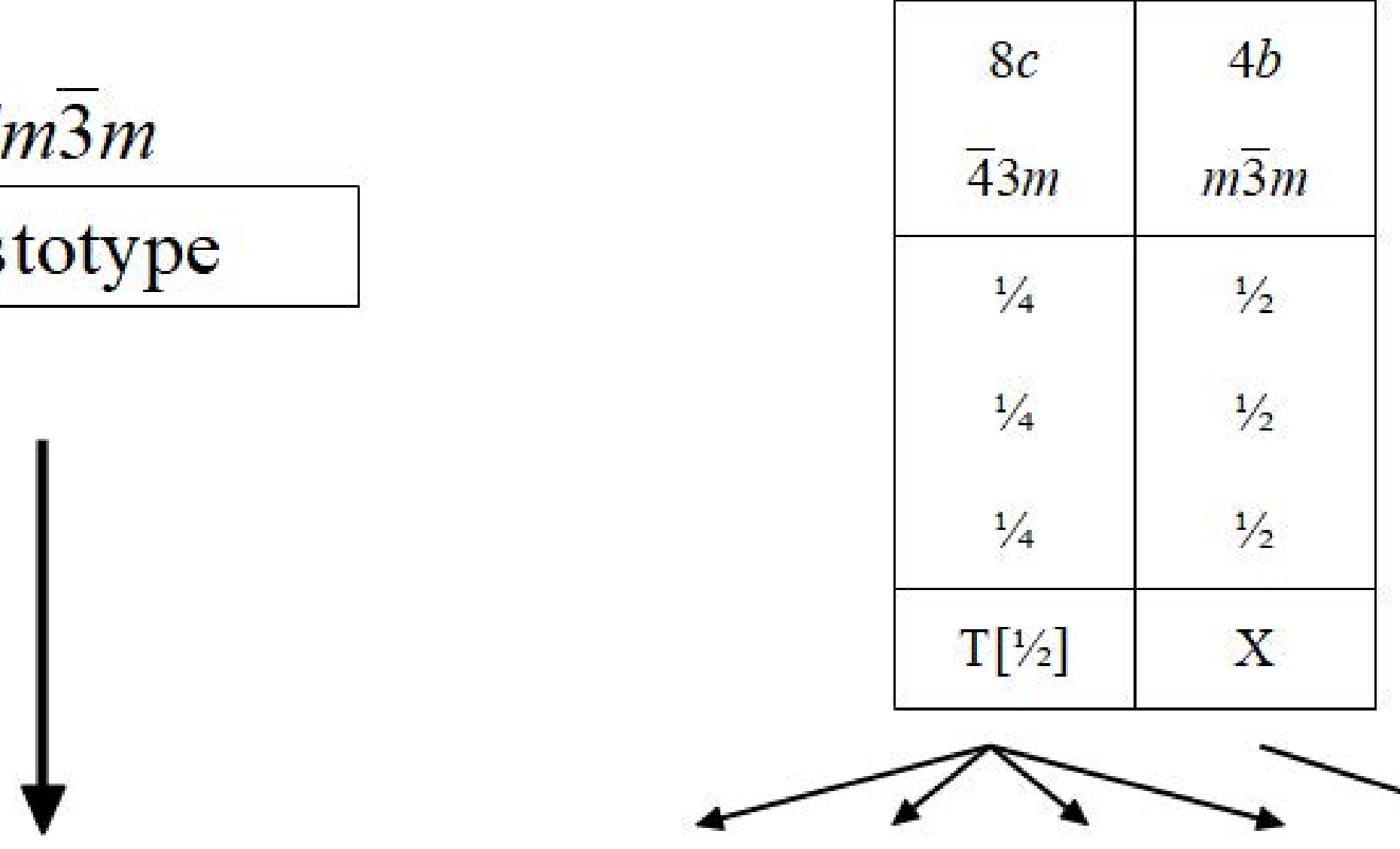

\section{hettotype}

$P \overline{4} 3 m$

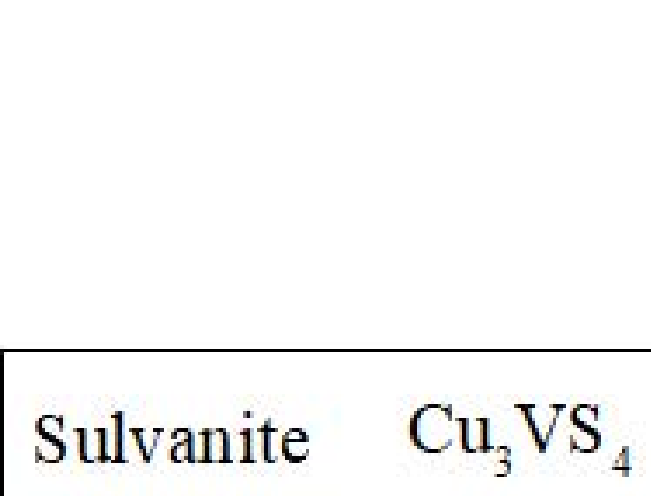

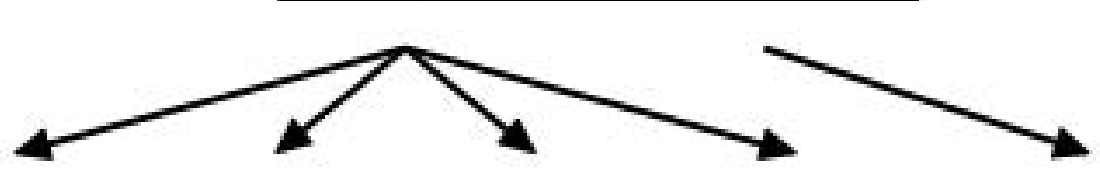

\begin{tabular}{|cccc|c|}
\hline$a$ & $3 c$ & $b$ & $3 d$ & $4 e$ \\
$\overline{4} 3 m$ & $\overline{4} 2 . m$ & $\overline{4} 3 m$ & $\overline{4} 2 . m$ & $.3 m$ \\
\hline 0 & 0 & $1 / 2$ & $1 / 2$ & 0.2500 \\
0 & $1 / 2$ & $1 / 2$ & 0 & 0.2500 \\
0 & $1 / 2$ & $1 / 2$ & 0 & 0.2500 \\
\hline $\mathrm{V}$ & $\square$ & $\square$ & $\mathrm{Cu}$ & $\mathrm{S}$ \\
\hline 0 & - & - & $1 / 2$ & 0.2372 \\
0 & - & - & 0 & 0.2372 \\
0 & - & - & 0 & 0.2372 \\
\hline
\end{tabular}




\section{$F m \overline{3} m$ \\ aristotype}

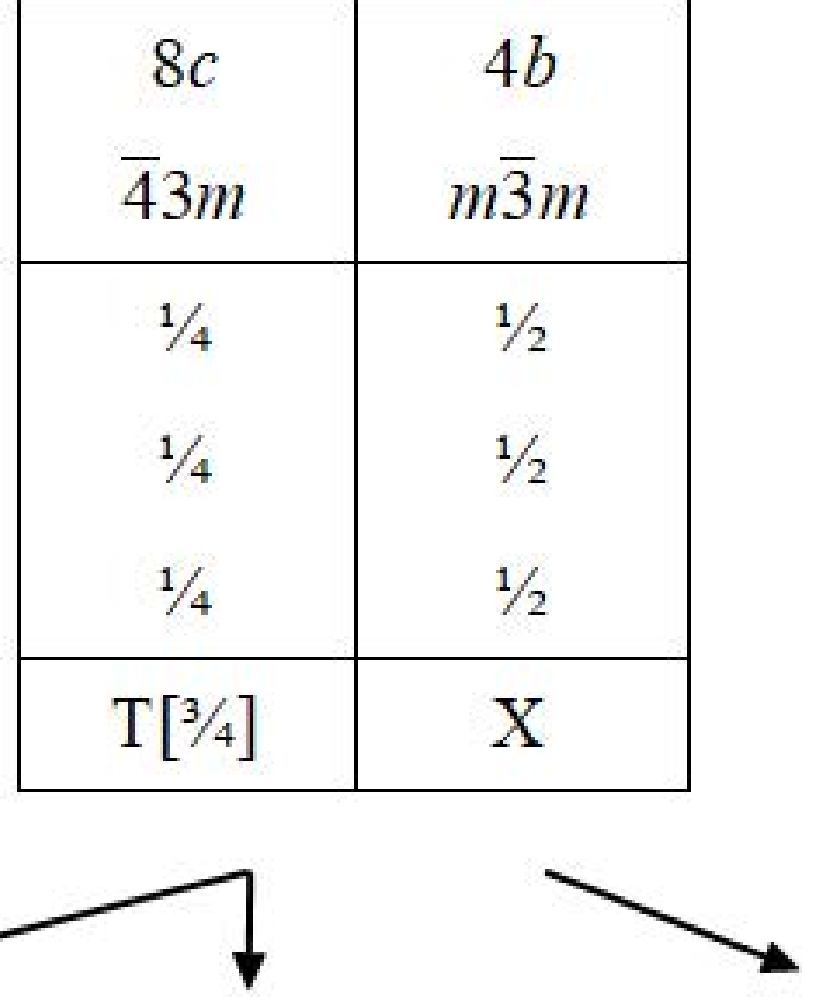

\begin{tabular}{|c|c|c|c|c|}
\hline$F 2$ & & $4 c$ & $4 d$ & $4 a$ \\
\hline hettoty & & 23. & 23. & 23. \\
\hline & & $1 / 4$ & $3 / 4$ & 0 \\
\hline & & $1 / 4$ & $3 / 4$ & 0 \\
\hline & & $1 / 4$ & $3 / 4$ & 0 \\
\hline Bornite & $\mathrm{Cu}_{5} \mathrm{FeS}_{4}$ & $\mathrm{Cu}[5 / 6], \mathrm{Fe}[1 / 6]$ & $\mathrm{Cu}[5 / 12], \mathrm{Fe}[1 / 12]$ & $\mathrm{S}$ \\
\hline & & $1 / 4$ & $3 / 4$ & 0 \\
\hline & & $1 / 4$ & $3 / 4$ & 0 \\
\hline & & $1 / 4$ & $3 / 4$ & 0 \\
\hline
\end{tabular}


$F m \overline{3} m$

aristotype

\begin{tabular}{|c|c|c|}
\hline $8 c$ & $4 a$ & $4 b$ \\
$\overline{4} 3 m$ & $m \overline{3} m$ & $m \overline{3} m$ \\
\hline $1 / 4$ & 0 & $1 / 2$ \\
$1 / 4$ & 0 & $1 / 2$ \\
$1 / 4$ & 0 & $1 / 2$ \\
\hline $\mathrm{T}[1 / 8]$ & $\mathrm{M}[1 / 2]$ & $\mathrm{X}$ \\
\hline
\end{tabular}




\section{$F m \overline{3} m$}

\section{aristotype}

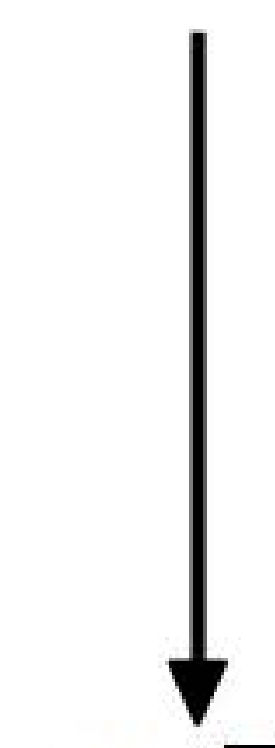

$F m \overline{3} m$

hettotype

\begin{tabular}{|c|c|c|c|}
\hline \multirow[t]{2}{*}{$F m 3 m$} & & \\
\hline & & $32 f$ & $32 f$ \\
\hline \multirow{4}{*}{\multicolumn{2}{|c|}{ hettotype }} & $.3 m$ & $.3 m$ \\
\hline & & 0.1250 & 0.1250 \\
\hline & & 0.1250 & 0.1250 \\
\hline & & 0.1250 & 0.6250 \\
\hline \multirow{4}{*}{\multicolumn{2}{|c|}{ pentlandite $\quad(\mathrm{Fe}, \mathrm{Ni})_{9} \mathrm{~S}_{8}$}} & $\mathrm{Fe}\left[\frac{1}{2}\right], \mathrm{Ni}[1 / 2]$ & $\square$ \\
\hline & & 0.1250 & - \\
\hline & & 0.1250 & - \\
\hline & & 0.1250 & - \\
\hline
\end{tabular}
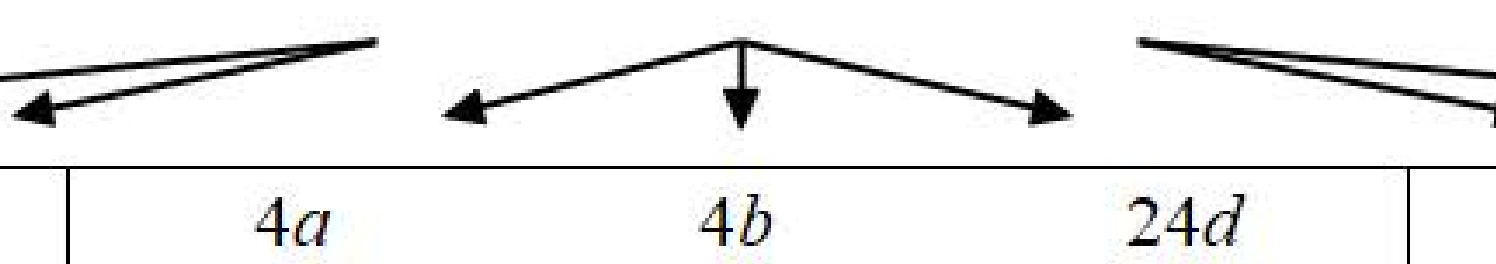


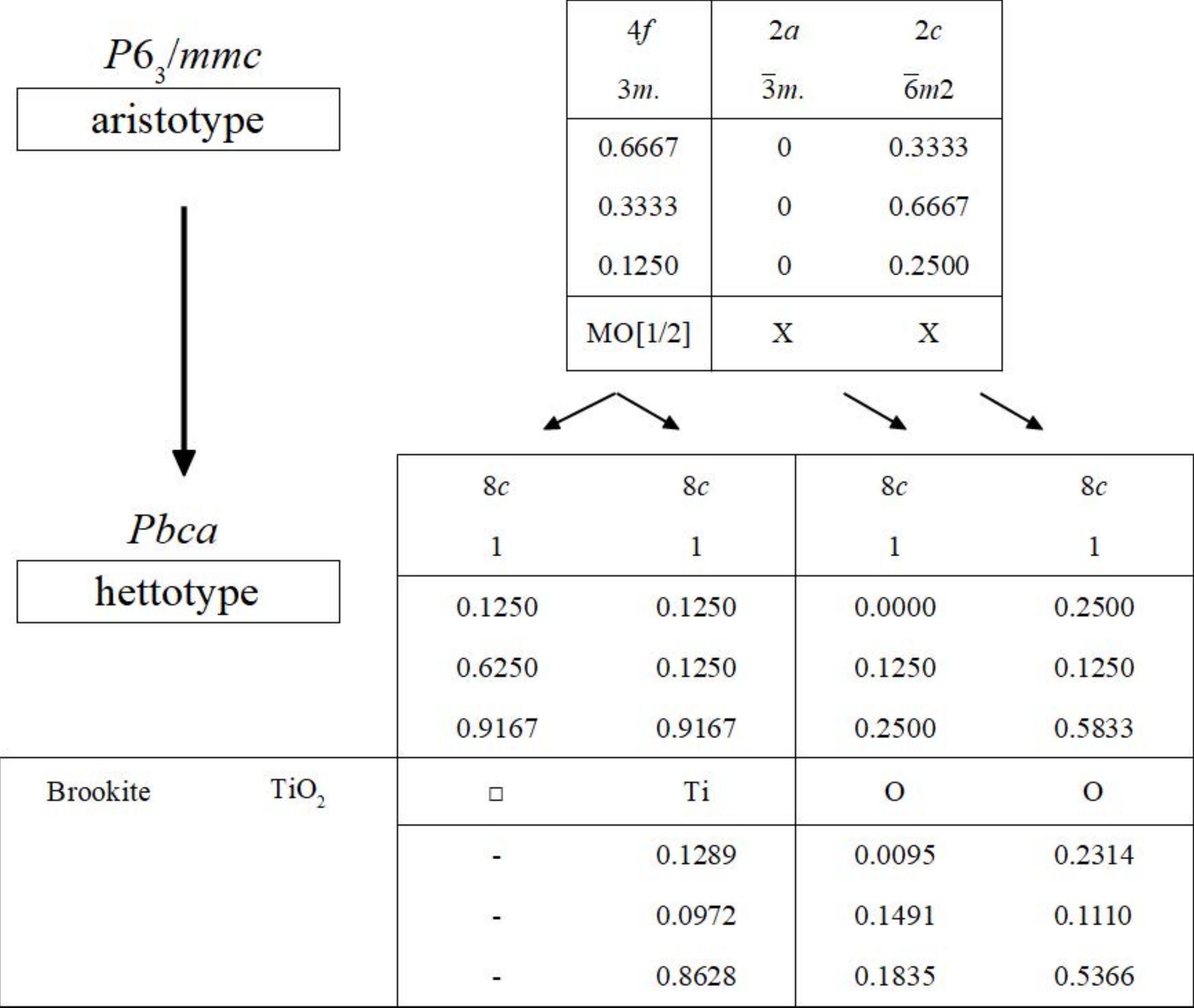


$\mathrm{PG}_{3} / \mathrm{mmc}$

\section{aristotype}

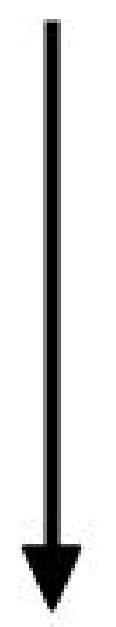

$\mathrm{Pb}_{3} / \mathrm{mmc}$

hettotype

\begin{tabular}{|cc|c|}
\hline $2 c$ & $2 b$ & $4 f$ \\
$\overline{6} m 2$ & $\overline{6} m 2$ & $3 m$ \\
\hline $1 / 3$ & 0 & $1 / 3$ \\
$2 / 3$ & 0 & $2 / 3$ \\
$1 / 4$ & $1 / 4$ & 0.6250 \\
\hline $\mathrm{P}$ & $\square$ & $\mathrm{X}$ \\
\hline$\downarrow$ & $\downarrow$ & $\downarrow$
\end{tabular}



\begin{tabular}{|cc|c|}
\hline $2 c$ & $2 b$ & $4 f$ \\
$\overline{6} m 2$ & $\overline{6} m 2$ & $3 m$. \\
\hline $1 / 6$ & 0 & $1 / 6$ \\
$2 / 6$ & 0 & $1 / 6$ \\
$1 / 4$ & $1 / 4$ & 0.6250 \\
\hline $\mathrm{P}$ & $\square$ & $\mathrm{X}$ \\
\hline $1 / 6$ & - & $1 / 5$ \\
$7 / 6$ & - & $1 / 6$ \\
$1 / 4$ & - & 0.6275 \\
\hline
\end{tabular}


$\mathrm{PG}_{3} / m m c$

\section{aristotype}

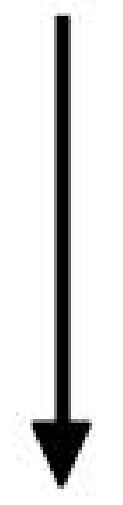

$\mathrm{P6}_{3} / \mathrm{mmc}$

hettotype

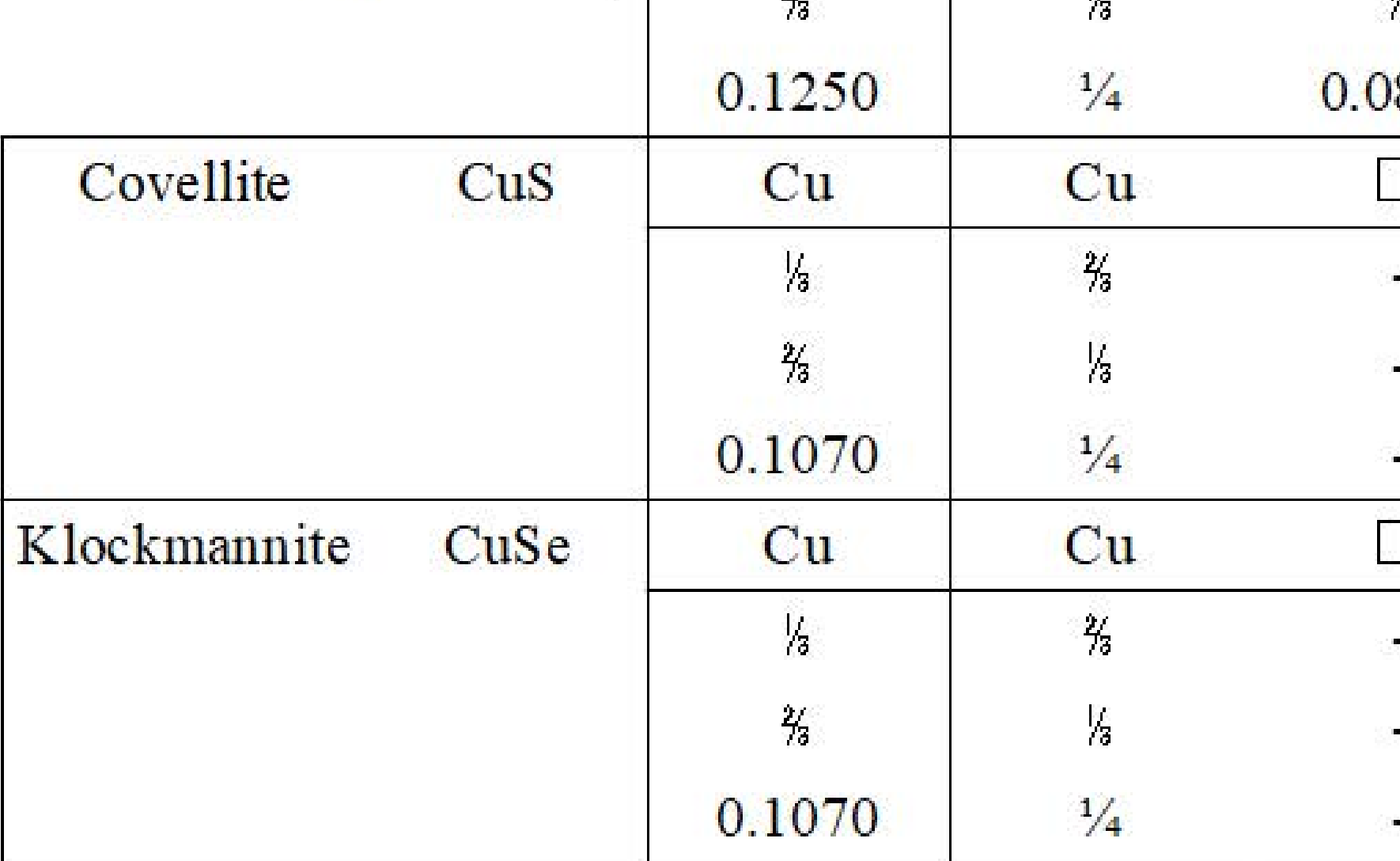

$$
\text { o. }
$$

0.1

$\mathrm{T}$

4

$3 m$

\% $/ 2$
,

m. $\quad \overline{6} m 2$

$1 / 3$

$1 / 4$
$\square$

